A TEN YEAR HISTORY OF

NATIONAL BUREAU OF STANDARDS ACTIVITIES UNDER THE BROOKS ACT (PUBLIC LAW 89-306)

INSTITUTE FOR COMPUTER SCIENCES AND TECHNOLOGY NATIONAL BUREAU OF STANDARDS

U.S. DEPARTMENT OF COMMERCE

WASHINGTON, D.C. 20234 



\section{A TEN YEAR HISTORY OF \\ NATIONAL BUREAU OF STANDARDS \\ ACTIVITIES UNDER THE BROOKS ACT \\ (PUBLIC LAW 89-306)}

Edited by

Grace Burns and

Shirley Radack

Institute for Computer Sciences and Technology

National Bureau of Standards

U.S. Department of Cornmerce

Washington, D.C. 20234
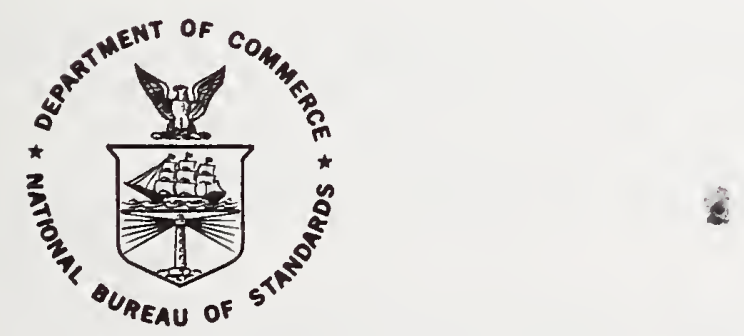

U.S. DEPARTMENT OF COMMERCE,

Dr. Betsy Ancker-Johnson, Assistant Secretary for Science and Technology

NATIONAL BUREAU OF STANDARDS, Ernest Ambler, Acting Director

Issued February 1977 


\title{
Foreword
}

This report has been prepared to assist NBS management and, in particular, the management of the Institute for Computer Sciences and Technology. We hope that it will be helpful also to other organizations concerned with how NBS is meeting its responsibilities under the Brooks Act (Public Law 89-306).

An internal task force of 31 ICST staff members began this study ten years after the passage of the Brooks Act, when the first significant standards and other important products of ICST activities had been in use long enough to have had an impact. Their study focused on activities under the Brooks Act, not on other important ICST activities (e.g., automation technology and export control).

The report is intended to be a factual, candid, and informative appraisal of NBS responses to its three Brooks Act responsibilities: providing advisory services, developing Federal automatic data processing standards, and conducting necessary research. The task force has prepared supplementary case studies of NBS work in selected technical areas which have the highest learning value for managers and scientists. The report also includes:

- summary of principal findings,

- ten year perspective on NBS' Brooks Act responsibilities that includes a review of Office of Management and Budget policy guidance to the Bureau and selected external groups' views that have helped mold the NBS program,

- ten year profile of the computer environment covering the growth of the Federal computer inventory, Federal computer applications and functions, and shifts in the technological character of Federal computer use,

- the procedure used by NBS for identifying Federal computer problems, and

- profile of the resources applied to the NBS computer science and technology program.

NBS has during the last five years conducted two comprehensive reviews of its responses to the Brooks Act. The first review was reported in NBS Report 10608 , Brooks Bill Issue Study of the National Bureau of Standards, dated September 1971. The current report and the Brooks Bill Issue Study provide a comprehensive look at the ten year history of the National Bureau of Standards' implementation of its responsibilities under Public Law 89-306. These two reports together provide an unusually complete, factual point of departure for assessing the past, understanding the present and planning the future.

The document has already been helpful to ICST management in identifying areas of work in which a reorientation or increased emphasis would be beneficial to the general purposes of the Brooks Act.

\author{
Ruth M. Davis, Director \\ Institute for Computer Sciences \\ and Technology
}





\section{Contents}

1. SLMMARY OF PRINCIPAL FINDINGS -

1.1 NBS Responsibilities

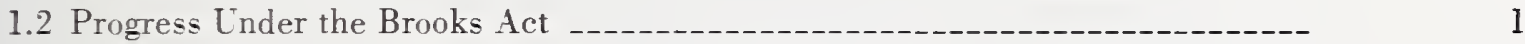

1.2.1. Advisory Services -

1.2.2. ADP Standards -

1.2.3. Research _-_- 1

1.3. GAO Reports on NBS' Brooks Act Activities _-_-_-_-_-_- 2

1.4. NBS Funding -

2. NBS` BROOKS ACT RESPONSIBILITIES _..--

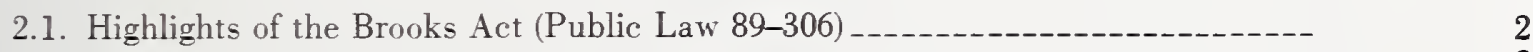

2.2. The NBS Role -

2.3. Authorities -

2.4. GAO Reports and Findings -

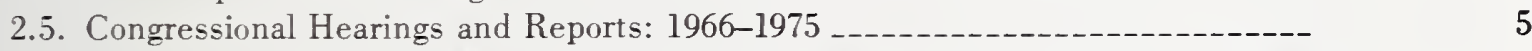

2.6. Informal Conferences. Meetings and Reports Dealing with the Brooks Act and NBS: 1966-1975 --

2.8. How NBS Responds to Its P.L. 89-306 Responsibilities -

3. ASSESSMENT OF THE FEDERAL COMPUTER ENVIRONMENT

3.1. Computing from 1965 to 1975 _- 10

3.1.1. Changes in Computing Systems between 1965-1975 _-_-_--------- 10

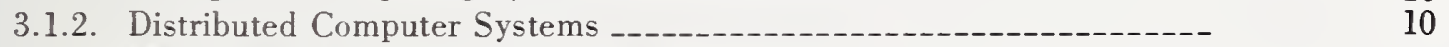

3.1.3. Micro- and Multiprogramming Systems _-_-_-_-_-_-_-_----- 10

3.1.4. Minicomputers and Microprocessors _-_-_-_-_-_-_-_-_-_-_-- 11

3.2. Computers in the Federal Government: 1965 and 1975

3.3. Identifying Problems to be Addressed in the NBS Brooks Act Program -------- 12

4. RESOURCES _. 14

5. OVERVIEW OF NBS RESPONSES TO BROOKS ACT RESPONSIBILITIES ------ 19

5.1. Advisory Services _-_- 19

5.1.1. Background _-_-_-_-_-19 19

5.1.2. Relevant Authorities -

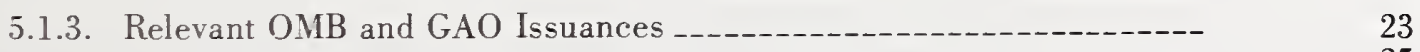

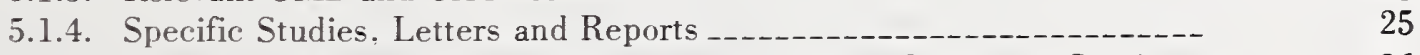

5.1.5. Selected Citations of Specific Requests for Technical Advisory Services 26

5.1.6. NBS Responses to Advisory Services Responsibilities _.-_-_-_-_-_-- 27 
5.2.1. Background _-

5.2.2. Definition of a Federal Standard _-_-_-_-_-_-_-_-_-_- 32

5.2.3. Two Schedules for the Development of a FIPS Standard _-_._-_._-_- 33

5.2.4. NBS Responses to ADP Standards Responsibilities _-_-_-_-_-_-_-- 35

5.2.5. Standards Assessment _-_-_-_-_-_-_-_-_-_-_-_-_- 41

5.2.6. Standards Validation, Testing and Calibration Services _-_._-_-_-_- 41

5.3. Research -

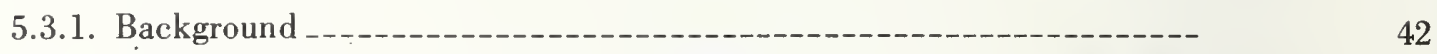

5.3.2. NBS Response to Assigned Responsibilities _-_-

6. CASE STUDIES

6.1. Computer Systems Performance Measurement _-_- 44

6.2. Adoption of the American Standard Code for Information Interchange (ASCII) as a Federal Information Processing Standard _............

6.3. Computer Peripheral Interface Standards _.

6.4. Remittance Processing System - -

6.5. Performance Measurement of Computer Networks

6.6. Data Encryption Standard _-_-_-

6.7. COBOL Standards and Validation Routines

6.8. Mechanical Translation _-_- 62

6.9. FORTRAN Standards and Validation Routines _. 63

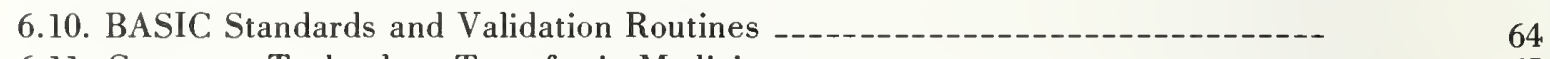

6.11. Computer Technology Transfer in Medicine

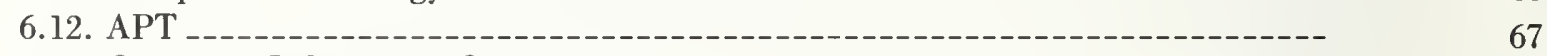

6.13. Computer Information Services

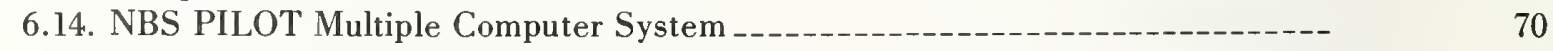

6.15. Development and Use of a Computer-based Graphical Display Terminal (MAGIC II)

6.16. Computer Magnetic Storage Media

Appendix

A General Accounting Office Reports Recommending Actions Related to the National Bureau of Standards' Mission

B List of Publications _-

\section{Listing of Tables}

Table 1. Excerpts from the OMB Policy Guidance Letter (December 15, 1966) to the Secretary of Commerce

Table 2. Topics and Recommendations Impacting on NBS from the Charlottesville Conference

Table 3. Topics and Recommendations Impacting on NBS from the Mrytle Beach Conference

Table 4. Selected Findings or Conclusions of the "Automatic Data Processing Strategy Study" of March 1975 Relevant to NBS

Table 5. Computers in the U.S.: 1965 versus 1975

Table 6. Computers in the Federal Government: 1965 versus 1975

Table 7. Profile of Congressionally Appropriated Funding for NBS' Computer Sciences and Technology Program in Response to the Brooks Act 
Table 8. Profile of the Estimated Obligation of Directly Appropriated Funds By Brooks Act Categories in the NBS Computer Science and Technology Program

Table 9. Estimated Funding Requested by NBS

Table 10. Obligation of NBS Resources

\section{Listing of Figures}

Figure 1. Computer Application by Federal Sector Activity

Figure 2. Categories of Computer Problems/Issues

Figure 3. Major Problems/Issues by Computer Applications

Figure 4. Selection of Problems and Organizations for Emphasis in NBS Program

Figure 5. The FIPS Process: Standard Developed Entirely Within the Government

Figure 6. The FIPS Process: Adoption of ANSI Voluntary Standard 


\section{Acknowledgment}

This report was prepared by a task force established by the Director of the Institute for Computer Sciences and Technology. Members of the task force were:

Zane Thornton, Chairman

Thomas Pyke, Co-Chairman

Marshall Abrams

Leroy Allison

Robert Blanc

Dennis Branstad

Richard Dunlavey

John Evans

Dennis Fife

Sidney Geller

David Gilsinn

Martha Gray

Trotter Hardy

Joseph Harrison

Madeline Henderson

Elizabeth Holberton

Edwin Istvan

Seymour Jeffery

George Lindamood

Judy Lyons

Hazel McEwen

Raymond Moore

Ted O'Neill

Shirley Radack

Susan Reed

Don Rippy

William Truitt

Mabel Vickers

Joseph Wegstein

Harry White

John Wood

Elaine Frye, Secretary 


\title{
A Ten Year History of National Bureau of Standards Activities Under the Brooks Act
}

\author{
Grace Burns and Shirley Radack, Editors
}

\begin{abstract}
This report presents the principal findings of a National Bureau of Standards task force which reviewed the activities and accomplishments of NBS from 1965 to 1975 under Public Law 89-306, the Brooks Act. The Brooks Act is concerned with the effective use of computers by the Federal Government and assigns the National Bureau of Standards responsibility for providing scientific and technological advisory services for automatic data processing, developing uniform Federal ADP standards and undertaking necessary research in computer science and technology. Program activities and a history of funding for each of these three major responsibilities are covered. Also included are case studies of individual program initiatives.
\end{abstract}

Key words: Brooks Act; ADP standards; computer science research; computers in the Federal Government; scientific and technological advisory services.

\section{Summary of Principal Findings}

\subsection{NBS Responsibilities}

The National Bureau of Standards is responsible under Public Law 89-306 dated October 30, 1965 for:

- providing scientific and technological consulting and advisory services to Federal agencies,

- developing uniform Federal automatic data processing standards; and

- undertaking necessary research in the sciences and technologies of automatic data processing computer and related systems.

By letter dated December 15, 1965 the Office of Management and Budget (then the Bureau of the Budget) provided policy guidance to NBS in carrying out these responsibilities.

\subsection{Progress Under the Brooks Act}

NBS has made significant substantive progress toward carrying out its assigned responsibilities under Public Law 89-306.

\subsubsection{Advisory Services}

NBS provided nearly $\$ 18$ million worth of reimbursable scientific and technological consulting and advisory services and technical assistance to Federal agencies during the period FY1965-FY1975. The spectrum of reimbursable services provided includes:

- feasibility studies to determine the need for a computer,

- assistance in the selection of computer systems,

- assistance in basic information system design,

- review of the effectiveness of existing ADP systems, and

- development of special data processing techniques.

\subsubsection{ADP Standards}

The preponderance of NBS effort over the last ten years (i.e., nearly four-fifths of its directly appropriated funds) has been directed to the development of ADP standards and guidelines. These standards and guidelines are issued as Federal Information Processing Standards Publications (FIPS PUBS).

NBS has developed 27 Federal Information Processing Standards (FIPS), 11 FIPS Guidelines and 6 FIPS program management documents. The FIPS standards produced cover the areas of computer hardware, software data, quality control, and safety and security safeguards.

NBS has provided the equivalent of approximately 80 man-years of support to the American National Standards Institute (ANSI) and associated groups in the development of voluntary commercial ADP standards. In addition, NBS coordinates and monitors the participation of some 150 technical experts from 19 other Federal agencies in the ANSI voluntary standardization program. Twenty voluntary ADP standards developed with Federal participation have been adopted, with appropriate modification, as Federal Information Processing Standards.

\subsubsection{Research}

During the early years of implementing the Brooks Act, NBS carried out modest research efforts in pattern recognition, techniques for manipulating and organizing chemical information, and the development of automatic graphic interface to a computer. During the period FY1970-FY1973, the Bureau explored methods of software quality control, program and data transferability methods, controlled accessibility of computer systems, and systems performance measurement and evaluation; these exploratory developments led to the establishment of new technical programs in software management, computer security, and computer system performance measurement. 


\subsection{GAO Reports on NBS' Brooks Act Activities}

The General Accounting Office has issued 12 reports which contain comments or findings about NBS' Brooks Act activities. These reports found NBS having inadequate resources to do an adequate job. Areas in which the GAO cited inadequacies were:

- interface standards,

- software management,

- performance measurement,

- technology transfer,

- data standards, and

- automated decision-making applications.

\subsection{NBS Funding}

NBS has received a total of $\$ 20.6$ million in directly appropriated funds to carry out its responsibilities under Public Law 89-306 during the period FY1965FY1975. Although the annual average over the 10 year period has been about $\$ 2$ million, annual funding for the computer science and technology program did not actually reach the $\$ 2$ million level until FY1971, some five years after enactment of Public Law 89306.

NBS has not had the resources to carry out all of the specific tasks contained in the OMB policy guidance letter of December 15, 1966. Major examples are:

- means for measuring compliance with Federal Information Processing Standards,

- guidelines and methods for monitoring the performance of systems studies and for implementing the results of such studies, and

- annual review of the accomplishments of and programs for Federally-sponsored research in computer sciences and technology.

\section{NBS' Brooks Act Responsiblities}

\subsection{Highlights of the Brooks Act (Public Law 89- 306)}

Public Law 89-306 (79 Stat. 1127) was enacted on October 30,1965 , as an amendment to Title I of the Federal Property and Administrative Services Act of 1949 (63 Stat. 377). The purpose of P.L. 89-306 is to "provide for the economic and ffficient purchase, lease, maintenance, operation, and utilization of automatic data processing equipment by Federal departments and agencies."

Under the Brooks Act:

- the Administrator, General Services Administration (GSA), was directed to coordinate and provide for the economic and efficient purchase, lease, and maintenance of automatic data processing equipment by Federal agencies,
- the Secretary of Commerce was authorized to provide scientific and technological advisory services to Federal agencies and the Administrator, GSA, to make recommendations to the President relating to the establishment of uniform Federal automatic data processing standards, and to undertake necessary research in computer sciences and technology, and

- the Office of Management and Budget (OMB) was assigned responsibility for exercising fiscal and policy control over the execution of authorities assigned to the Administrator, GSA, and the Secretary of Commerce.

\subsection{The NBS Role}

The Brooks Act assigned no policy making responsibilities to the Secretary of Commerce as it did to the Office of Management and Budget and the General Services Administration. The Act did not carry any funding authority with it. It did authorize the Secretary of Commerce to:

- provide scientific and technological advisory services relating to automatic data processing and related systems to Federal agencies and the Administrator, GSA,

- make appropriate recommendations to the President relating to the establishment of uniform Federal automatic data processing standards, and

- undertake necessary research in the sciences and technologies of automatic data processing, computer and related systems.

The authorities assigned to the Secretary of Commerce by P.L. 89-306 were delegated to the Director, NBS, and, subsequently, to the Institute for Computer Sciences and Technology (ICST). Specifically, NBS/ICST was assigned the three major technical responsibilities described in the Brooks Act and was directed to undertake specific activities detailed in policy guidance issued by the Office of Management and Budget.

The Office of Management and Budget, in a letter dated December 15, 1966, provided policy guidance to the Secretary of Commerce implementing Public Law 89-306. The letter transmitting the policy guidance stated:

\footnotetext{
"It is widely recognized that major hindrances to improving the use of ADP are the absence of: (a) standardization in character sets, input-output media, and interfaces which provide for compatible interchange of information and interoperation of systems and equipment, (b) standardization of computer programming languages, and (c) yardsticks for evaluating software and its effects upon the performance of the computing system. The Department (of Commerce) should concentrate on actions which will overcome these deficiencies."
}

Excerpts from the OMB policy guidance letter of December 15, 1966, are summarized in table 1 . 


\section{TABLE 1}

\section{EXCERPTS FRON THE OMB POLICY GUIDANCE LETTER (DECEMBER 15, 1966) to THE SECRETARY OF COMMERCE}

BROOKS ACT STATEMENT: Provide scientific and technologi$\mathrm{cal}$ advisory services relating to automatic data processing and related systems to Federal agencies and the Administrator of General Services.

\section{OMB POLICY GUIDANCE}

a. Provide guidelines for use by agencies in conducting systems studies, including consideration of systems interrelationships.

b. Provide guidelines and methods for monitoring the performance of systems studies and for implementing the result $s$ of such studies.

c. Provide criteria to assist in evaluating software and hardware developments that may be considered during the systems studies.

d. Provide technical guidelines for preparing solicitations of proposals, including the specification of system requirements.

e. Provide guidelines, criteria and techniques for evaluating and selecting equipment and related software, giving priority emphasis to criteria for measuring the effectiveness and efficiency of software. Data on this subject will also be furnished to GSA for consideration in the procurement of computers.

f. Maintain a reference index of computer programs to minimize the need for the development of programs already developed. tested and in use elsewhere.

g. Provide guidelines for evaluating installation and systems performance on a continuing basis.

h. Keep abreast of the state-of-the-art developments in ADP equipment, techniques and languages and evaluate these developments in terms of their current or potential impact upon the Government's use of equipment and software and its ADP management policies. Make these findings known promptly to the Office of Management and Budget.

BROOKS ACT STATEMENT: Make appropriate recommendations to the President relating to the establishment of uniform Federal automatic data processing standards.

OMB POLICY GUIDANCE

a. NBS will undertake to increase compatibility in automatic data processing in the Federal Government by recommending Federal standards related to ADP equipment, techniques and computer languages. (Responsibility for recommending standards for data elements and codes was retained by $\mathrm{OMB}$ and later assigned to NBS by Executive Order 11717, May 9. 1973.

b. Develop, issue and maintain a statement of the Federal Government's standardization objectives and needs.

c. Survey and keep abreast of ADP standardization activities within the Federal government. United States of America Standard Institnte (USASI), and elsewhere: and initiate and promote activities as necessary to achieve the Government"s objectives.

d. Study and provide recommendations for Federal ADP standards. e. Study and provide recommendations on use within the Federal government of each appropriate United States Standard approved by the USASI in the area of ADP equipment, computer languages and techniques.

f. To the extent feasible and desirable, develop and recommend means for measuring compliance with Federal standards.

g. Provide for the technical maintenance of Federal ADP standards.

h. Recommend procedures to be used in the Federal Government for adopting Federal standards and developing and implementing plans therefor.

i. In the development of Federal standards. NBS/ICST will communicate and work closely with all Federal agencies (and with manufacturers, private industry, and State and local governments when required and advantageous) to assure proper consideration of their needs and views and to obtain their cooperation in the development process.

j. Provide day-to-day guidance and monitorship of an Executive Branch program to promote the development and testing of voluntary commercial standards for automatic data processing equipment, techniques and computer languages.

k. Participate in activities of the $\mathrm{X} 3$ Committee on Computers and Information Processing of the American National Standards Institute (ANSI), its subcommittees and task forces and in the activities of the International Organization for Standardization as requested by ANSI.

1. Arrange and insure appropriate representation and active participation from other Federal agencies on the 13 Committee, subcommittees and task forces to complement ICST"s participation with additional expertise from the operating environments of the Government.

m. Monitor and coordinate all such participation bs all Federal agencies to assure its consistency with the Federal gowernment's objectives.

BROOKS ACT STATEMENT: Undertake the necessary research in the science and teclunologies of antomatic dat a processing computer and related systems.

\section{OMB POLICY GUIDANCE}

a. Sponsor, monitor, and undertake research and development activities in the computer and information sciences and technologies. including system design. oriented primarily toward Govermment application.

b. Maintain current awareness of on-going basic and applied research and development activities conducted by ofher agencies. by Federally-sponsored contractors and grantees. and by the private sector of the economy. Develop means for making such activities known and the results. incluling appropriate evaluations. available to Federal agemeies for their benefit.

c. Research and development activities will be sponsored or undertaken, as appropriate. for the following purpuses:

- To supplement ageney research efforts when neeresary to meet Govermment-wide requirements or to provide solutions to problems of comeern to several different ageneies.

- To initiate efforts to solve large-scale and difficult problems sufficiently unique to special needs of (iovernment that out side intere'sts are not likely to undertahe vigurous and timely action. 
- To evaluate and apply advanced concepts to the development, organization and implementation of automatic data processing, computer and related systems, including the innovation or extension of techniques needed for improved cost effectiveness in the conduct of agency programs through the use of computers and related techniques.

- Conduct exploratory research in order to provide the technological bases for future standardization activities and to maintain the competence of the technical staff engaged in technical advisory services, testing and evaluation, and standardization activities.

- To identify continuing Research and Development (R\&D) requirements for use by NBS/ICST. other agencies, academic and other organizations and industry in planning and coordinating $R \& D$ programs in the area of computer and information sciences and technology.

d. NBS should conduct an annual review of accomplishments of and programs for research in computer sciences and techniques, in conjunction with $\mathrm{OMB}$ and other Government agencies engaged in sponsoring research in computer sciences to assess accomplishments and to provide guidance for programs.

\subsection{Authorities}

The NBS/ICST program to provide ADP scientific and technological advisory services to Federal agencies, recommend uniform Federal ADP standards, and conduct necessary research in computer sciences and technology is operated primarily under the statutory authority of the Brooks Act. During the 10 years since enactment of this Act, however, NBS' responsibilities in the computer science and technology area have been interpreted or expanded by the following:

(1) Office of Management and Budget letter dated December 15, 1966, subject: Policy Guidance to the Department of Commerce (National Bureau of Standards) in the Implementation of Public Law 89-306.

(2) Office of Management and Budget Circular A-108, dated July 1, 1975, subject: Responsibilities for the Maintenance of Records About Individuals by Federal Agencies.

This circular assigns responsibility to the Secretary of Commerce for issuing standards and guidelines on computer and data security in accordance with OMB guidance relative to the Privacy Act of 1974.
(3) Executive Order 11717 dated May 9, 1973

This Executive Order transferred to the Secretary of Commerce all functions being performed by the Office of Management and Budget relating to the establishment of Government-wide automatic data processing standards, including the function of approving standards on behalf of the President. The Order resulted in NBS receiving responsibility for the Federal data standards program which OMB retained when it issued its 1966 policy guidance on implementation of Public Law 89-306.

(4) Office of Telecommunications Policy letter dated September 1, 1971

In this letter to the Assistant Secretary for Science and Technology, DOC, the Director, Office of Telecommunications Policy (OTP) requested NBS to provide to OTP technical advice and analysis in teleprocessing matters and to represent the United States at appropriate international meetings.

(5) Department of State letter dated March 10 , 1972

In this letter to R. M. Davis, Director, Center for Computer Sciences and Technology (CCST). H. Pollack. Director, Bureau of International Scientific and Technological Affairs, accepts CCST'S offer to provide technical advice and support to the Department in its role in formulating and implementing foreign policy.

\subsection{GAO Reports and Findings}

Since enactment of Public Law 89-306, the General Accounting Office has issued (or has in draft form) 12 reports that contain comments, findings and/or recommendations about NBS' Brooks Act activities. These reports (listed in appendix A) have been generally consistent in citing inadequacy of resources and stressing the necessity for NBS to do more just to minimally meet government needs and carry out the Bureau's Brooks Act responsibilities. 
Principal areas in which the GAO has cited inadequacies in NBS' activities are:

- Interface Standards

- Software Management

Documentation

Standard programming languages

evaluation (validation)

Software specifications (quality controls)

- Performance Measurement

- Technology Transfer

- Data Standards

- Computerized Model Development

- Automated Decision Making Applications

- Automation Technology for Manufacturing
(GAO Report of June 24, 1969)

(GAO Report of June 30, 1971)

(GAO Report of August 22, 1972)

(GAO Report of June 3, 1974)

(GAO Report of December 29, 1972)

(GAO Report of October 8, 1974)

(GAO Report of May 16, 1974)

(GAO Draft Report, August 1975)

(GAO Report of May 1976)

(GAO Draft Report, 1975)
GAO has been both realistic and understanding in its findings. A typical example of its findings ("Acquisition and Use of Software Products for Automatic Data Processing Systems in the Federal Government," B-115369, June 30, 1975) is:

"Computer users in the Federal Government have been independently evaluating software products with no uniform formalized set of standards against which to make judgments. The emphasis placed on such evaluations has been to satisfy the immediate needs of the user. There have been duplicate technical evaluations of similar software products and of the acquisition of varying types of software for the purpose of satisfying like data processing needs.

"NBS was directed by OMB in 1966 to perform technical evaluations of software products being acquired by Federal data processing installations. We were advised by NBS officials that they had been unable to execute these responsibilities due to the lack of financial and manpower resources.

"We believe that the use of a single technical evaluation procedure, using existing expert resources in the Government and documenting the findings for future reference, would eliminate duplicate technical evaluation efforts."

\subsection{Congressional Hearings and Reports: 1966- 1975}

There have been seven Congressional Hearings since the passage of the Brooks Act in which NBS program activities have been a topic and in which NBS officials have testified. These are:
(1) Hearings before a Subcommittee of the Committee on Government Operations, House of Representatives, July 1967:

The purpose of the Hearing as stated by Congressman Brooks was "to hear from those directly involved (BOB, GSA, NBS) in this management effort ... to learn of their successes ... to define the problems confronting them as we seek fuller implementation of this management program and even greater efficiency and economy in the use of Government data processing."

(2) The Proxmire Hearings on Economy in Government, July 1970:

"We believe that the development of a standard interface will promote industry competition and result in certain economies." "... the National Bureau of Standards should be directed to develop a Federal standard interface program in order to achieve a significant savings ... from increasing the compatibility of major components with mainframe equipment." (Elmer B. Staats, Comptroller General)

(3) The hearings before the Government Activities Subcommittee of the Committee on Government Operations, House of Representatives, May 20, 1971: 
The purpose of this Hearing as stated by Congressman Brooks was ". . . to obtain testimony ... as to the progress that has been made in the implementation of Public Law 89-306 . . "Our interest is particularly oriented to the problems that have been encountered as this Government-wide coordinated system of management has been under implementation over the period of the last five years."

(4) The NBS Oversight Hearings before the Subcommittee on Science, Research and Development of the House Committee on Science and Astronautics of September 1971:

The purpose of the Hearing was to give Congress a complete overview and review of the activities of NBS. Questions addressed compatibility of computers, computer networking, quality and amount of NBS computer equipment, impact of the computer on the labor market, and the role of IBM in the computer industry.

(5) The Hearing before the Government Activities Subcommittee of the Committee on Government Operations, House of Representatives, May 16, 1972:

The purpose of this Hearing was to consider HR 13200, Section 2 of which proposed a $\$ 100,000,000$ annual appropriation for NBS to spend to support basic research in data processing technology.

(6) Hearings before the Foreign Operations and Government lnformation Subcommittee of the Committee on Government Operations, July 17, 1973:

The purpose of these Hearings was to examine ". . Federal use of information and communications technology to meet the needs of society". . . "to examine a variety of Federal systems which demonstrate how advanced technology can be utilized to improve...
Federal information activities" ... to "examine what kinds of safeguards are needed in each case to protect against misuses ... how each system guarantees the privacy of individual case files..."

(7) Hearings before the Senate Committee on Government Operations and the Judiciary Subcommittee on Constitutional Rights, June 19, 1974:

Hearings were held on a "series of bills proposing controls on Government and commercial data banks and computers." Each of these bills was "aimed at safeguarding the rights of privacy of the individuals who are the subjects of these information systems." The Director of NBS' Institute for Computer Sciences and Technology testified that "in order for any legislation passed to be really useful, it has to be technologically implementable."

Only one of these Hearings was concerned directly with the question of the adequacy of resources for NBS. This was the Hearing on HR 13200 held on May 16, 1972. The Hearing proceedings were not published, and there was no legislative action on the proposed $\$ 100,000,000$ annual appropriation for NBS.

\subsection{Informal Conferences, Meetings and Reports Dealing With the Brooks Act and NBS: 1966-1975}

Two conferences and two reports dealing with the implementation of the Brooks Act are singled out for attention as being most meaningful to NBS' activities. They are:

(1) The Charlottesville (Virginia) Conference of September 1969.

(2) The Myrtle Beach (South Carolina) Conference of June 1970.

The principal topics and recommendations relevant to NBS are listed in table 2 and table 3 below:

TABLE 2. Topics and recommendations impacting on NBS from the Charlottesville Conference

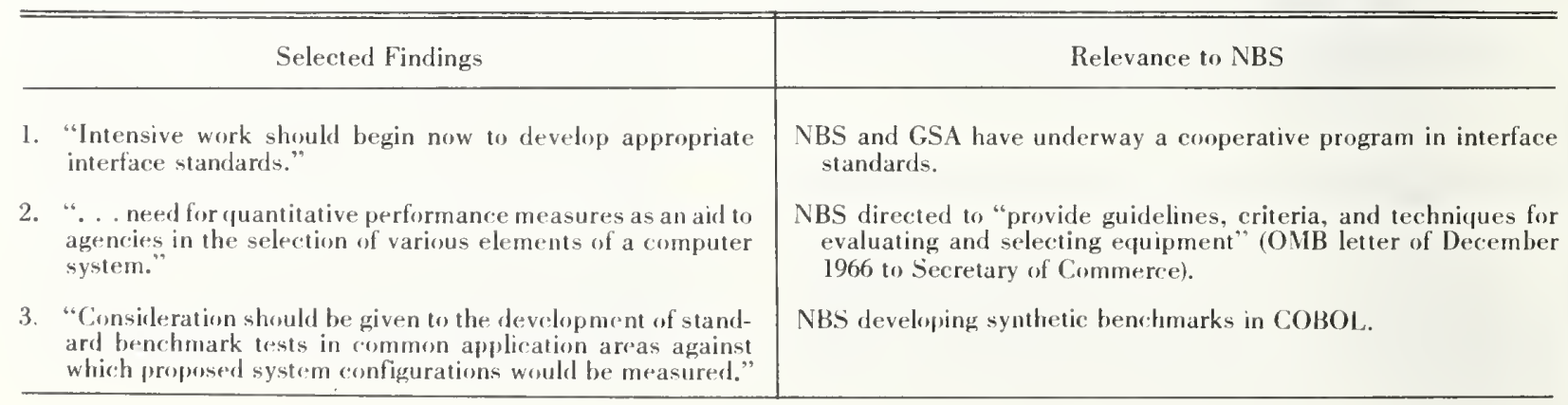


TABLE 3. Topics and recommendations impacting on NBS from the Myrtle Beach Conference

\begin{tabular}{|c|c|}
\hline Selected Findings & Relevance to NBS \\
\hline $\begin{array}{l}\text { 1. "Reaffirmation of the need for appropriate } \mathrm{I} / \mathrm{O} \text { interface } \\
\text { standards." }\end{array}$ & NBS and GSA have underway a cooperative program. \\
\hline $\begin{array}{l}\text { 2. "Consideration should be given to taking an inventory of } \\
\text { software in use by Federal agencies." }\end{array}$ & $\begin{array}{l}\text { NBS directed to "maintain a reference index of computer programs.. } \\
\text { (OMB letter of December } 1966 \text { to Secretary of Commerce) }\end{array}$ \\
\hline $\begin{array}{l}\text { 4. "Defer cataloging of application packages until an acceptable } \\
\text { format is established by NBS." }\end{array}$ & $\begin{array}{l}\text { NBS developed FIPS PUB } 30 \text { (standard form for describing com- } \\
\text { puter programs). }\end{array}$ \\
\hline
\end{tabular}

\subsection{Reports}

There have been two notable special reports that bear on the NBS Computer Science and Technology Program. They are:

(1) The Brooks Bill Issue Study of the National Bureau of Standards (NBS Report 10608 ), September 1971.

This report was prepared by NBS/ICST in response to an OMB request dated April 7, 1970, for a study on the issue:

"What can be done to make the contribution of the National Bureau of Standards more effective in achieving greater efficiency and economy in Government ADP operations, as envisioned in the Brooks Bill (P.L. 89-306)?"*

The report, informally stated as satisfactorily responsive to the $\mathrm{OMB}$ request. has served as the basis for the NBS program since FY1972.

(2) "Automatic Data Processing Strategy Study." prepared for GSA. March 1975: Decisions and Designs, Inc.

The findings of this report support some of the specific activities directed by the December 1966 OMB guidance letter to NBS. As noted earlier NBS ability to pursue these actions is limited by its resources. The report also proposed several new activities such as the establishment of a central Federal audit review activity and the use of the Federal ADP revolving fund for the development of software validation services. NBS and other Federal agencies as appropriate are following up on both of these proposals.

The more significant of the findings of this report relevant to NBS are identified and short comments on their relevance are made in table 4. 
.1. "The quality of ADP services would be enhanced and their costs decreased by the use of private industry to satisfy the Federal Government's needs for the ADP systems and operations."

2. "Care should be taken in the publication of evaluation criteria and weights in solicitation documents..."

"Solicitations and source selected criteria should be improved in terms of clarity and consistency."

3. "[GSA should] provide coordination with respect to plans for centralization of computing facilities both within and among user agencies."

4. "The efforts of the Federal Telecommunications Standards Committee (FTSC) may be enhanced. . . This would require an analysis of the degree and nature of interoperability requirements... which would give new directions and priority to the Federal standards development activity."

5. "[GSA Automated Data and Telecommunications Service (ADTS) should] establish a technical analysis support facility which will be capable of providing assistance to those agencies which are not GSA-certified."

6. ". . a central Federal audit review activity should be initiated."

7. "GSA and NBS [should] explore the concept of class retirement by its after-the-fact audit of type characteristics, . . . as an element of its approval of agency ADP plans."

8. ... "[Software] exchange is enhanced by employing standard formats and data elements and NBS is developing such standards"...

9. . . "Cost evaluation made at the component level are necessarily fragmented and incomplete, unless true componentlevel interchangeability exists."

10. "[The ADP] Fund should be used by GSA ADTS to encourage software generalization and/or exchange efforts by a system of credits to software developers and charges against the subsequent users."

11. GSA, OTP and NBS should continue to review interagency plans regarding interconnectivity, sharing, etc.
NBS directed to "provide guidelines, criteria and techniques for evaluating and selecting. . . software, giving priority emphasis to criteria for measuring the effectiveness and efficiency of software" (OMB letter of December 1966 to Secretary of Commerce) This task becomes MORE IMPORTANT as greater reliance is placed on private industry.

NBS directed to provide criteria to assist in evaluating software and hardware developments that may be considered during the systems studies and to provide technical guidelines for preparing solicitations of proposals, including the specification of system requirements.

GSA should explore the establishment of central multiple-access computer facilities (or utilities) building upon the research and evaluation findings of the NBS, DOC and other agencies on the effectiveness of such systems." (OMB letter of May 4, 1966 to Administrator, GSA)

NBS was instrumental in setting up the FTSC. NBS is having FIPSCAC review FIPS objectives and requirements.

OMB directed NBS to perform such functions in its December 1966 policy guidance letter. OMB and GSA should request the necessary funding for these functions to be done by NBS.

GAO, GSA and NBS are in the process of recommending that NBS provide the needed technical support for such activity. See draft GAO report on Automated Decisionmaking Applications.

See comment under \#6.

NBS has scheduled dates for needed standards in its FIPS program.

NBS Interface Standards program has with GAO encouragement recently received more resources and has near-term milestones regarding interchangeability standards and guidelines.

GSA and NBS are exploring the use of the ADP Fund for development of software validation services.

No additional direction needed.

\subsection{How NBS Responds to Its Brooks Act Respon- sibilities}

The NBS response to the Brooks Act takes many forms depending upon the specific responsibility being addressed and the demands of a particular problem. The principal forms of response are:

(1) Federal Information Prcessing Standards (FIPS) for Government-wide implementation. These standards are issued in the categories of hardware, software, data, quality control and safety and security safeguards.

(2) FIPS guidelines that provide technically sound recommendations and information to assist Federal agencies in coping with specific automatic data processing problems. The guidelines are developed and issued when there is a perceived, widespread need for uniform technical guidance and a FIPS standard is inappropriate or cannot be developed in the required time frame. 
(3) FIPS management publications that describe standardization program objectives, detail procedures for developing and using ADP standards, provide indices of FIPS standards and guidelines, and define agency responsibilities within the FIPS program.

(4) Standard Reference Materials (SRM), calibration services and high precision techniques for measuring the quality and performance of computer magnetic storage media, e.g., magnetic tape, cassettes, cartridges, and disks. These products are used by the General Services Administration to test and certify magnetic media for Federal procurement, and by industry for quality control in the manufacture of magnetic media.

(5) Technical publications reporting on research in computer science and technology undertaken to provide a basis for advisory services to Federal agencies or to establish a technical foundation for the development of FIPS standards and guidelines.

(6) Handbooks of reference information and data to assist computer professionals in carrying out specific functions such as software development and computer system performance measurement.

(7) Technical assistance and advisory services to Federal agencies. Generally, this work takes two forms: direct technical input to policymaking by central management agencies, e.g., Office of Management and Budget and the General Services Administrative, and reimbursable interagency agreements where NBS "contracts" to provide specified ADP services and products to the sponsoring agency in solving a specific ADP problem. The products of these interagency agreements go directly to the sponsoring agency and on occasion, depending upon the nature of the problem addressed, are made available to other agencies and nonGovernment requestors. A few other agency projects result in the development of prototype hardware systems that are turned over to the sponsoring agency.

(8) Scientific and technical conferences, workshops, and symposia are used extensively to keep abreast of computer technology, to disseminate the results of NBS computer research, to focus attention on specific technical problems, and to identify trends in agencies' requirements for computer science and technology. NBS sponsors many of these conferences, workshops and symposia by itself; the Bureau also collaborates with professional societies, universities and trade associations in jointly sponsoring some of these activities. Wherever appropriate, NBS publishes pro- ceedings of its conferences and symposia as a means of achieving secondary dissemination of technical information.

(9) Extensive interaction with Federal agencies. Technical representatives of Federal agencies play an active role in NBS' computer science and technology program. Agency personnel serve as members of task groups established to develop FIPS standards, and as members of the FIPS Coordinating and Advisory Committee that helps establish ADP standards program objectives and requirements and has oversight of task groups set up to develop specific standards.

(10) Monitorship and guidance of the Executive Branch program of participation in the development of voluntary industry ADP standards. NBS arranges for Federal participation in the committees and working groups of the American National Standards Institute, and coordinates such participation to assure its consistency with the Federal Government's objectives.

(11) Establishment of validation centers for compilers and other software products.

\section{Assessment of the Federal Computer Environment}

In order to develop a meaningful perspective of NBS' Brooks Act Program, one must take into account the evolution of computer technology and the extent to which the Federal Government has exploited that technology. The Federal Government has been a major user of computers since the beginning of the computer era nearly 30 years ago. In the early 1950 's the Federal Government sponsored virtually all computer activities and computer research and development. As computers proliferated in the private sector, however, the percentage of computers controlled by the Government decreased from nearly 100 percent in the early 1950's to 8.7 percent in 1965 and, finally, to 4.1 percent in 1975 . (See note, table 6.)

The first part of this section attempts to profile the computer environment in 1965 and 1975 . It provides statistical data on computers in both the Federal Government and the private sector for the periods of interest.

The second part of this section continues to profile the Federal computer environment by describing a procedure used to identify those problems that are addressed in the NBS Brooks Act program. This procedure is based on the analysis of types of computer applications, Federal activity sectors where computers are used, and generally acknowledged problems and issues in computer usage as expressed by other Federal agencies, General Accounting Office reports, Congressional hearings and reports, and industry representatives. The output of the procedure 
is a set of problems and issues that deserves priority attention.

The third part addresses the identification and selection process used to determine the specific problems that are addressed by the NBS Computer Science and Technology Program.

\subsection{Computing from 1965 to 1975}

\subsubsection{Changes in Computing Systems between 1965-1975}

In the eyes of many observers, 1965, the year in which the Brooks Act became law, was a pivotal year in the history of the computer industry. With the delivery of the first 3rd-generation computer systems in that year, profound and lasting changes were initiated in the practice of computing and in the computer industry, changes that are still underway today.

The 3rd-generation computer systems announced and delivered in the mid-1960's offered significant improvements in speed, capacity, flexibility, reliability, and (especially) cost over their predecessors. The use of hybrid and integrated circuit semiconductor technology in central processing units made submicrosecond cycle times commonplace. Advances in magnetic core technology made possible central memories having cycle times commensurate with those of the central processing units and with capacities several times greater than in previous computers. Other advances in magnetic and electromechanic technology made possible a wider range of computer peripheral devices offering increased performance in terms of data transfer rates, storage access times, storage capacities, and reliability.

Of even greater consequence than these advances in hardware were the changes in software and software practice effected by the advent of the $3 \mathrm{rd}$ generation. Although operating systems, file management systems, and other special or general purpose software systems had been developed for some of the larger 2nd-generation computers, such complex software packages were a necessity (rather than a sometimes desirable option) in 3rd-generation computer systems. This fact, coupled with the increased complexity of 3rd-generation system architecture, and amplified by the trends toward decreased hardware costs and increased programmer costs, gave rise to a situation in which the cost of system software exceeded that of hardware.

Other significant differences in the practice of system architecture between 2nd and 3rd-generation computers gave rise to changes in the computing industry. With upward and downward compatibility across the entire IBM System/360 product line, old distinctions between scientific and business oriented computers became obsolete. The building-block approach to system configuration, wherein a variety of memory sizes, channel configurations, and peripheral equipment were available for each modcl, made the "standard configuration" of a given computer system a thing of the past. As a consequence, each hardware unit was priced separately, with the cost of the software being "bundled' into the price into the CPU. This fact, plus the market aggregation resulting from the use of the same interface for each peripheral throughout all models of the System $/ 360$ series, occasioned the formation of companies whose sole business it was to manufacture and market "plug-compatible" peripheral devices, such as disks, tapes, printers, and (eventually) even central memory units.

Computer manufacturers other than IBM, in order to compete with the IBM 360 line, were forced to discontinue or at least significantly modify their past practices of marketing two or more somewhat distinct product lines, each tailored to specific markets. This, in turn, also made these companies subject to competition from plug-compatible peripheral suppliers. Perhaps as a result of this and also because of the unanticipated magnitude of difficulties encountered by the major mainframe manufacturers in developing the complex system software and applications packages for 3rd-generation systems, the practice of software "unbundling"- - that is, separate pricing of hardware and software-began in the late 1960's. Again, this opened the way for the creation of a new genre of firm in the computing industry, the independent software house.

Changes in the lease-to-purchase price ratios also gave rise to the advent of third-party computer leasing firms, and the drastically increased number of computer installations using systems made up of equipment from several different suppliers created a demand for independent computer maintenance firms.

The years from 1965 to 1975 have been characterized as a period of "consolidation," reflecting the fact that most of the predominant practices in computing today already existed in 1965, at least in experimental or rudimentary form. Although the difference between then and now is that these practices have become commonplace, the changes, however gradual, have been significant.

\subsubsection{Distributed Computer Systems}

In hardware, the building-block approach to system configuration has evolved into decentralized systems. As the cost of semiconductor circuitry has dropped rapidly, new options have been opened to computer engineers in allocating processing functions among the CPU, channel, controller, and terminal or peripheral device. This, coupled with the maturation of software and communications technology for computer networks has resulted in the distributed computing systems of today.

\subsubsection{Micro- and Multiprogramming Systems}

Microprogramming, a concept which dates back to 1951 but which first received widespread use in a commercial product line in the System $/ 360$, is often the means used to implement distributed processing capability. More significantly, microprogrammin: 
has also provided a "bridge" between hardware and software, not only by facilitating system designs in which the hardware provides an optimal environment for the software but also by permitting systems and even applications functions heretofore carried out in software to be implemented in hardware with significantly improved cost/performance ratios.

The use of microprogramming to provide increased efficiencies in compilation and execution of programs written in higher-level languages has also made assembler language programming almost a thing of the past. Despite the introduction of new programming languages such as PL/1, APL, BASIC, and ALGOL 68 , most computer programs today are written in FORTRAN and COBOL, languages dating back to the late 1950's.

Despite the difficulties encountered in perfecting 3rd- generation operating systems embodying multiprogramming, this concept is employed in all but a very small number of highly specialized, dedicated computer systems today. Moreover, the time-sharing concepts pioneered in the early 1960 's reached sufficient maturity to give rise to a number of commercial time-sharing computer service bureaus in the late 1960 's. Of late, these service bureaus have suffered to some extent from competition provided by portable programmable calculators, but the techniques and concepts which were proven in that service bureau environment-for example, virtual memory-are now an integral part of modern computer networks.

\subsubsection{Minicomputers and Microprocessors}

Even the minicomputer, which now promises to overtake the more traditional "general-purpose mainframes" in constituting the dominant factor in the computing industry, was present in the early 1960 's in the form of products from Digital Equipment Corporation (DEC), Computer Control Corporation (now a subsidary of Honeywell), and Autonetics. Minicomputers have comprised part of the leading edge of the movement toward unbundled software, purchased systems, and distributed systems employing dedicated processors for specialized functions.

Today the microprocessor threatens to overtake the minicomputer in what was formerly the latter's exclusive domain, the original equipment manufacturers (OEM) computer market. As a result, instead of attaching "other things" to computers, computers are now being built into other devices. While this is making possible the intelligent terminals and other devices essential to distributed computer systems, it is having much more far-reaching consequences in application areas such as scientific instrumentation, home appliances, automobiles, and entertainntent (including children's games).

Although present day trends toward networking and distributed systems are expected to continue for some time to come, it is difficult to predict new technological breaktliroughs and their attendant effects. Some inclication of what the future will bring can be gained, however, from current research areas: ultra-high-speed circuits, such as Josephson junction devices; mass-memory systems based on magnetic bubble, charge-coupled device, laser, or electron beam technology; hand-written character and speech recognition; and graphic display output techniques.

It is relatively safe to predict that whatever changes occur will be introduced in an evolutionary, rather than revoluntionary fashion. Although the claim may be correct that the computing industry has now become technology-driven rather than marketdriven, there is much too large an existing investment in capital goods, inventories, trained personnel, and leased equipment for the industry to introduce new technologies and techniques which are totally incompatible with present-day systems. Although the introduction of the IBM System/360 in April 1964. involved new CPUs, memories, peripheral devices, and software all at the same time, systems today are being introduced in piecemeal fashion, and the pieces are designed in such a way as to be useable with older system components as well as those planned for announcement in the not-too-distant future.

\subsection{Computers in the Federal Government: 1965 and 1975}

In the early 1960 's it was often necessary to piece together computer systems from various products which were not necessarily designed to be compatible with one another. Since this usually required the design of special interface hardware and/or software and since the requisite expertise to do this was often not present in the Government agencies involved. technical assistance from NBS was often required. This situation is now changed. Advances in computer component technology make it possible for Federal agencies to use commercial computer products. Even in the rare cases where it is still necessary to integrate and/or interface special equipment for a particular purpose, the technical expertise required to do so is more often available within the Federal agency involved or from private firms.

Other changes which have occurred in the U.S. computer industry and in the use of computers in the Federal Government are shown in tables 5 and 6 . The number of computers las increased significantly, although the rate of growth in the Federal Government is only one-half that of the U.S. as a whole. As in 1965 , the Government continues to purchase a larger portion of its computers than U.S. computer users in general. This may aceount at least partially for the higher average cost of computers in the Government. since purchased systems are not replaced as cuickly as leased systems when new models are announced with better performance per dollar.

Another reason for higher average computer costs in the Government may be the Government's traditional role as the chief sponsor and user of very large scale computers such as are used in defense and space programs. However, as the dat a in tables 5 and 6 suggest, the proportion of "super" computers in Government applieations has declined significantly. 


\begin{tabular}{|c|c|c|}
\hline & 1965 & 1975 \\
\hline Numbers of Computers & 25,165 & 209,061 \\
\hline $\begin{array}{l}\text { Purchased } \\
\text { Leased }\end{array}$ & $\begin{array}{r}7,165(28.5 \%) \\
18,000(71.5 \%)\end{array}$ & $\begin{array}{r}155,586(74.4 \%) \\
53,475(25.6 \%)\end{array}$ \\
\hline $\begin{array}{l}\text { Purchase value } \\
\text { Average value }\end{array}$ & $\begin{array}{l}\$ 7.5 \text { Billion } \\
\$ 298,000\end{array}$ & $\begin{array}{l}\$ 37.8 \text { Billion } \\
\$ 181,000\end{array}$ \\
\hline \multicolumn{3}{|l|}{ Number of computers in three price ranges } \\
\hline System purchase price less than $\$ 200 \mathrm{~K}$ & $16,000(63.6 \%)$ & $164,451(78.7 \%)$ \\
\hline System purchase price between $\$ 200 \mathrm{~K}$ and $\$ 1.5 \mathrm{M}$ & $8,625(34.3 \%)$ & $41,043(19.6 \%)$ \\
\hline System purchase price greater than $\$ 1.5 \mathrm{M}$ & $540(2.1 \%)$ & $3,567(1.7 \%)$ \\
\hline \multicolumn{3}{|l|}{ Number of computer systems from various manufacturers } \\
\hline $\begin{array}{l}\text { Burroughs } \\
\text { CDC } \\
\text { DEC } \\
\text { Data General } \\
\text { Hewlett-Packard } \\
\text { Honeywell \& GE } \\
\text { IBM } \\
\text { NCR } \\
\text { Univac \& RCA } \\
\text { Varian } \\
\text { Xerox } \\
\text { Other }\end{array}$ & $\begin{array}{c}835(3.3 \%) \\
900(3.6 \%) \\
\text { (See note a) } \\
0 \\
0 \\
1,265(5.0 \%) \\
14,285(56.8 \%) \\
1,305(5.2 \%) \\
3,985(15.8 \%) \\
0 \\
(\text { See note a) } \\
2,590(10.3 \%)\end{array}$ & $\begin{array}{r}3,971(1.9 \%) \\
2,416(1.1 \%) \\
41,082(19.7 \%) \\
15,040(7.2 \%) \\
12,340(5.9 \%) \\
9,950(4.8 \%) \\
54,829(26.2 \%) \\
5,026(2.4 \%) \\
4,845(2.3 \%) \\
4,125(2.0 \%) \\
1,651(0.8 \%) \\
54,186(25.9 \%)\end{array}$ \\
\hline Source: International Data Corporation & & \\
\hline
\end{tabular}

a Included in figures for "other" in 1965 data.

\subsection{Identifying Problems to be Addressed in the NBS Brooks Act Program}

NBS makes every effort to match its limited resources to the ADP problems that are most pressing for Federal agencies. The identification and selection process is difficult and has been the subject of special study efforts; one approach is described below.

NBS, using inputs from Federal agencies, the General Accounting Office, the Congress and representatives of industry, has compiled the major computer applications by generic type. The principal computer applications are listed below:

\section{Principal Computer Applications}

\section{(1) Data ${ }^{1}$ Acquisition and Validation}

Real-time sensors

Nonreal-time dat a collection

Aut omated data reading

\section{(2) Recordkeeping (Information Storage and Re-} trieval)

Personal records (for current operational use) Management data records (e.g., profit, budget)

"Data" and "information" are used interchangeably depending upon traditional usage in the computer field.
Administrative data records (e.g., payroll)

Operational data records (e.g., inventory, daily sales, transaction records, laboratory experiment records)

Historical, bibliographical and/or research records (e.g., census, judicial, hist ory archival, library records)

(3) Management Information Services (Management Information Storage, Manipulation, Analysis, Retrieval and Display)

\section{(4) Real-Time Control}

Moving vehicles (e.g., commercial aircraft, satellites, targetted weapons, mass rapid transit)

Operational systems (e.g., electric utility distribution networks, telephone systems, railroad systems, police department activities, computer-aided instruction)

Information systems (e.g., electronic fund transfer systems, retail point-of-sale and supermarket check-out systems, automated warehousing and distribution, airline reservation systems)

Automated laboratory experiment systems

Automated production Continuous process control 
TABLE 6. Computers in the Federal Government: 1965 versus 1975

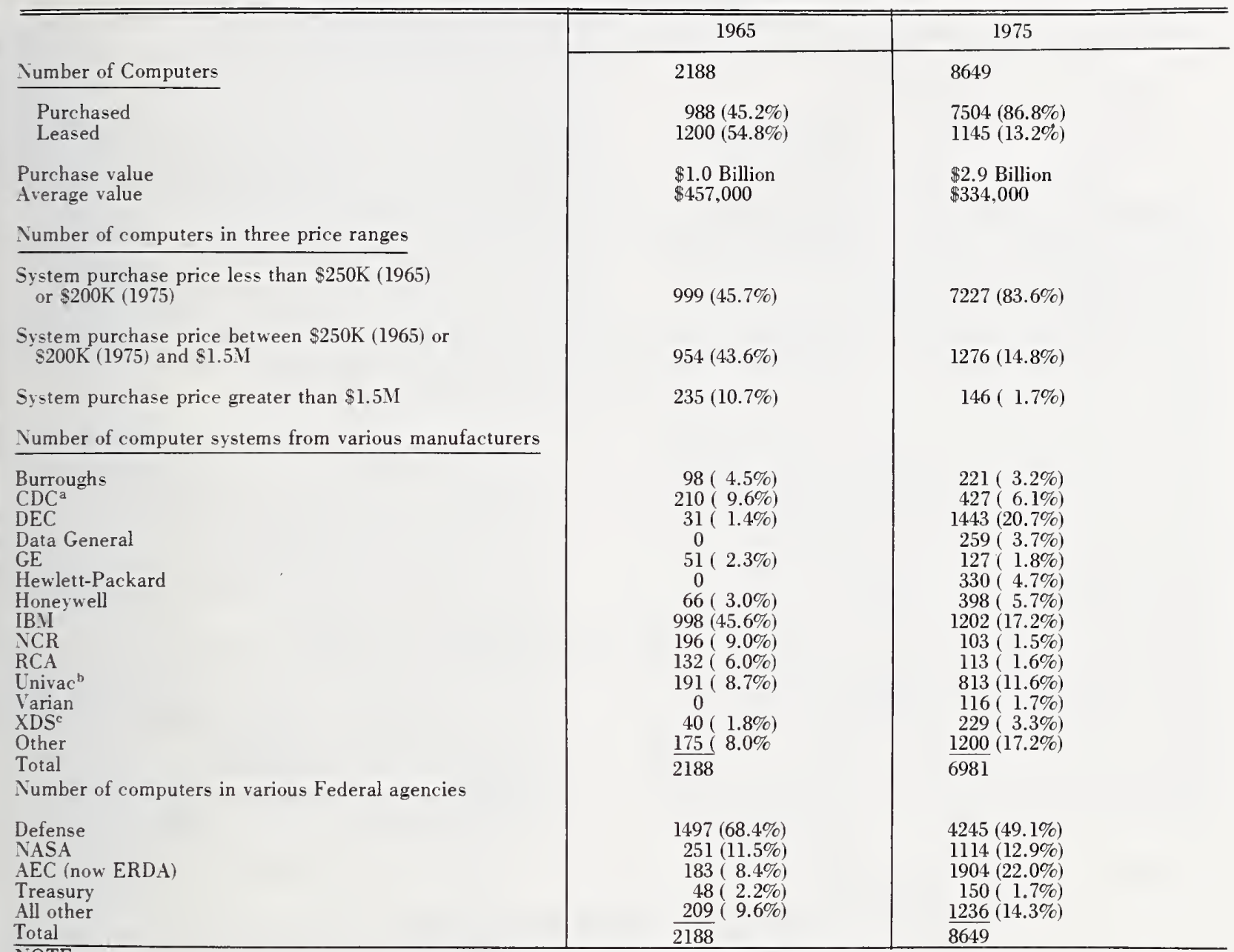

NOTE:

Source: Inventory of Automatic Data Processing Equipment in the Federal Government, General Services Administration, 1965 and 1975. This inventory excludes analog computers and digital computers built or modified to special Government design and integral to a weapons or space system.

\footnotetext{
a includes Bendix

b includes EMR

${ }^{c}$ includes SDS
}

Discrete parts manufacturing

Discrete production lines

Teleoperators and/or remote manipulators

(5) Real-Time Monitoring

Individual identification (e.g., controlled-entry areas, computer network access, emergency medical services, voting, credit transactions)

Individual health care (e.g., coronary care units, intensive care units, automated medical instrumentation, patient monitoring)

Vehicle, personal location monitoring

Environmental monitoring (e.g., air pollution, water pollution)

Area monitoring (e.g., electronic area surveillance, house protection services)
Quality control monitoring

Meter reading

(6) Modeling and Simulation

Economic

Systems design, performance, operation

Product performance

Planning

War-gaming

System, product

Nondestructive evaluation

Technology prediction, assessment

(7) Scheduling, Allocation, Dispatching 
(8) Scientific and Research Investigations

\section{(9) Specialized Applications}

Automated photocomposition

Automated stenotype

Next, NBS matched these computer applications with Federal sector activities. Figure 1 shows the computer applications relevant to each category of Federal activity.

The next step in the process was to identify the principal problems and issues of continuing concern in the computer and automatic data processing field. Again, inputs were drawn from Federal agencies, GAO reports, the Congress, and industry. The identified problems and issues are shown in figure 2.

Selected highest priority technical and technology problems and issues identified in the preceding process were then matched against computer applications categories (from fig. 1); the resulting matrix is shown in figure 3.

The culmination of the entire process is illustrated in figure 4. The dominant computer applications and their sectors of widest impact were intersected with problem and issue categories to produce a list of problems and issues that should receive priority attention. By identifying the major trade and professional associations within the sectors of widest impact, one can then produce a list of such associations with which NBS should work in attempting to resolve the identified priority problems and issues.

\section{Resources}

This section provides a summary of the funding history of the NBS Computer Science and Technology Program undertaken in accordance with authorities assigned to the Secretary of Commerce by the Brooks Act. The tables provided here profile the funds requested and appropriated for the period FY1965-FY1977, and show the allocation of directly appropriated funds to program functional areas.

In order to illustrate the emphasis that has been placed on the different aspects of the Bureau's Brooks Act responsibilities, funding data have been aggregated under broad activity categories as defined in the Act and the Office of Management and Budget implementing Policy guidance. The Brooks Act categories are:

- develop uniform Federal automatic data processing standards,

- provide scientific and technological advisory services to Federal agencies, and

- conduct necessary research in computer sciences and technologies. (This research directly supports the standards development category shown above.)

The OMB policy guidance categories are:

- provide scientific and technological advisory services to Federal agencies,

- participate in the development of voluntary commercial ADP standards,

- develop uniform Federal ADP standards,

- conduct necessary research, and

- provide computer services to NBS.

\section{COMPUTER APPLICATION BY}

FEDERAL SECTOR ACTIVITY

\begin{tabular}{|c|c|c|c|c|c|c|c|c|c|}
\hline \multirow[b]{2}{*}{ FEDERAL SECTOR ACTIVITY } & \multicolumn{9}{|c|}{ COMPUTER APPLICATIONS } \\
\hline & 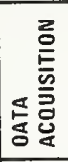 & 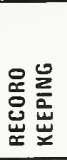 & 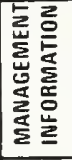 & 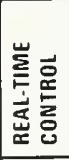 & 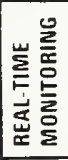 & 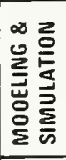 & 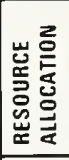 & 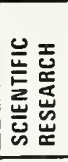 & 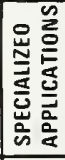 \\
\hline NATIONAL OEFENSE & - & - & $\bullet$ & - & - & - & $\bullet$ & - & $\bullet$ \\
\hline NATIONAL SECURITY & - & - & - & - & $\bullet$ & - & & - & \\
\hline LEGISLATIVE & - & $\bullet$ & $\bullet$ & & - & & & & \\
\hline $\begin{array}{l}\text { JUOICIAL } \\
\text { PUBLIC SAFETY }\end{array}$ & - & ? & - & - & - & & - & & - \\
\hline WELFARE SERVICES & - & - & - & & & & & & 0 \\
\hline RESEARCH \& OEVELOPMENT & - & - & $\bullet$ & & & $\bullet$ & & 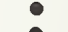 & \\
\hline PUBLIC HEALTH & - & - & - & & $\bullet$ & $\bullet$ & & $\bullet$ & \\
\hline HOUSING \& URBAN SERVICES & - & - & - & & & - & & & \\
\hline FINANCIAL & - & - & - & & & & 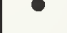 & & 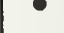 \\
\hline TRANSPORTATION & - & $\bullet$ & - & $\bullet$ & $\bullet$ & - & & - & \\
\hline INTERNATIONAL AFFAIRS & & - & - & & & 0 & & & \\
\hline COMMERCE & - & $\bullet$ & $\bullet$ & & & & - & & \\
\hline PUBLIC LANDS & & 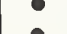 & 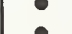 & & & & & & \\
\hline NATURAL RESOURCES & & 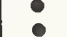 & 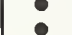 & & & - & 0 & & • \\
\hline GENERAL SCIENCE, SPACE & & & & & & & & & \\
\hline \& TECHNOLOGY & - & - & - & - & - & - & & & $\bullet$ \\
\hline EDUCATION & & $\bullet$ & $\bullet$ & & & & & & \\
\hline
\end{tabular}

Figure 1 


\section{CATEGORIES OF COMPUTER PROBLEMS/ISSUES}

\section{TECHNICAL}

- INADEQUATE SECURITY SAFEGUARDS

- LACK OF PERFORMANCE MEASUREMENT TECHNIQUES

- NEED FOR IMPROVED METHODS OF NETWORKING

- TECHNOLOGY

SOFTWARE - Mathematical MOdels

- MEASUREMENT \& EVALUATION TECHNIOUES

- PROGRAM TRANSFERABILITY

- SOFTWARE SUPPORT FDR MINICOMPUTERS

DATA

- QUALITY CONTROL

STRUCTURE

- FILE STRUCTURE \& OATA MANAGEMENT

MEMORY

- VERY LARGE StORAGE DEVICES

ARCHITECTURE - OPERATING SYSTEMS

- COMPUTER SYSTEM OESIGN

- VERY LARGE STORAGE DEVICES

INPUT/OUTPUT - COMPUTER GRAPHICS

- HIGH OENSITY STORAGE MEOIA

- ARCHIVAL PRDPERTIES OF STORAGE MEOIA

MANAGERIAL

- INADEQUATE SECURITY SAFEGUARDS

- INADEQUATE SOFTWARE MANAGEMENT

- INADEQUATE INFORMATION MANAGEMENT PRACTICES

- DISSIPATION OF COMPUTER MANPOWER SKILLS

- INEFFICIENCY IN COMPUTER UTILIZATION

- LACK OF CONCERN FOR CONSUMER OF SERVICES
ECONOMIC

- PREDATORY MARKET PRACTICES

- LACK OF QUALITY CONTROL OF COMPUTER SERVICES

- NEED FOR MARKETPLACE STANDARDS

- NEED FOR IMPROVED NETWORKING METHODS

MARKETPLACE

- INADEQUATE INFORMATION FOR THE CUSTOMER

- LACK OF PERFORMANCE MEASURES

- LACK OF QUALITY CONTROL FOR COMPUTER SERVICES

- INADEQUATE SELECTION TECHNIOUES FOR THE CUSTOMER

\section{SOCIETAL}

- POOR QUALITY SERVICES FOR THE PUBLIC

- LACK OF GOOD INFORMATION MANAGEMENT PRACTICES

- CONSUMER IGNORANCE OF COMPUTER'S ROLE

\section{LEGAL \\ - PREDATORY MARKET PRACTICES \\ - NEED FOR MARKETPLACE STANDARDS \\ - INADEQUATE PROTECTION OF DATA \\ - MONOPOLISTIC PRACTICES \\ - LACK OF INTERFACE STANDARDS \\ - INADEQUATE INFORMATION FOR THE CUSTOMER}




\section{MAJOR PROBLEMS/ISSUES \\ BY COMPUTER APPLICATION}

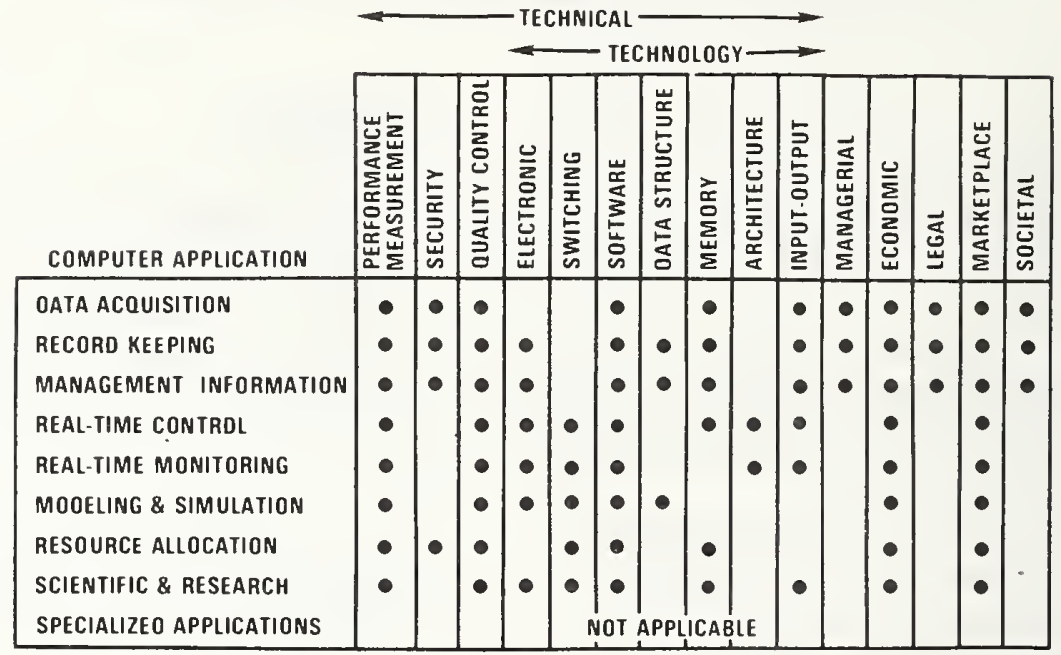

Figure 3

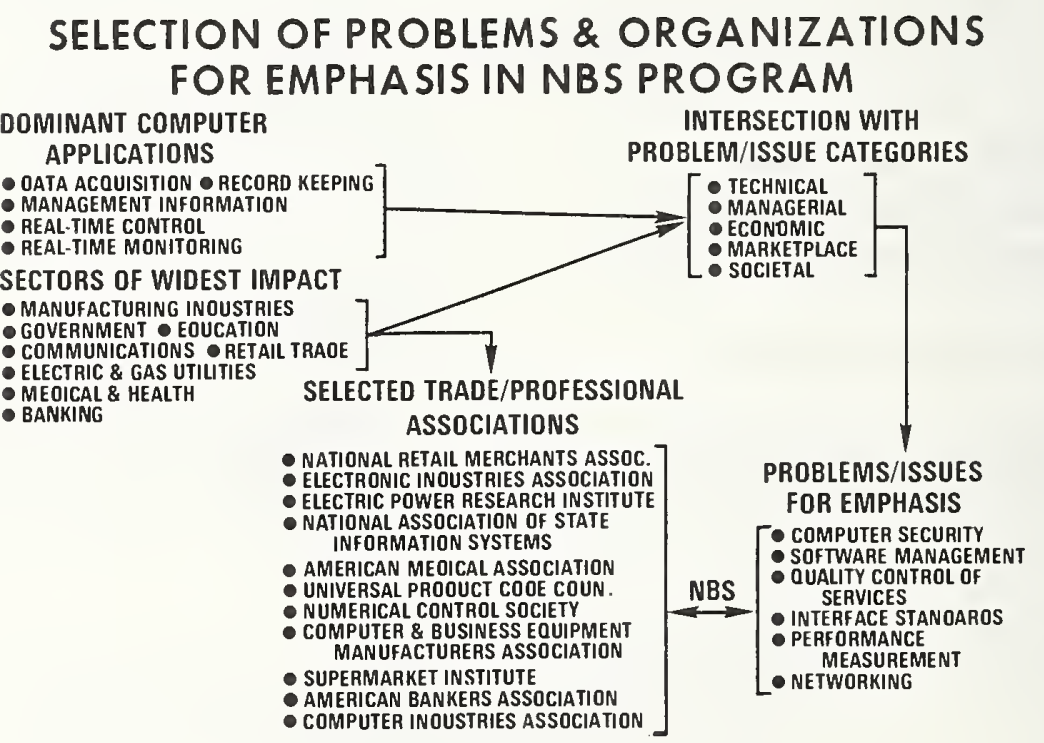

Figure 4

There are three sources of money to fund the Computer Science and Technology Program. Direct Congressional appropriations provide the backbone funding for the development of standards, necessary research and some advisory services. Reimbursements from other agencies fund a major portion of the advisory services and technical assistance provided upon request to other agencies. Fees collected from the users of central computer resources cover the majority of the costs of providing computer services at NBS. The funding data presented in this section are limited to Congressional appropriations only.
The fiscal year totals for funds requested, appropriated and allocated have been derived from NBS Budget Division records by analyzing funds for each ICST program subelement (i.e., Computer Security, Computer Utilization, Computer Networking and Performance Measurement, and Functional Applications of Computer Technology) and aggregating them by Brooks Act function or $\mathrm{OMB}$ policy guidance category. These resultant estimated aggregations are considered to have an acceptably high degree of accuracy, particularly for the period FY1970-FY1977 where records are more complete than for earlier years. 
Table 7 is a profile of the Institute for Computer Sciences and Technology's (ICST) directly appropriated funding for the period FY1965-FY1977. It traces for each fiscal year the actions taken on the ICST budget request at each managerial level. the amount appropriated by the Congress, and, finally, the actual funds allocated to ICST for application to its program. The table shows that, during the period FY1965-FY1977 (projected), NBS requested approximately $\$ 44$ million for the Computer Science and Technology Program. The Congress appropriated 67.4 percent or nearly $\$ 30$ million of the amount requested.

Table 7 shows that the aggregate funds allocated to ICST matches the amount appropriated by the Congress. It should be noted. however, that nearly $\$ 1.7$ million of directly appropriated funds were not allocated to ICST: this amount is counter-balanced (to within $\$ 160,000$ ) by base adjustments and the allocation of funds stemming from NBS reprogramming actions to support high priority efforts such as computer security, particularly in the later years of the time period.

Table 8 shows the estimated obligation of Congressionally appropriated funds by each of the three Brooks Act categories of responsibility assigned to NBS. Because Category 3 (Research) is directly supportive of standardization activities, it can be combined with Category 1 to show that, for the period FY1965-FY1977, 80 percent of all Congressionally appropriated Brooks Act funds were applied to the development of standards. Of the remaining funds. 15.5 percent were applied to Scientific and Technological Advisory Services and 4.4 percent were applied to NBS Computer Services.

Table 9 shows the estimated funding requested by NBS for the period FY1973-FY1977 for the Computer Science and Technology Program. The funds are shown by the five categories of activity provided in O.MB policy guidance letter dated December 15 , 1966. The fiscal year span portrayed in this table covers the period since reorientation of the Computer Science and Technology Program in accordance with the NBS Brooks Bill Issue Study dated September 1971 prepared in response to an OMB request for a study of "what can be done to make the contributrion of the NBS more effective in achieving greater efficiency and economy in Government ADP operations, as envisioned in the Brooks Act. It shows a 5 percent increase in the allocation of funds to the development of standards.

Table 10 shows the estimated obligation of Congressionally appropriated funds and associated manprswer by each of the five OMB policy guidance categories for the period FY1973-FY1977.

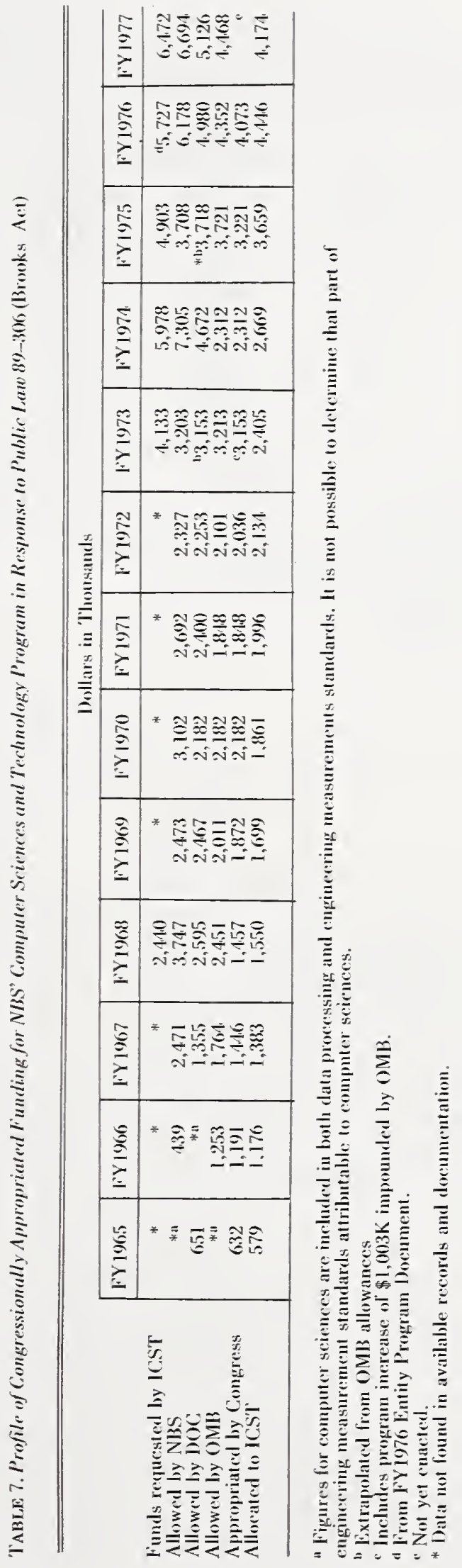


TABLE 8. Profile of the Estimated Obligation of Directly Appropriated Funds by Brooks Act Categories in the NBS Computer Science and Technology Program

\begin{tabular}{|c|c|c|c|c|c|c|c|}
\hline \multirow{3}{*}{$\begin{array}{l}\text { Fiscal } \\
\text { Year } \\
\end{array}$} & \multirow{3}{*}{$\begin{array}{c}\text { Total Funds } \\
\text { Available } \\
\$ 000\end{array}$} & \multicolumn{6}{|c|}{ Funds Obligated by Brooks Act Category* } \\
\hline & & \multicolumn{2}{|c|}{ I } & \multicolumn{2}{|c|}{2} & \multicolumn{2}{|c|}{3} \\
\hline & & $\$ 000$ & $\%$ & $\$ 000$ & $\%$ & $\$ 000$ & $\%$ \\
\hline $\begin{array}{l}1965 \\
1966 \\
1967 \\
1968 \\
1969 \\
1970 \\
1971 \\
1972 \\
1973 \\
1974 \\
1975 \\
1976 \\
1977\end{array}$ & $\begin{array}{r}579 \\
1176 \\
1383 \\
1550 \\
1699 \\
1861 \\
1996 \\
2134 \\
2405 \\
2669 \\
3659 \\
4446 \\
4174 \text { EST }\end{array}$ & $\begin{array}{r}365 \\
813 \\
952 \\
1008 \\
1019 \\
1065 \\
1285 \\
1302 \\
1256 \\
1431 \\
2750 \\
3161 \\
2995\end{array}$ & $\begin{array}{l}63.0 \\
69.1 \\
68.8 \\
65.0 \\
60.0 \\
57.8 \\
64.4 \\
61.0 \\
52.2 \\
53.6 \\
75.2 \\
71.1 \\
71.8\end{array}$ & $\begin{array}{l}114 \\
161 \\
210 \\
184 \\
131 \\
184 \\
224 \\
465 \\
256 \\
589 \\
645 \\
642 \\
812\end{array}$ & $\begin{array}{r}19.6 \\
13.6 \\
15.2 \\
11.9 \\
7.7 \\
9.9 \\
11.2 \\
21.8 \\
10.6 \\
22.1 \\
17.6 \\
14.4 \\
19.5\end{array}$ & $\begin{array}{l}100 \\
202 \\
221 \\
358 \\
549 \\
597 \\
232 \\
301 \\
774 \\
565 \\
169 \\
166 \\
158\end{array}$ & $\begin{array}{r}17.3 \\
17.1 \\
16.0 \\
23.1 \\
32.3 \\
32.1 \\
11.6 \\
14.1 \\
32.3 \\
21.2 \\
4.6 \\
3.7 \\
3.8\end{array}$ \\
\hline $\begin{array}{l}\text { Totals } \\
\text { Percent of Total }\end{array}$ & $\$ 29,731$ & $\$ 19,402$ & $65.3 \%$ & $\$ 4,617$ & $15.5 \%$ & $\$ 4,392$ & $14.8 \%$ \\
\hline
\end{tabular}

Approximately 4.4 percent of total directly appropriated funds were allocated to NBS computer services support which is not included in either of the three Brooks Act Categories.

* 1 = Development of Standards

$2=$ S\&T Advisory Services

$3=$ Research

TABLE 9. Estimated funding requested by NBS (\$000)

\begin{tabular}{|c|c|c|c|c|c|c|c|c|c|c|}
\hline \multirow[b]{2}{*}{ Category } & \multicolumn{2}{|c|}{ FY1973 } & \multicolumn{2}{|c|}{ FY1974 } & \multicolumn{2}{|c|}{ FY1975 } & \multicolumn{2}{|c|}{ FY1976 } & \multicolumn{2}{|c|}{$\begin{array}{c}\text { PROJECTED } \\
1977\end{array}$} \\
\hline & $\$$ & $\begin{array}{l}\% \text { of } \\
\text { total } \\
\text { funds }\end{array}$ & $\$$ & $\begin{array}{l}\% \text { of } \\
\text { total } \\
\text { funds }\end{array}$ & $\$$ & $\begin{array}{l}\% \text { of } \\
\text { total } \\
\text { funds }\end{array}$ & $\$$ & $\begin{array}{l}\% \text { of } \\
\text { total } \\
\text { funds }\end{array}$ & $\$$ & $\begin{array}{r}\% \text { of } \\
\text { total } \\
\text { funds }\end{array}$ \\
\hline Advisory Services & 785 & 24.5 & 796 & 10.9 & 315 & 8.5 & 689 & 11.2 & 642 & 9.6 \\
\hline $\left.\begin{array}{l}\text { Voluntary Standards } \\
\text { Federal Standards }\end{array}\right\}$ & 1441 & 50.0 & 4311 & 59.0 & 2692 & 72.6 & 4595 & 74.4 & 5613 & 83.9 \\
\hline Research & 857 & 26.8 & 1990 & 27.2 & 624 & 16.8 & 827 & 13.5 & 295 & 4.4 \\
\hline Computer Services & 120 & 3.7 & 208 & 2.8 & 77 & 2.1 & 67 & 1.1 & 144 & 2.2 \\
\hline Total Funds & $\$ 3203$ & & $\$ 7305$ & & $\$ 3708$ & & $\$ 6178$ & & $\$ 6694$ & \\
\hline
\end{tabular}

Summary of percentages of total funds requested by category for the entire period FY1973—FY1977

Advisory Services

Voluntary Standards)

Federal Standards $\}$

Research

Computer Services
$11.9 \%$

$68.9 \%$

$16.9 \%$

$2.3 \%$ 


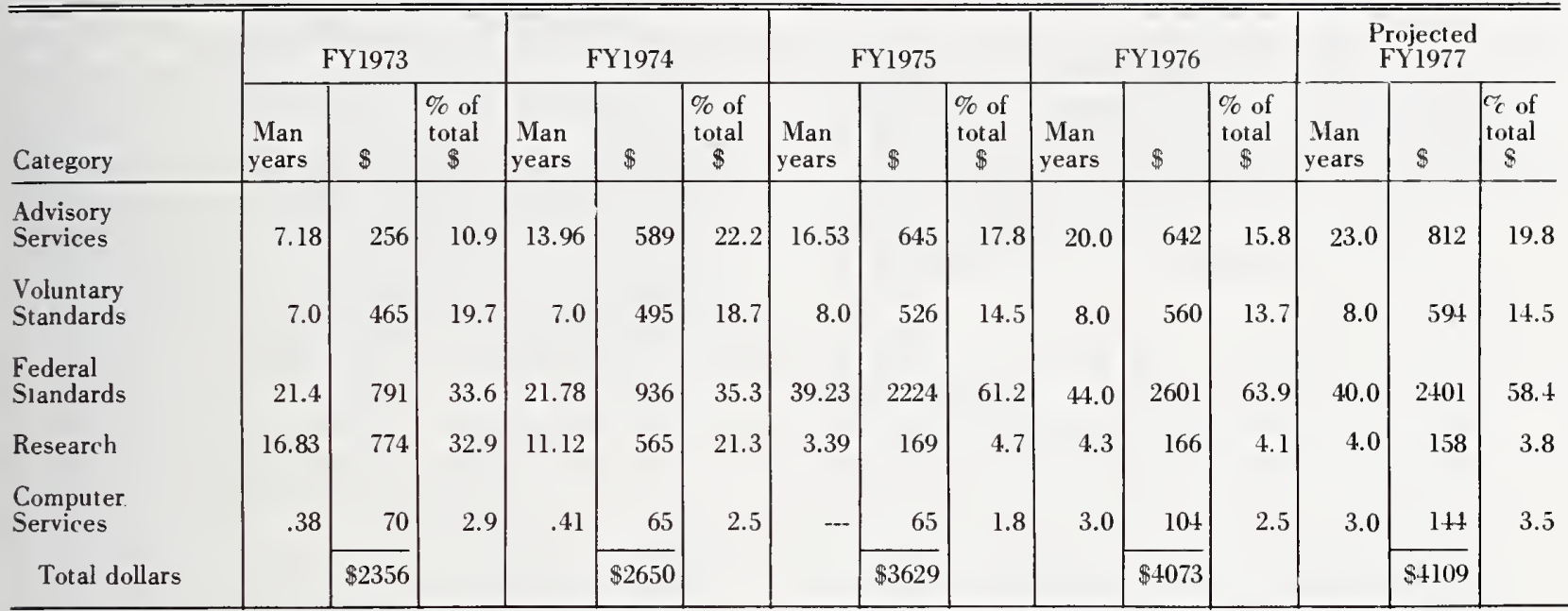

Summary of percentage allocations to category for entire period FY1973-FY1977

$\begin{array}{lc}\text { Advisory Services } & 17.5 \% \\ \text { Voluntary Siandards* } & 15.7 \\ \text { Federal Standards* } & 53.2 \\ \text { Research* } & 10.9 \\ \text { Computer Services } & 2.7 \\ * 79.8 \% \text { of all funds were allocated to the development of standards }\end{array}$

\section{Overview of NBS Responses to Brooks Act Responsibilities}

This section of the report describes the actions NBS has taken relative to its assigned Brooks Act responsibilities. The section is divided into three parts: (1) Advisory Services, (2) ADP Standards, and (3) Research. These sections are subdivided into the specific tasks assigned to NBS by the OMB policy guidance letter of December 15, 1966 with each subsection containing a description of NBS implementing action.

\subsection{Advisory Services}

\subsubsection{Background}

The Brooks Act assigned NBS responsibility: "To provide agencies . . . with scientific and technological advisory services relating to automatic dat a processing and related systems." The OMB Policy Guidance Letter of December 15, 1966 stated that:

"The Center will provide scientific and techonological advisory and consulting services 10 executive agencies on automalic dat a processing. Upon request of Federal agencies, the Center will, 1o the extent possible, provide direcl assislance on specific projects and monitor the technical performance of commercial contracls."
NBS has made substantive progress toward carrying out this responsibility.

Since its establishment in 1966 as a Center within the National Bureau of Standards, the organization known since 1972 as the Institute for Computer Sciences and Technology has directed a significant portion of its resources to providing advisory services aimed at helping Federal agencies solve ADP related problems. The bulk of the advisory service activity in the initial five year period of the Center was devoted to systems analysis type work directly supporting Federal agencies who were incorporating new computer hardware or software systems into their operations. By-and-large these activities were specific applications oriented. The general thrust was to help other agencies run computers better and to do, research for them on specific problems which arose in connection with their computer applications.

Starting in FY1972 this program activity was reoriented so as to place more stress upon support to Federal poliey-making offices concerned with the impact of the use of computers within our society. and upon improvements in Governmental operations which might be facilitated through the use of computerized techniques. Through this reorientation, emphasis was given to solving problems common to several agencies. Thus the work in this program area now encompasses five general categories: support to 
policy formulation, technology assessment, support to U.S. international activities in ADP, specific applications in Federal agencies, and information services.

Consultative and advisory services have been provided to more than 30 Federal agencies with specific problems in a broad range of subjects. The following are examples of these activities:

- feasibility study assistance to determine the need for a computer-National Labor Relations Board,

- computer selection assistance-Peace Corps, Civil Service Commission, Department of Labor, Patent Office, National Center for Health Statistics, Bonneville Power Authority,

- assistance in basic information system design-Food and Drug Administration, National Institutes of Health, Small Business Administration, Treasury Department, National Center for Radiological Health,

- review of the effectiveness of existing systems-Naval Oceanographic Office, General Services Administration-Communications Service, Department of Health, Education, and Welfare, Agency for International Development, Army Map Service, and

- development of special data processing techniques-U.S. Patent Office.

Area of work which are of general assistance to all agencies include:

- the conduct of feasibility studies,

- guidelines for computer performance evaluation,

- guidelines for network performance evaluation, and

- the operation of a computer information service to provide access for Government agencies to the growing store of computer science information and experience.

In order that the knowledge and experience developed in course of fulfilling the technical advisory services responsibility be made available for general use throughout Government, the Institute has undertaken to codify such experience through reports, technical notes, monographs, and other formal publication means. These have generally been made available as NBS publications under the Bureau's publication system. In the period FY 1965 to FY 1975, nearly one hundred such reports were published as the product of advisory services rendered to more than twenty Departments and agencies in the Federal
Government as well as to organizations such as the Engineering Foundation, the American National Standards Institute and the Council on Library Resources. While relatively few of these publications were prepared directly for the central management agencies (GSA and OMB), it should be noted that the bulk of the STRS technical effort of the Institute is directly keyed to technical aspects of the central management responsibilities of those agencies. It must of course, be recognized that the true "product" of this effort lies not in the publication of reports, but in the improved effectiveness and efficiency of the ADP operations of the agencies brought about through the advisory activity itself.

A list of publications resulting from advisory services is contained in appendix $B$.

\subsubsection{Relevant Authorities}

(1) Extracts from the February 1965, Report to the President on the Management of Automatic Data Processing in the Federal Government, by the Executive Office of the President, Bureau of the Budget, Washington, D.C. 20503

\section{The National Bureau of Standards}

Under its authority to develop standards, perform scientific research and advise Government agencies on scientific and technical problems, the $\mathrm{Na}$ tional Bureau of Standards has engaged in the following automatic data processing activities:

-NBS, to the extent its limited resources permitted, has provided technical advice and assistance to executive agencies in information problem analysis, computer systems design, development of system specifications, and equipment selection.

-NBS research in the computer sciences began with its direct involvement in the design, construction, programing, operation and use of the first computers built. Dating from the late 1940's computer science research at NBS has continued to the present and includes the provision of advisory services in the application of computer sciences to the problems of various executive agencies.

\section{Problem of advanced system design}

The tremendous effect of system design on the efficiency and effectiveness of computer applications makes it desirable that means be developed for assuring that techniques of high quality system design are utilized. The problem is compounded by the fact that designing systems involves an evolving technology that calls for a high degree of individual competence applied to unique situations.

The selection of equipment requires extensive knowledge of the use for which the equipment is 
intended and of the performance of available machines. In making the selection, procedures are needed that are not overly expensive. lead to the right choice, and encourage competition.

This problem has been met in part by the National Bureau of Standards, Department of Commerce, which has upon request provided assistance to agencies, to the extent possible. The demands for assistance have far exceeded resources to service them. Other agencies have at times cooperated by lending trained personnel-often at a sacrifice to their own programs. In other cases, commercial sources have been used to carry out studies.

There is a need for a pool of trained personnel who can be called upon, as needed, to help agencies-particularly smaller ones-in solving problems related to computer systems.

The needs of agencies for assistance in the analysis and design of computer-based systems must be met. Because the National Bureau of Standards has performed this role in the past, to the extent its resources permitted, and because of its established competence in this field, it seems logical that its resources should be expanded to meet more fully the needs of agencies for assistance in systems work.

\section{Recommendations}

The Department of Commerce, through the National Bureau of Standards, should expand the advisory services currently being provided to agencies in the analysis and design of computer-based systems. Its resources allocated for this purpose should be increased to the extent required to meet such needs as fully as possible.

\section{Problem of marginal uses}

Ordinarily, the greatest advantage for the Government is derived when a computer is devoted to accomplishing the missions of an agency, as opposed to routine administrative tasks. Examples are numerous: they include the use of computers in administering veterans' benefits, social security benefits, and the tax system; in tracking satellites; in performing theoretical investigations for scientific programs; in predicting demands for electric power; in weather forecasting; and in controlling air traffic. There are advantages in using computers for administrative tasks such as payroll and personnel accounting. However, since administrative functions normally are a relatively small part of total operations, the potential benefits $t$, be derived from these applications are limited.

\section{Recommendations}

The Department of Commerce should determine the extent to which the resources of the National Bureau of Standards need to be expanded to serve as a research center on computer science and technology, primarily oriented toward Government applications, and to serve as an advisory service and consulting center for all Government agencies.

\section{The Report:}

Proposed the enactment of legislation by the Congress which would (a) constitute an expression of congressional policy and interest with respect to effective and economical use of auto $\mathrm{m}_{\mathrm{a}}$ atic data processing equipment, and (b) strengthen the authorities for the development, testing and implementation of standards; the performance of research in computer sciences and the provision of advisory services by the National Bureau of Standards; and the establishment of a revolving fund to finance arrangements for the joint utilization of computer facilities.

(2) Extract from Public Law 89-306 (Brooks Act), dated October 30, 1965

An Act

To provide for the economic and efficient purchase, lease, maintenance, operation, and utilization of automatic data processing equipment by Federal departments and agencies.

". . The Secretary of Commerce is authorized (1) to provide agencies, and the Administrator of General Services in the exercise of the authority delegated in this section, with scientific and technological advisory services relating to automatic data processing and related systems, . . ."

(3) Extract from OMB Policy Guidance paper to implement the Brooks Act which is an enclosure to Bureau of the Budget letter to Secretary of Commerce dated December 15, 1966.

\section{Basic Policy}

The provisions of P.L. 89-306 will be administered in a manner that is consistent with the prime objective of encouraging the use of ADP by Government agencies to achieve greater productivity and reduced costs in the discharge of their respective agency program responsibilities.

Responsibility to carry out these functions for the Secretary has been assigned to the Center for Computer Sciences and Technology 
(CCST), an organization within the Institute for Applied Technology, National Bureau of Standards.

In carrying out its responsibilities, the Center should maximize the utilization of existing capabilities and facilities even when they reside in agencies not specifically identified in P.L. 89-306.

The interrelationships among the central management agencies identified in P.L. 89-306 and the using agencies, coupled with the dynamic nature of the ADP technology, require that a special effort be made to expedite policy development and implementation ....

\section{Initial Guidelines}

\section{Advisory and Consulting Services}

The Center will provide scientific and technological advisory and consulting services to executive agencies on automatic data processing. Upon request of Federal agencies, the Center will, to the extent possible, provide direct assistance on specific projects and monitor the technical performance of commercial contracts. In addition, the Center will:

- provide guidelines for use by agencies in conducting systems studies, including consideration of systems interrelationships,

- provide guidelines and methods for monitoring the performance of systems studies and for implementing the results of such studies,

- provide criteria to assist in evaluating software and hardware developments that may be considered during the svstems studies,

- provide technical guidelines for preparing solicitations of proposals, including the specificiation of system requirements,

- provide guidelines, criteria and techniques for evaluating and selecting equipment and related software, giving priority emphasis to criteria for measuring the effectiveness and efficiency of software; data on this subject will also be furnished to GSA for consideration in the procurement of computers,

- maintain a reference index of computer programs to minimize the need for the development of programs already developed, tested and in use elsewhere, and
- provide guidelines for evaluating installation and systems performance on a continuing basis.

The Center will keep abreast of the state-ofthe-art developments in ADP equipment, techniques and languages and will evaluate these developments in terms of their current or potential impact upon the Government's use of equipment and software and its ADP management policies. Findings in this regard will be made known promptly to the Bureau of the Budget.

It is essential for NBS staff who are consulting with agencies in system design to be fully aware of on-going system developments, whether performed in-house or under contract for other Government agencies. In this connection, a study should be made and reported to the Bureau of the Budget soon after January 1 , 1967, to explore the feasibility of developing a system by which each Federal agency would keep the NBS informed of all ADP system design study projects. In additon to the possibility of NBS maintaining a current index of projects in progress, consideration should be given to requiring agencies to provide NBS, for a central reference file, copies of the reports of such information systems studies.

(4) Extract from Title 15 (Code of Federal Regulations)-Commerce and Foreign Trade

\section{SUBTITLE A- OFFICE OF THE SECRE- TARY OF COMMERCE}

\section{PART 6-STANDARDIZATION OF DATA ELEMENT AND REPRESENTATIOND (as amended May 9, 1973)}

... Responsibilities

\section{... National Bureau of Standards}

...Provide technical assistance, as requested and within the limits of available resources to Federal departments and agencies on matters concerning the utilization of automatic data processing and standardization.

(5) Extracts from NBS Organic Act. (As given in U.S. Dept. of Commerce, NBS, Administrative Manual.)

\subsection{1 .01}

\section{BASIC LEGISLATION}

The National Bureau of Standards was established on March 3, 1901, by "An Act to Establish the National 
Bureau of Standards“" (31 Stat. 1449). Extensive amendements were made in 1950 by passage of Public Law 81-619 (64 Stat. 371): in 1956 by Public Law 81-940 (70 Stat. 959): and in 1958 by Public Law $85-890$ (72 Stat. 1711). The provisions of the organic act and amendments are merged in the following statement of basic legislation quoted from Title 15 of the United States Code.

\subsection{1 .03}

FUNCTIONS OF SECRETARY

(15 U.S.C. 272)

"The Secretary of Commerce (hereinafter referred to as the "Secretary") is authorized to undertake the following functions:

"(e) Advisory service to Government agencies on scientific and technical problems.

"In carrying out the functions enumerated in this section: the Secretary is authorized to undertake the following activities and similar ones for which need may arise in the operations of Government agencies, scientific institutions. and industrial enterprises:

$\therefore(19)$ the compilation and publication of general scientific and technical data resulting from the performance of the functions specified herein or from other sources when such data are of importance to scientific or manufacturing interests or to the general public, and are not available elsewhere, including demonstration of the results of the Bureau's work by exhibits or otherwise as may be deemed most effective, and including the use of Tational Bureau of Standards scientific or technical personnel for parttime or intermittent teaching and training activities at educational institutions of higher learning as part of and incidental to their official duties and without additional compensation other than that provided by law."

\subsection{1 .04}

FUNCTIONS: FOR WHOII EXERCISED

(15 U.S.C. 273)

"The Bureau is authorized to exercise its functions for the Government of the United States and for international organizations of which the United States is a member: for governments of friendly countries: for any State or municipal government within the United States: or for any scientific society. educational institution. firm. corporation. or individual within the United States or friendly countries and scientific societies. educational institutions. firms. corporations. or individuals therein shall be in coordination with other agencies of the United States Government. in particular the Department of State in respect to foreign entities. All requests for the services of the Bureau shall be made in accordance with the rules and regulations established in sections 276 and 277 of this title (15 U.S.C.)."

\subsection{1 .07}

\section{SERVICE CHARGES}

(15 U.S.C. 275a)

-The Secretary shall charge for services performed under the authority of section 273 of this title. [15 U.S.C.] except in cases where he determines that the interest of the Government would be best served by waiving the charge. Such charges may be based upon fixed prices or costs. The appropriation or fund bearing the cost of the services may be reimbursed. or the Secretary may require advance payment subject to such adjustment on completion of the work as may be agreed upon."

\subsubsection{Relevant OMB and GAO Issuances}

(1) Extract from OUB Circular A-71. dated March 6. 1965. Subject: Responsibilities for the Administration and Management of Automatic Data Processing Activities

Responsibility of the Department of Commerce: provide advisory and consultative services to executive agencies on the methods for developing information systems based on the use of computers and the programming and languages thereof.

(2) Extract from GAO report of December $29.197-2$ on - Veans for Increasing the Use of Defense Technology for Urgent Public Problems."

\section{Chapter 6 and Appendix III.}

“The communication gap between technology developers and potential users is a significant barrier to the transfer process particularly where their technical disciplines and problems are not similar. Although there are several clearinghouses for passice documentary information collection. storage. retrieval, and dissemination. there is no comparable centralized Federal service to augment actice technology transfer proceess. . One way to help accomplish this objective is the establishment of a centralized interdisciplinary team."

"The team would serve as consult ants to agencies seeking information and guidance concerning the availability of technology and resources relerant to their needs and would advise techmohys developers of potential secondary applications. The team would deal directly on a person-to-person basis with the using and developing arencies senior professional staff nembers assigned to liaison activities to facilitate techology transfer. It could also organize conferences and symposia to discuss problems common to a number of agencies." 
"As we visualize it, the team should be organizationally attached to a technology-oriented agency with no vested programmatic or conflicting mission interests. The entire group should be funded by the cognizant agency ihrough a special OMB provision or a separate appropriation. We are not suggesting any specific agency through a special OMB provision or a separate appropriation. We are not suggesting any specific agency for this role. However, we believe that the National Bureau of Standards (NBS) and NSF warrant consideration."

"The Department of Commerce indicated that NBS would be an appropriate location for the team, especially in view of its extensive interagency technology activities, in which it continually acts as a transfer agent. According to the Department, adequate funding must be provided to support the increased staff that will be needed. Other agencies also expressed concern over the need to obtain funds required to implement our recommendation."

\section{NATIONAL BUREAU OF STANDARDS}

NBS is a principal focal point within the Government for applying physical and engineering sciences to the advancement of technology in industry and commerce. In addition to conducting research, NBS (1) provides technical services to promote the use of available technology and to facilitate technological innovation in industry and Government, (2) cooperates with public and private organizations in developing technological standards and test methodologies, and (3) provides advisory and research services for Federal, State, and local Government agencies.

NBS has a long history of successful working relationships with Government agencies and private industry in the development of standards and the solution of national problems. NBS maintains its own laboratories and has the administrative measures to engage private industry assistance for adaptive engineering tasks. NBS has professional stature and acceptance throughout the scientific and technological community, including the Government, professional societies, trade associations, academic and nonprofit institutions, and private industry.

In hearings before the Subcommittee on Science, Research, and Development, House Committee on Science and Astronautics, in July 1971, the Secretary of Commerce stated, in part, that:

"Our objectives in technology are readily described. We must strive to:

"Remove barriers impeding the use of existing technology.
"Stimulate better use of existing technology.

"Remove barriers impeding the development and use of new technology.

"Stimulate the development and use of new technology."

(3) Extract from GAO Report on "Acquisition and Use of Software Products for Automatic Data Process. ing Systems in the Federal Government, B-115369, June 30, 1971

\section{Principal Findings}

“. . The acquisition practices followed by Federal agencies were necessitated because of limited activity by central management agencies of the Government in providing policy guidance for acquiring and utilizing computer software. (See ch. 5.) There is a definite need for:

. . A catalog, inventory, or central reference index of computer programs that have been developed, tested, or in use by the Government."

\section{Recommendations or Suggestions}

“. . Director of the National Bureau of Standards establish and maintain a reference index of computer programs. .."

“. . . On October 27, 1970, a representative of the Systems Development Division of NBS reported on a study that was made to identify data management systems software packages. This study identified 159 data management systems packages. Sixty-five of the packages were found to be written in Formula Translator Language (FORTRAN) or Common Business Oriented Language (COBOL) and 47 of these 159 packages were identified as being in the public domain. This last fact is important to Federal users, as some of these were developed by the Government and are available without charge."

"This report of NBS personnel filled a void for this type of information. Potential users of data management systems now have a starting point for their studies. . . These evaluations, if made by a central agency such as NBS, would eliminate the need for all potential users to perform independent studies, and would help to standardize the criteria used in the evaluation processes."

\section{Catalog of Available Programs}

“In December 1966, OMB instructed NBS to main- 
tain a reference index of computer programs so that the need for development of programs already developed, tested, and being used elsewhere in the Government can be minimized. A catalog or reference index of available programs had not been prepared by NBS at the time of our study. This subject was explored during the two conferences sponsored by OMB on the management of computer systems. The proposal was considered to be conceptual by sound, but because of the potential magnitude of the task involved, the report of the Myrtle Beach conference suggested that some selectivity should be exercised in determining the contents of the catalog.

We believe that such a catalog would assist potential users in selecting software in an unbundled environment, in providing access to information on advances in the state-of-the-art, and in minimizing the possibility of writing programs already developed.'

\section{Recommendations}

". . Additionally, we recommend that the Director of the National Bureau of Standards:

-Establish and maintain a reference index of computer programs. ..."

\subsubsection{Specific Studies, Letters and Reports}

\section{Extracts from Brooks Bill Issue Study}

The Brooks Bill Issue Study identified two programmatic areas extant in ICST which directly related to the Advisory and Consulting Service mandates of the Brooks Act:

"Selected Computer Applications" and "Supporting S\&T Advisory Services."

Each element is the outgrowth of ICST responsibilities under the Brooks Act and the 1901 Organic Act, amplified by both the Policy Guidance paper and the needs of the evolving Federal computer environment.

Selected computer applications: The objective of this NBS program is to ensure that adequate technical support and developmental activities are available for those areas of computer applications most important to the Federal Government. Recommended projects in this area are characterized by a need for cooperative efforts between NBS and the appropriate mission-oriented agency. In particular, ADP problems are affecting the quality of Gavernment service in the following areas: health care delivery services; welfare and medical payment services; education services, both in formal educational and in continuing education; law enforcement; mass transportation; and data management systems.
Again, work in this area is required by a specific citation in the Policy Guidance, and by the stated purpose of the Brooks Bill. Several areas have been identified for which the Government has a major share of the responsibility, within which major problems exist, and to which proper computer application can make a significant improvement. Examples are health care delivery, law enforcement, mass transportation, and many others.

Projects in this area of Specific Computer Applications are characterized by the necessity for cooperative efforts involving the ICST and the appropriate mission-oriented organizations. Self-generated and self-evaluated work in computer applications is impossible. In many instances, portions of the funds expended by the ICST are obtained from other agencies. Generally, the posture of the Institute is more healthy when the funding responsibility is shared with the concerned agency. Exceptions, however, are made on a case-by-case basis. One notable example in the Institute's history is the fingerprint project, initially funded totally by the ICST and later jointly with the Federal Bureau of Investigation (FBI). This project has also been one of the most successful application-oriented endeavors of the Institute's funding from Other Agencies.

Supporting scientific and technological advisory services: NBS has recently redirected much of its work in this area so as to put less emphasis on solving specific problems on an agency-by-agency basis. Instead, priority will be given to resolving $F$ ederal policy-making problems in ADP and to solving problems common to several agencies. Work in this program area falls into five general categories: support to formulation of ADP policies; technology assessment and forecasting; support to U.S. international activities in ADP; support to other Federal agencies; and information services.

A large number of agencies have been and will be served on a wide variety of problems. For example, the U.S. Office of Education was assisted in the evaluation of computer-related education research programs; the Post Office was helped with a time-sharing system used to direct mail to servicemen overseas; an automatic accounting system was developed for the Agricultural Research Service; and many agencies have been assisted in the development of procurement specifications for computer systems. This type of assistance can only be expected to increase as more and more agencies turn to computer usage, and as the reputation of the Center for service of this type becomes more widely known. 
The current ICST technical program reflects the changing character and emphasis of the Center's scientific and technological advisory services. Since its establishment, the Center has directed the majority of these services toward helping Federal agencies solve specific ADP problems; only a small part of the effort was aimed at supporting those few Federal agencies which have broad policy-inaking responsibilities in the area of automatic data processing. Starting in FY1972, ICST has reoriented its scientific and technological advisory services program to put more stress on support to such Federal policy-making and policy-influencing agencies as the Office of Management and Budget, General Service Administration, Office of Science and Technology, Office of Telecommunications Policy, National Science Foundation, National Academy of Science, General Accounting Office, Federal Council on Science and Technology, Department of State, and the Civil Service Commission. In spite of this change in emphasis, however, ADP consulting and advisory services will continue to be made available to other agencies to assist in solving specific ADP management and application problems.

The ICST Scientific and Technological Advisory Services program is made up of five general areas of activity:

(1) Support to the formulation of ADP policies

(2) Technology assessment and forecasting

(3) Support to U.S. international activities in automatic data processing

(4) Support to other Federal agencies

(5) Information services.

During FY 1971, ICST provided such services to some 45 organizations in 16 Departments and independent Agencies. These services, provided on a cost reimbursable basis, cover a wide range of activities including systems analysis, system specifications and requirements definition, system design, computer programming, preparation and analysis of automation proposals, and equipment selection.

In the performance of its mission and functions, ICST must necessarily be a broker of information services. It must collect, organize and maintain significant quantities of information in the ADP and computer sciences and technology areas both for its own consumption and for delivery to Federal customers. The types of information to be collected include di- rectories, inventories and listings of ADP software, hardware systems and services, stateof-the-art surveys and reports, research and technical reports, product specifications, etc.

5.1.5. Selected Citations of Specific Requests for Technical Advisory Services

FBI: January 17, 1967 letter from J. Edgar Hoover, Director of the FBI, to John Eberhard, Acting Director, CCST/ NBS, requesting NBS to continue work relating to automating the fingerprint identification system on a reimbursement basis.

IRS: August 31, 1971 Purchase Order, from J. Mitchum, Internal Revenue Service to J. Skillington, Chief of Budget Division, NBS requesting the provision of services and equipment to create a prototype model of a data entry station for a remittance processing system.

OTP: September 1, 1971 letter from Deputy Director, OTP to the Assistant Secretary for Science and Technology, DOC, recognizing "distinct and special role in assisting OTP in carying out its functions assigned by the President in the area of computers and communications." Requests NBS to provide technical advice and analysis in teleprocessing matters and to represent the United States at appropriate international meetings.

NRMA: December 17, 1971 letter from J. H. Wakelin, Jr., Assistant Secretary for Science and Technology, DoC to Mr. Williams, President, National Retail Merchants Association (NRMA) offering the support of NBS in the development of voluntary standards and performance specifications for automated systems of merchandise and customer identification. This letter was in response to the NRMA President's June 1971 letter to the Secretary of Commerce requesting technical assistance.

STATE: March 10, 1972 letter from H. Pollack, Director, Bureau of International Scientific and Technological Affairs, to R. M. Davis, Director, CCST, accepting the offer of CCST to make available its institutional resources to advise the Department in its role in formulating and implementing forcign policy, in 
the form of technical advice and resources for dealing with computer related issues and providing technical support and suggesting appropriate technical representation in international meetings. (This letter supports ICST responsibilities in work with the Organization for Economic and Cooperative Development Agency for International Development United $\mathrm{Na}$ tions, with AID, and with the United Nations.)

GAO: February 19, 1974 Interagency Agreement between ICST/NBS and the Office of Federal Elections, General Accounting Office, for the development of operational guidelines for election administrators to insure accuracy and security of the vote-tallying process using ADP equipment.

FTC: February 29, 1974 letter from R. Jast and S. Feldman, Federal Trade Commission to R. M. Davis, requesting ICST assistance in investigating possible violations for the Fair Credit Reporting Act having to do with computerized credit reporting systems.

DIBA: April 4, 1974 letter from R. L. Hildebeidel, Director, Office of Budget, Domestic and International Business Administration (DIBA), Department of Commerce to Ralph Simmons, ICST, attaching Reimbursable Agreement for technical support to Office of Economic Analysis (OEA) centering on categorization and potential use of computer installations in specific foreign countries and of new export applications.

JUSTICE: October 16, 1974 letter from Deputy Assistant Attorney General requesting technical support for $1 B M$ antitrust case and October 31, 1974 letter from Assistant Attorney General recognizing that the support of ICST in the preparation of the Government's antitust case ". . would be absohtely essential," and that ICS'T support would be needed ". . .to secure the most teethnically competent smpport staff available to the government."
5.1.6. NBS Responses to Advisory Services Responsibilities

(1) ASSIGNED NBS

RESPONSIBILITY: Provide guidelines for use by agencies in conducting systems studies, including consideration of systems interrelationships.

OMB Policy Guidance Letter to the Department of Commerce (December 15, 1966)

NBS has made substantive progress toward carrying out this responsibility.

A substantial proportion of the NBS technical notes, information reports, and special publications issued by the Institute for Computer Sciences and Technology over the past 10 years were published to serve as guidelines for use by other Federal agencies in accomplishing system studies or in planning for new ADP systems and facilities. Examples of recent such publications include the following:

Characterization and Testing of Interactive Graphics for Computer-Aided Design and Engineering, S. Treu, (NBSIR 73-289) 1973.

Guidelines for the Use of Computer Technology in the Developing Countries, R. A. Simmons. (NBSIR 73-423) 1973.

Effective Use of Computing Technology in V'oteTallying. R. G. Saltman. (NBSIR 75-687) 1975.

Software Testing and Network Services. R. B. Stillman and B. Leong-Hong, (NBS Tech. Note 874) 1975.

Exploring Privacy and Data Security Costs-A Summary of a Workshop, J. L. Berg. (NBS Tech. Note 876) 1975.

Standards Analysis for Future II IT MCCS Computer Networking. D. Fife. (NBSIR 7t-5i(0)197t.

In addition to providing these monidelines directly to the agency of prime interest coften the ageney which requested the assistance and provided the fundine for the activity). the suidance eontained in these reports is publicized thromgh mechanisms such als workshops and seminars als well as throngh the Bureatis publication notifi- 
cation procedures. In certain instances, the significance of the guidelines is such as to occasion special distributions. For example, the Clearinghouse on Federal Elections of the General Accounting Office (now the Elections Commission) considered the guidelines contained in the report on the use of computers in vote-tallying to be of such significance as to warrant special distribution of the report directly to the senior election administrator in every jurisdiction in the United States with a population of 25,000 persons or more.

(2) ASSIGNED NBS

RESPONSIBILITY: Provide guidelines and methods for monitoring the performance of systems studies and for implementing the results of such studies.

OMB Policy Guidance Letter to the Department of Commerce (December 15, 1966)

NBS has not undertaken to carry out this responsibility.

By referring to methods for monitoring the performance of systems studies, there is implicit in this responsibility a direct managerial oversight function. Discussions with senior ICST individuals who were present during the early years of the center indicate that it was not deemed appropriate for NBS to undertake such oversight functions as it moved toward carrying out the responsibilities mandated under the Brooks Act. Reporting requirements upon agencies which were imposed under OMB and GSA Circulars tended to minimize the urgency of this requirement. Inasmuch as the resources provided to the Institute did not reach the levels of requirement anticipated in order to fulfill all mandated responsibilities no action was taken with respect to carrying out this responsibility as initially put forward in the OMB guidance letter.

(3) ASSIGNED NBS

RESPONSIBILITY: Maintain a reference index of computer programs to minimize the need for the development of programs already developed.

OMB Policy guidance Letter to the Department of Commerce (December $15,1966)$

...Director of the National Bureau of Standards should establish and maintain a reference index of computer programs...

GAO Report B-115369, June 30,1971

The NBS has made substantive progress toward carrying out this responsibility.

A catalog or reference index of available programs had not been prepared by NBS as of the time the GAO study was underway. The subject was explored at two conferences subsequently sponsored by the Office of Management and Budget on the management of computer systems, but because of the potential magnitude of the task involved it was concluded that selectivity should be exercised in accomplishing such a catalog.

In October 1970, the Center for Computer Sciences and Technology of the National Bureau of Standards reported to the GAO on a study that was made to identify data management systems software packages. The study identified some 159 such packages. Of these, 65 were found to be written in FORTRAN or COBOL; 47 were identified as being in the public domain, and available for use by the Government without charge. The GAO noted that this report by NBS filled a void for this type of information and provided a starting point for the carrying out of the recommendation contained in the GAO report.

In October 1972 the Index of Data Management Software Packages was published by NBS in direct response to the above assigned responsibility. Subsequently the maintenance and expansion of an index of computer programs was incorporated as an on-going project activity within the program of the Institute for Computer Sciences and Technology. At the present time this index contains over 10,000 computer programs and is available as a central reference for use by all Federal agencies as well as State and local Governments in selecting available software and to minimize the possibility of developing programs similar to those which are already in existence.

The Computer Information Section of the Institute receives approximately 150 inquiries per year about this index.

(4) ASSIGNED NBS

RESPONSIBILITY: Provide guidelines for evaluating installation and systems performance on a continuing basis.

OMB Policy Guidance Letter to the Department of Commerce (December 15, 1966) 
NBS had made substantive progress toward carrying out this responsibility.

The VBS has not undertaken to enter into a direct managerial oversight role with respect to determining the continuing basis by which agencies apply the guidelines for evaluation of installation and systems performance. Rather NBS has confined its activities to the development and assessment of measures and techniques by which systems performance can be evaluated, and to disseminating this information to concerned Federal agencies.

Representative NBS publications reflecting NBS activity carried out in support of the responsibility to provide guidelines for evaluating systems and installation performance follow:

A Computer Test Program to Assess Adroitness in Indexing Operations, George W. Reitwiesner, (NBS Report 9470) 1967.

Performance Measurement of Remote Access Computer Systems, M. D. Abrams, (NBS Report 10381$) 1970$.

Performance Measurement of Interactive Graphics Systems in Support of Computer Aided Design and Engineering, T. N. Pyke, Jr., et al, (NBS Report 10 451) 1971.

A Set of Problems to Evaluate Scientific Computers, G. W. Reitwiesner, (NBS Report 10 883) 1972.

Evaluation of Information Systems: A Selected Bibliography with Informative Abstracts, M. M. Henderson, (NBS Tech. Note 297) 1967.

Data Communications System Throughput Performance Using High Speed Terminals on the Dial Telephone Network, D. S. Grubb, (NBS Tech. Note 779) 1973.

Computer System Capacity Fundamentals, D. J. Kuck. (NBS Tech. Note 851) 1974.

Computer Performance Evaluation, H. J. Highland, (NBS Sp. Pub. 401) 1974.

Computer Performance Evaluation: Report of the 1973 NBS/AMC Workshop, T. E. Bell. B. W. Boehm and S. Jeffrey, (NBS SP. Pub. 406) 1975.

Guidelines for Benchmarking ADP Systems in the Competitive Procurement Environment (FIPS PUB 42) 1975.

In addition, each year since 1973 the Institute has co-sponsored with the Association for Computing Machinery a "Computer Performance Evaluation Workshop" by which the latest criteria and techniques for evaluating systems performance are brought to the attention of Federal computer and installation managers.

(5) ASSIGNED NBS

RESPONSIBILITY: Keep abreast of the state-of-the-art developments in ADP equipment, techniques and languages and evaluate these developments in terms of their current or potential impact upon the Government's use of equipment and software and its ADP management policies.

OMB Policy Guidance Letter to the Department of Commerce (December 15, 1966)

NBS has made substantive progress toward carrying out this responsibility.

Fulfillment of this responsibility is inherent to the conduct of the technical program of the Institute for Computer Sciences and Technology of NBS. New programmatic elements have been introduced into the activities of the Institute as a direct consequence of new state-of-the-art developments in ADP technology. Significant examples of new activities incorporated since FY 1966 include:

- teleprocessing and computer networking,

- performance measurement,

- software management, and

- computer security.

Underlying the Institute s overall program has been a modest effort in the computer sciences research (later identified as exploratory development) which looked to the leading edge of the state-of-the-art in this technology. This activity was zero funded commencing in FY 1975 because of pressing priority requirements in other aspects of the Institute's program which required reprogramming of resources away from such exploratory development activity.

An important ongoing activity deriving from the total technical program of the Institute is the continuing effort to keep agencies of the Government abreast of new developments in ADP techniques and technology. NBS has aggressively undertaken to sponsor symposia and workshops for this purpose, and has provided qualified speakers to relevant scientific and professional assemblies. Certain of these symposia have already assumed the stature of "traditional" meetings, for example, the NBS-sponsored annual meetings on "MiniComputer and Micro-Computer Technology" 
and the now annual "Simulation Conferences." Over the past 10 years the Institute for Computer Sciences and Technology has sponsored or participated in workshops and colloquia on an average of almost one per month. About half of these relate to the state-of-the-art requirements of this responsibility.

The Institute program in technology assessment has been especially helpful to the Office of Export Administration in determining the "exportability" of advanced design computers. It has also provided direct support to the determination of the U.S. position in NATO on technology to be released to the Soviet Bloc countries. Currently, this effort is focused on the state-of-the-art to improve the safeguards against diversion of the use of advanced computer technology with the hope of broadening the export opportunities for U.S. suppliers of computer technology.

(6) ASSIGNED NBS

RESPONSIBILITY: Be fuly aware of on-going system developments, whether performed inhouse or under contract for other Government agencies.

OMB Policy Guidance

Letter to the Department of Commerce (December 15, 1966)

NBS has undertaken to fulfill the requirement to be fully aware of ongoing system developments in other Government agencies whether being performed in-house or under contract.

Although the Institute has undertaken to become familiar with major new system developments taking place within other agencies of the Federal Government, and has explicitly made its expertise available when requested by other agencies, it has been found to be impractical to systematically review all system plants, extensions, or new implementations put forward by other Federal agencies. Agency reporting requirements which were subsequently established under OMB and GSA Circulars tended to minimize the urgency of this requirements.

(7) ASSIGNED NBS

RESPONSIBILITY: $A$ study to be made and reported to the Bureau of the Budget soon after January 1,1967 , to explore the feasibility of developing a system by which each Federal agency would keep the $N B S$ informed of all $A D P$ system design study projects.
OMB Policy Guidance Letter to the Department of Commerce (December 15, 1966)

NBS has not undertaken to carry out the study called for in the OMB Policy Guidance Letter.

Under the provisions of OMB Circular A-83, all Federal agencies are required to report annually to $\mathrm{OMB}$ regarding the $\mathrm{ADP}$ equipment which they have in inventory. Additionally, under the provisions of OMB Circular A-54, dealing with policies on selection and acquisition of ADP equipment, Federal agencies are required to report to $\mathrm{OMB}$ concerning future plans for ADP systems and system design plans underway. Under the provisions of Executive Order 11717, the responsibility for the collection of such information was transferred to the GSA.

It is also noted that under the provisions of the Brooks Act, responsibility with respect to the establishment of systems requirements is explicitly retained by the head of each Federal agency.

Discussions with individuals within ICST who were present during the early years of the Center indicate that the requirements of the above responsibility were carefully discussed with OMB, and it was mutually agreed in light of the above, and in consideration of the limited resources available to the Institute, that it did not seem appropriate for this responsibility to be pursued as a priority item, if at all. The subsequent refinement of the reporting procedures called for under the above cited circulars obviated further need for NBS to carry out the study contemplated by the above guidance.

(8) ASSIGNED NBS

RESPONSIBILITY: Provide criteria to assist in evaluating software and hardware developments that may be considered during the systems studies.

OMB Policy Guidance Letter to the Department of Commerce (December 15, 1966)

Although NBS has not undertaken to provide criteria specifically for consideration during the referenced systems studies, NBS has made substantive progress toward providing criteria for use by Federal agencies in evaluating software and hardware.

A substantial portion of the NBS Technical Notes, Information Reports, and special publications issued by the Institute for Computer Sciences and Technology over the past ten year period incorporate criteria to be applied by Federal agencies performing systems studies or planning new ADP systems and facilities. 
Illustrative of the numerous publications produced by NBS over the 10 year period which serve to fulfill the role of providing criteria to assist in evaluation of software and hardware developments are the following recent ICST publications:

A Technical Index of Interactive Information Systems, D. Fife, K. Rankin, E. Fong, J. Walker and B. Marron, (NBS Tech. Note 819) 1974.

Concepts in Quality Software Design, S. L. Stewart, (NBS Tech. Note 842) 1974.

Computer System Capacity Fundamentals, D. J. Kuck, (NBS Tech. Note 851) 1974.

The Service Concept Applied to Computer Networks, M. D. Abrams and I. W. Cotton, (NBS Tech. Note 880) 1975.

These publications are aimed at ADP service and facility managers for use in state-of-the-art assessments preparatory to system design and selection processes and provide specific evaluation techniques designed to identify areas of possible improvement in both the hardware and software portions of computer systems.

NBS was instrumental in bringing about the establishment of the Federal Simulation Laboratory (FEDSIM) now being operated by the U.S. Air Force. Through this facility the operation of advanced and complex computer systems being contemplated for procurement or implementation within the Federal Government can be simulated, and the results of the simulation used to assist in evaluating the software and hardware proposed for use in such systems.

\section{9) ASSIGNED NBS}

RESPONSIBILITY: Provide technical guidelines for preparing solicitations of proposals, including the specification of system requirements.

OMB Policy Guidance Letter to the Department of Commerce (December 15. 1966)

NBS has made substantive progress toward carrying out this responsibility.

During the 1966 to 1970 timeframe a smbstantial portion of the other agency funded work of the Institute for Computer Sciences and Technology was directed toward assisting agencies of the Federal Government develop the specifications and recuirements for either new eomputer systems or for expansions to existing systems. This inchuded both direet participation with those agenerics and the CSA for the preparation of solicitations, as well as assistance in the evaluation of bid responses. For example, the study of data base management systems, reported in NBS Tech. Note 887, Six Data Base Management Systems-Feature Analysis and User Experience was used to help develop the Request for Proposal (RFP) and subsequent proposal evaluations leading to the final selection of a system for the Federal Aviation Agency.

A sampling of NBS reports and technical notes reflecting NBS activity which was carried out in support of the preparation of systems specifications or evaluations of proposals follows:

Report of a Study of Requirements and Specifications for Serial and Monograph Microrecording for the National Library of Medicine, E. J. Forbes, et al, (NBS Report 9446) 1966.

Remittance Processing System, P. D. Shupe. Jr., P. Meissner and J. R. Park, (NBSIR 74 577-1) 1974.

Effective Use of Computing Technology in Vote-Tallying, R. G. Saltman, (NBSIR 75687) 1975.

A Semi-Automated Single Fingerprint Identification Systen, J. H. Wegstein. (NBS Tech. Note 481) 1969.

The M40 Fingerprint Matcher, J. H. Wegstein, (NBS Tech. Note 878) 1975.

Benchmarking and Workload Definition: A Selected Bibliography with Abstracts. J. L. Walkowicz. (NBS Sp. Pub. 405) 1974.

In addition, the Federal Information Processing Standards publications. Which now include some 27 Standards, are directly applicable to the preparation of specifications and the evaluation of proposals. having been made mandatory upon all Federal agencies for procurement purposes through incorporation into current Federal procurement management regulations.

(10) ASSIGNEI) NBS

RESPONSIBILI'TY: Proride gnidelines. criteria and tochnique's for eraluating and sclecting equipment and related softuare. giving priority emphasis to criteriafor measuring the effectivene'ss and efficiency of softucare. llata on this subject will also be furnished to Gist for 
consideration in the procurement of computers.

OMB Policy Guidance Letter to the Department of Commerce (December 15, 1966)

NBS has made substantive progress toward carrying out this responsibility.

In 1971, the ICST program was reoriented to give additional emphasis to developing a technical basis for the documentation, validation, correctness, quality control during development, and sharing of software, particularly that used within the Federal Government. This activity is carried out under the software management program of the Computer Utilization element of the Institute's overall program. The Institute has been working toward issuance of a "Software Engineering Handbook" which will provide to Federal systems planners the most complete compilation of meaningful software design and performance measurement practices developed through this technical activity.

Similarly, computer system performance measurement was established as a specific technical effort within the Institute and is currently being carried out under both the Computer Utilization and Computer Networking elements of the Institute's overall program. Each year since 1973 the Institute has co-sponsored with the Association for Computing Machinery a "Computer Performance Evaluation Workshop" looking to the identification of the most appropriate criteria for use by the Federal Government. Close coordination and participation with the GSA has been maintained in carrying out these activities.

The following are representative examples of NBS publications resulting from this technical activity:

Set of Debugging and Monitoring Facilities for Improving the Diagnostic Capabilities of a Compiler, E. Fong, (NBS Tech. Note 763)

1973 (concerned with the quality of software and assurance that software is effective and maintainable).

NBS FORTRAN Test Programs, Volumes, 1, 2, and 3, F. E. Holberton and E. Parker (NBS Sp. Pub. 399) 1974.

Software Testing and Network Services, R. B. Stillman and B. Leong-Hong, (NBS Tech. Note 874) 1975 (provides an initial identification of effective software test and measurement tools for use in an environment of computers which are networked together).
In addition, the following Federal Information Processing Standards specifically responsive to the requirements of this responsibility have been issued:

COBOL, (FIPS PUB 21-1) 1975.

Flowchart Symbols and Their Usage in Information Processing, (FIPS PUB 24) 1973

Standardization of Data Elements and Representations, (FIPS PUB 28) 1973.

Interpretation Procedures for Federal Standard COBOL, (FIPS PUB 29) 1974.

Software Summary for Describing Computer Programs and Data Systems, (FIPS PUB 30) 1974.

Guidelines for Documentation of Computer Programs and Automated Data Systems, (FIPS PUB 38) 1976.

Aids for Program COBOL Conversion (FIPS PUB 21-21-1), (FIPS PUB 43) 1975.

The GSA has incorporated these standards into current Federal Procurement Management Regulations, as mandatory upon all Federal agencies for procurement purposes.

\subsection{ADP Standards}

\subsubsection{Background}

The Brooks Act directs NBS to develop "uniform Federal automatic data processing standards." The OMB policy guidance letter of December 15, 1966 spelled out 10 specific tasks pursuant to this responsibility. NBS responses to these 10 tasks are addressed later in this section.

\subsubsection{Definition of a Federal Standard}

The National Bureau of Standards defines a standard to be a prescribed set of conditions and requirements, of general or broad application, established by authority or agreement, to be satisfied by a material, product, process, procedure, convention, test method; and for the physical, functional, performance, or conformance characteristics thereof.

The essential ingredients for arriving at standards are defined to be:

- a set of alternatives,

- a method for agreeing upon a selection to be used,

- a group which agrees to abide by the selection, and 
- a means for insuring compliance (for a mandatory standard).

In the United States, most standards are voluntary, except for those relating to public health and safety and environmental effects or those used by Government in its business activities.

The Brooks Act in 1965 assigned a unique responsibility to the Secretary of Commerce by authorizing him to make recommenations for the establishment of uniform Federal "computer" standards. NBS went about satisfying the essential ingredients for arriving at standards by:

- Setting up in 1968 the Federal Information Processing Standards Coordinating and Advisory Committee (FIPSCAC). FIPSCAC was formalized as a public advisory committee on January 3, 1973. FIPSCAC consists of between 15 and 30 members from U.S. Government agencies and other public and private organizations. Standards developed under the authority of the Brooks Act are called Federal Information Processing Standards (FIPS).

The establishment of FIPSCAC satisfied the second standards-making requirement listed above, i.e., "a method for agreeing upon a selection to be used" from a set of alternatives for any standard.

- FIPSCAC and its Task Groups develop the set of alternatives to be considered in arriving at each standard and thus satisfies the first ingredient listed above for arriving at standards.

- The Brooks Act specifies Federal agencies as the group to abide by the selection of each FIPS standards.

- The Brooks Act satisfied the third essential ingredient for arriving at a standard (see listing above), i.e., "a group which agrees to abide by the selection.'

- There has never been a means for insuring compliance with FIPS standard.

OMB in its December 1966 policy guidance letter to the Secretary of Commerce directed NBS "to the extent feasible and desirable, develop and recommend means for measuring compliance with Federal standards."

The only enforcement mechanism that exists is in the procurement process. For those FIPS standards that are applicable to procurement and are implemented through the Federal Property Management Regulations (FPMR's) the enforcement mechanism is the pertinent Federal procurement regulation.
In other instances compliance requirements as they are now interpreted probably derive their only explicitness from President Nixon's statement in his memorandum to the Director, OMB, dated April 30, 1971 in which he stated.

"I expect that Federal agencies will apply these standards whenever their use will lead to greater operational efficiency and reduced costs."

The tradition established since 1968 has been that all Federal agencies are expected to comply with each FIPS standard unless they formally decide to waive its provisions. In such instances of non-compliance the waiver procedure as set forth in each published FIPS standard required that agency heads coordinate their proposed waiver with the NBS. Waivers should not be made until a reply is received from NBS; however, the final decision for granting the waiver is a responsibility of the agency head.

Recognizing that no means existed for insuring compliance with standards and that hence an essential ingredient in stand ards-making was lacking, NBS proposed to OMB in 1971 that

- Each agency should be assigned responsibility for ensuring compliance with FIPS standards, and that,

- A reporting system should be established under which agencies would regularly report to OMB the extent of standards implementation for each of their individual systems and installations.

Such procedures would provide the first real measure of agency compliance with FIPS standards. However, today in 1976 there are no means for insuring compliance with FIPS standards.

\subsubsection{Two Schedules for the Development of a FIPS Standard}

There are two primary approaches that can be followed in the development of Federal Information Processing Standards: (1) Development of a standard entirely within the Federal Government, and (2) Adoption of a standard developed by the American National Standards Institute (ANSI).

\section{Development of a Standard Entirely Within the Fed- eral Government}

In this case, experience shows that it takes an average of about three years to develop the standard. The process is started by the identification of the requirements for a particular standard and the preparation of a statement of the scope of work. This is done by the Federal Information Processing Standards Coordinating and Advisory Committee (FIPSCAC), a public advisory committee chaired by NBS and having representation from Federal agencies and the private sector. FIPSCAC's identification of the requirements for a standard and preparation of 
a work statement may span a period of some six months.

The actual development of a standard is carried out by a FIPS Task Group made up of representatives of all interested Federal agencies and, as appropriate, representatives from the private sector. The development and drafting of the standard requires an average of 12 months of effort, depending upon the complexity of the standard and other factors.

Coordination of the standard and the resolution of any differences involving it takes another five months of work. The draft standard is sent directly to the FIPS point of contact in each Federal agency for review and comment. Concurrently, the draft standard is published in the Federal Register for review and comment by all interested parties including industry and the private sector.

The completed standard is forwarded to the Secretary of Commerce who approves it in accordance with the authorities delegated to him by Executive Order 11717 dated May 9, 1973. Upon approval by the Secretary, the standard is published by the Government Printing Office as a FIPS Publication. Concurrently, the FIPS Task Group that developed the standard collaborates with the General Services Administration to develop implementation procedures if, as happens in many cases, the standard is to be implemented through the GSA Federal Property Management Regulations (see fig. 5).
Developing and Adopting an ANSI Standard as a FIPS Standard

The process of developing and adopting an ANSI standard as a FIPS standard is significantly longer than that for developing a standard entirely within the Federal Government. On the average, this process takes about five years.

This process starts with the establishment of a joint industry and Government group under the ANSI X3 Committee (Computers and Information Processing). This activity including the formulation of requirements and scope of work takes an average of 12 months to complete. The ANSI process is oriented toward insuring that all interested parties are given an equal opportunity to participate in the standardization process.

Actual development of the ANSI standard usually spans a period of 35 months, again depending upon the complexity of the standard and the general level of interest in the standard. Representatives of interested Federal agencies, coordinated by the NBS, participate actively in the development of the standard. They insure that Federal interests, requirements and objectives are accounted for in the development of the standard.

Once the ANSI standard has been developed, NBS forms a FIPS Task Group to handle the adoption of the standard as a FIPS standard. As necessary, the Task Group modifies the standards and makes the required adjustments to effect its adoption as a Federal standard. When this work has been completed, the standard goes through the

THE FIPS PROCESS: ADOPTION OF ANSI VOLUNTARY STANDARD

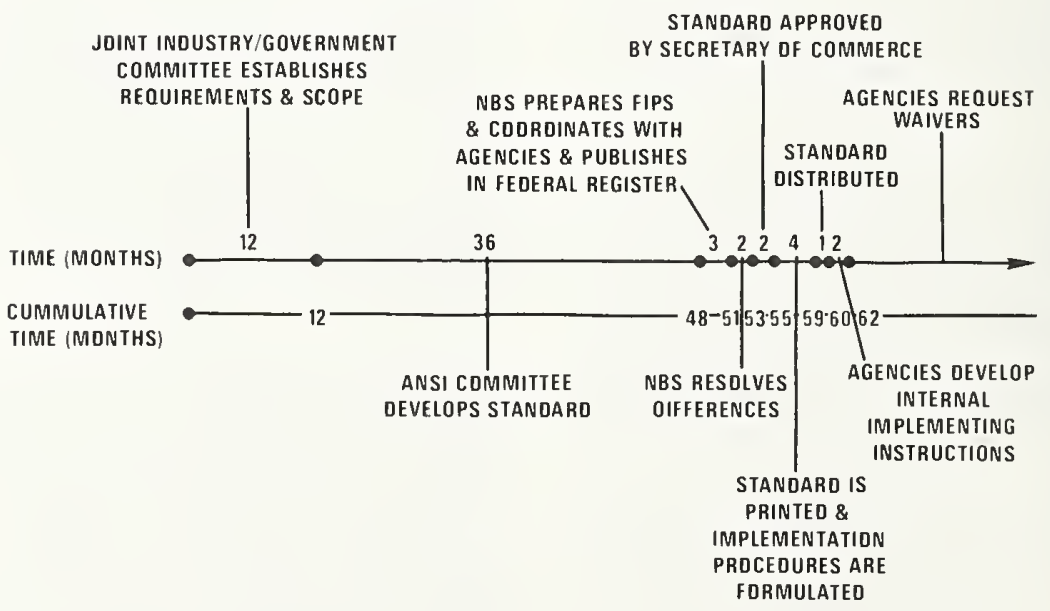

Figure 5 


\section{THE FIPS PROCESS: STANDARD DEVELOPED ENTIRELY WITHIN THE GOVERNMENT}

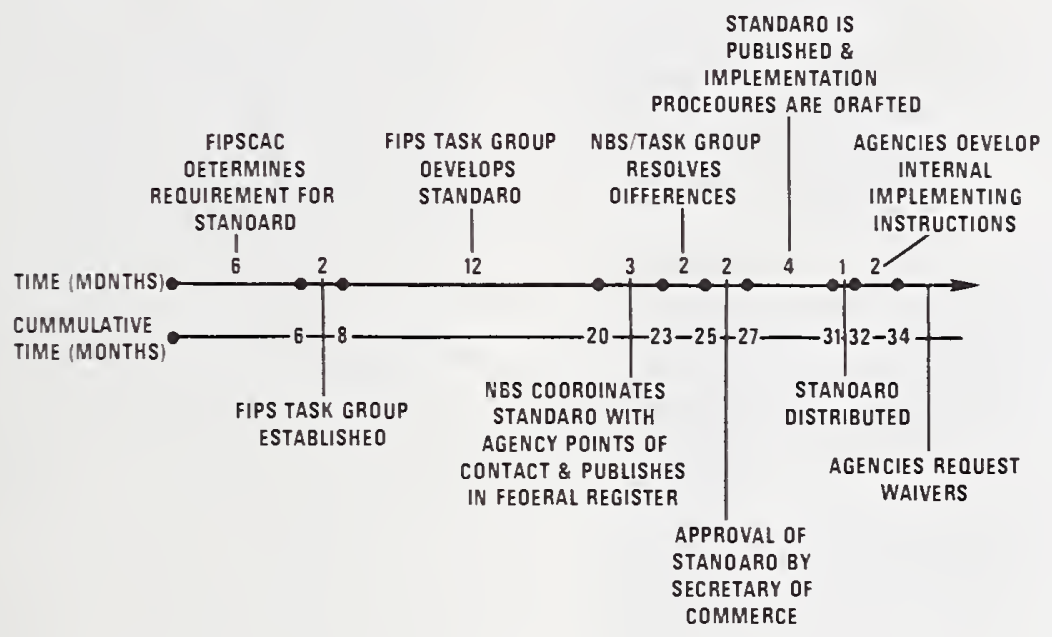

Figure 6

same process as that previously specified for the standard developed entirely within the Government (see fig. 6).

\subsubsection{NBS Responses to ADP Standards Responsibilities}

The Brooks Act assigned to the Secretary of Commerce the authority to "make appropriate recommendations to the President relating to the establishment of uniform Federal automatic data processing standards. The Secretary of Commerce assigned the ADP standards function to the $\mathrm{Na}$ tional Bureau of Standards. The Office of Management and Budget policy guidance letter dated December 15, 1966 assigned 10 specific standards related responsibilities to NBS:

(1) Participate in activities of the X3 Committee on Information Processing of the American National Standards Institute (ANSI), its subcommittees and task forces, and in activities of the International Organization for Standardization as requested by ANSI.

(2) Arrange and insure appropriate representation and active participation from other Federal agencies on the X3 Committee, subcommittees and task forces to complement the Institute's participation with additional expertise from the operating environment of the Government.

(3) Monitor and coordinate all such participation by all Federal agencies to assure its consistency with the Federal Government s objectives.
(4) Study and provide recommendations for Federal ADP standards.

(5) Study and provide recommendations on the use within the Federal Government of each appropriate United States Standard approved by the American National Standards lnstitute in the area of ADP equipment. computer languages, and techniques and data elements and codes.

(6) Provide for technical maintenance of Federal ADP standards.

(7) Develop, issue and maintain a statement of the Federal Government "s standardization objectives and needs.

(8) Recommend procedures to be used in the Federal Government for adopting Federal standards and developing and implementing plans thereof.

(9) Provide leadership of an Executive Branch program for standardization data elements and representation.

(10) To the extent feasible and desirable. develop and recommend means for measuring compliance with Federal standards.

Descriptions of progress in carrying out each of these responsibilities are provided in the following.

(1) ASSIGNED NBS

RESPONSIBILITY: Participate in actitities of the $\mathrm{X} 3$ Committee on 
Information Processing of the American $\mathrm{Na}$ tional Standards Institute, its subcommittees and task forces, and in activities of the International Standards Organization as requested by ANSI.

NBS, during the past 10 years, has actively supported the voluntary industry standards activities through sustained participation in the numerous technical groups established under the auspices of the American National Standards Institute, the Electronics Industry Association and the National Microfilm Association. More than 35 professionals from ICST have contributed to the voluntary standards efforts over the past 10 years. Although we do not maintain a precise accounting of expenditures for participation on voluntary standards activities, it is estimated that over the past 10 years we have provided the equivalent of 80 man years or approximately $\$ 4 M$ to these efforts. NBS professionals currently are active on 39 technical groups which are involved in the development of voluntary industry standards. Our last count identified some 60 industry-sponsored groups working on computer standards.

During the past ten years, over 60 voluntary standards have been developed. Of these, 20 have been adopted as Federal Information Processing Standards. Of these, four were developed by NBS and later became industry standards. There currently are 66 proposed voluntary standards in various phases of development.

We have recognized in the development of Federal standards that we need to interact with the computer industry and other using organizations. The voluntary industry standards activities provide the principal forum and the mechanism for this interaction. We feel that our continued active support of these industry groups is justified based upon the benefits enjoyed by the computer community at large. This is not only beneficial to the Federal Government, but also to State and local governments, other user groups and the computer industry.

As a result of our involvement in these activities, we have observed several weaknesses in the voluntary standards process that deter effective standards development and implementation. Principal among these are:

- Industry standard efforts are dominated by the six major computer manufacturers who can afford a full-time standards staff. Most smaller producers and nearly all users cannot afford the cost involved in standards participation.

- The economic and operational benefits of standards have not been adequately identified and quantified in order to allow proper management decisions in regard to establishing priorities and allocating standards resources. In most using organizations, standards are considered as a marginal overhead expense and are not associated with contributing to the operational performance of the organization or contributing to increased profits. Accordingly, standards support is one of the first functions to be eliminated or reduced during periods of recession or limited funding resources.

- In the computer field, voluntary industry standards are not as widely recognized or complied with as in other technical and industrial areas. The marketplace standards continue to be the corporate standards of the major manufacturers and not voluntary industry standards. It is apparent within the computer industry that marketing considerations take priority over standards. There currently is no strong user influence to cause a change in this practice. The Federal Government has over 8000 computers and is the largest single user. However, in terms of market-place leverage, this is less than 10 percent of the installed computers. In terms of the largest manufacturer, Federal computer sales represent less than 1 percent of the company's total sales.

- The time required to develop approved voluntary industry standards is unnecessarily long, running from a minimum of three years upwards. This is due to several factors: (1) the volunteer nature of participation and support; (2) the lack of adequate management controls in a committee structured activity; (3) infrequent meetings of technical groups; and, (4) the absence of sense of urgency.

(2) ASSIGNED NBS

RESPONSIBILITY: Arrange and insure appropriate representation and active participation from other Federal agencies on the X3 Committee, subcommittees and task forces to complement the Institute's participation with additional expertise from the operating environment of the Government. 
The participation of other Federal agencies in voluntary industry standards activities over the past ten years has been of major significance to both the Federal standards program and the voluntary industry efforts. Other Federal agencies currently have 156 professionals involved in the work of 37 different voluntary standards groups. Nineteen agencies provide participants in these activities. The Department of Defense is the most active with over 81 participants.

As a result of our NBS standards efforts and the close coupling we have with industry and Government groups, we are able to identify those subjects and groups where there is a Federal interest or requirement. Depending upon the availability of technical and administrative resources with individual agencies, we encourage and support their participation in voluntary industry standards efforts. No centralized funding arrangements have been requested or made available for supporting agency representatives participation. Accordingly, in regard to this function, NBS encourages standards participation by other agencies and depends upon the individual resources of each agency for their support of voluntary industry standards efforts.

In addition to the benefits obtained from the contributions made by individual agency participants in the development of voluntary standards, NBS has been able to benefit from augmentation of the technical base for the Federal standards program through the combined technical competencies of the participating Federal agencies. Also, the sharing of user experiences and problems with representatives from other Government agencies and industry has usually provided an effective environment for standards development. Except in those instances where the major computer manufacturers have not desired standards (e.g., device interface standards, operating system control languages standards and disk format standards) have there been any major difficulties in the development phase of standards. This does not mean that there have not been technical problems and delays involved, but does mean that there has been sustained progress in meeting identified standards objectives. The approval and implementation phases of the standards process are indeed more complex and require different competencies and handling. In both the Federal and voluntary industry standards programs, this important aspect of standardization is recognized by appropriate separation of the technical and management functions and responsibilities.

(3) ASSIGNED NBS

RESPONSIBILITY: Monitor and coordinate all such participation by all Federal agencies to assure its consistency with the Federal Government's objectives.

NBS monitors and coordinates Federal participation on voluntary industry standards through the official ADP standards point of contact designated by each Federal agency and through the standards task groups established under the sponsorship of the FIPSCAC, a public advisory committee chartered by the Department of Commerce to provide recommendations concerning the Federal ADP standards program.

NBS provides active participation in the planning activities of the voluntary industry groups that are concerned with the assessment of additional standards that are needed by the computer community. This is a function of the American National Standards Institute's Information Systems Standards Management Board and the X3 Standards Planning and Requirements Committee (SPARC). As new standards development projects are identified and initiated, a determination is made as to the extent the subject is of interest to Federal users. If there is interest, Federal participation is afforded either by the assignment of a participant from NBS, arranging for participation from those Federal agencies that have expressed a need for the standard and can provide competent participants, or through the participation of a member of an established FIPS Task Group considering the same subject.

To promote more effective communications concerning ADP standards activities at the Federal, national and international levels, NBS provides in its FIPS PUB 12 (FIPS Index) a description of each standards development project and a listing of the Federal participation provided.

\section{(4) ASSIGNED NBS}

RESPONSIBILITY: Study and provide recommendations for Fed. eral ADP Standards.

To date, the ADP Standards Program has produced 44 FIPS publications which include 27 standards, 11 guidelines and 6 management information documents. President Johnson approved the first three FIPS which were published in November 1968. The Director of the Office of Management and Budget was later delegated the signatory authority for standards on behalf of the President and he approved the next 18 FIPS. In August of 1973, OMB's responsibilities with respect to government-wide ADP standards (including approval authority) were transferred to the Secretary of Commere by Executive Order 11717. Six FIPS have since been approved by the Secretary under the provisions of the Executive Order.

In addition to the 27 FIPS standards published since the establishment of the program, 11 guidelines have been issued. It became apparent 
early in the standards program that certain subjects did not lend themselves to the strict definition of a standard. Where there were requirements for recommended practices, these were accommodated in the FIPS publications series as guidelines. Some of these technical guides also serve to clarify and provide aids for implementing approved standards.

In September 1968, OMB assigned to NBS responsibility for establishing and maintaining a FIPS Register to serve as the official Federal source of information pertaining to Federal ADP standards. In addition to the 38 standards and guidelines in the FIPS Register, NBS has published six management information documents. These include a Federal Information Processing Standards Index (FIPS PUB 12), a periodic compilation of information concerning standards activities at the Federal, national, and international levels; Objectives and Requirements of the FIPS Program (FIPS PUB 23); and the Federal regulation for the Data Standards Program (FIPS PUB 28).

It is anticipated that an additional 50 standards and guidelines will be developed during FY 1976 through FY 1978.

In the telecommunications standards area, NBS collaborates with the National Communications System in the development of joint standards that are common to computers and communications applications. Similarly, NBS is cooperating with the Archivist of the United States in the joint development of standards in the fields of micrographics and word processing.

The NBS ADP standards program is additionally augmented by the standards program of the computer industry and trade and professional associations including the Computer and Business Equipment Manufacturers Association (CBEMA), the Computer Industry Association (CIA), the Association for Computing Machinery (ACM), the Electronics Industry Association (EIA), the Institute of Electrical and Electronic Engineers (IEEE), the American Bankers Association (ABA), and the National Retail Merchants Association (NMRA). As a result of these associations, NBS is frequently called upon to provide assistance and inputs to standards problems that are common to the computer community.

(5) ASSIGNED NBS

RESPONSIBILITY: Study and provide recommendations on the use within the Federal Government of each appropriate United States Standard approved by the American National Standards Institute in the area of $A D P$ equipment, compuier languages and techniques, and data elements and codes.
During the past 10 years, NBS has actively supported the standards activities of the technical groups established under the auspices of the American National Standard Institute, the Electronics Industry Association and the National Microfilm Association. More than 35 professionals from ICST have, on a continuing basis, contributed to over 60 of the voluntary standards that have been developed to date. Of these, 20 have been adopted as Federal Information Processing Standards. Four of these were developed by NBS and later became industry standards. There currently are sixty-six proposed voluntary standards in various phases of development, which as they are approved or in the final approval process, will be evaluated by NBS to determine their applicability and further adoption as Federal standards.

Not all ANSI standards meet the needs and objectives of Federal Government users and thus are not recommended as Federal standards. In certain instances, it has been determined that there is no Government requirement for voluntary industry standards relating to MICR, embossed credit cards, 200 CPI magnetic tape, etc. In other cases, it has been determined that some ANSI standards cannot be adopted for Federal use without modification, because of certain technical incompatibilities or deficiencies (e.g., FORTRAN, magnetic tape labels). Assistance is being provided by the Federal Government to correct these problems and make these standards compatible with Federal Government requirements so that they can be adopted for Federal use. Agreement has been reached between NBS and GSA that certain standards, particularly those relating to media will be implemented by GSA as Federal purchase specifications (e.g., ANSI standards dealing primarily with physical properties of media including cards, magnetic tape, and disk media).

(6) ASSIGNED NBS

RESPONSIBILITY: Provide for technical maintenance of Federal $A D P$ standards.

According to established procedures, voluntary industry standards developed and adopted by the American National Standards Institute are automatically reviewed every five years, and as a result are revised, confirmed, or withdrawn. To date, 20 voluntary industry standards have been adopted as FIPS. Concurrent with the ANSI review effort, action is taken to have the corresponding Federal standard reviewed to assure that it continues to meet the objectives and requirements of the Federal Government. Through participation on ANSI committees, NBS and other Federal Government participants are directly involved in these reviews. Currently under review by both ANSI and the Federal Govern- 
ment are the data communications standards pubiished in FIPS PUBS 16, 17, 18, and 22 and the ASCII standard in FIPS PUBS 1 and 7. Recent examples of maintenance activities include the revised ANSI COBOL adopted as revised FIPS PUB $21-1$ and FIPS PUB 3-1 on magnetic media.

Wie plan to review every five years or more frequently. depending upon charging requirements or technical content. those Federal standards which are not based on voluntary industry standards.

As each Federal standard is issued, a maintenance authority is identified. For the current data standards. maintenance support is provided on a continuing basis by the Department of State, the Office of Management and Budget, the General Services Administration. and the Bureau of the Census. NBS promulgates change notices as these are received from the maintenance authority and publishes revised standards as necessary. For example, we are publishing the fifth revision to FIPS PUB 8 on Standard Metropolitan Statistical Areas which is maintained by the Office of Management and Budget.

In allocating resources to standards efforts, it is essential to recognize that standards must be maintained and provide the support necessary to be responsive to user requirements. Maintenance functions. in addition to keeping standards documents current. also include the essential function of advising users on how to obtain standards information and provide technical advice of their implementation as requested. In this regard, the ICST Office of ADP Standards Management serves as the focal point within NBS for answering and referring queries received from the using agencies. Over 500 queries are processed by this office each month.

(7) ASSIGNED NBS

RESPONSIBILITY: Develop, issue and maintain a statement of the Federal Government's standardization objectives and needs.

As an early step in carrying out its responsibility for the Federal Information Processing Standards Program. NBS established an interagency committee comprising representatives from the Federal departments and agencies that are major users of computer systems. The first undertaking of this committee. the Federal Information Processing Staudards Coordinating and Advisory Committee was to draft a statement containing the objectives and requirements of the FIPS Program.

In March 1970. the draft statement prepared by FIPSCAC was officially coordinated with all Federal departments and agencies and in November 1972, the Office of Management and Budget approved the objectives for the standards program which were issued by NBS in February 1973 as FIPS PUB 23. The objectives of the FIPS Program are categorized into six major areas: (1) Data, Programs, and Components, (2) Data Communications, (3) Computer Performance: (4) Applications and Data, (5) Personnel and Environment, and (6) Acquisition and Reassignment of ADP Products.

In December 1975, FIPSCAC initiated a review of the current objectives and requirements of the FIPS program to identify further items for standards based upon changing technological and operational conditions. In particular, the Privacy Act of 1974 caused new constraints that needed to be considered in the design and use of computer systems involving personal data. Extended use of minicomputer, intelligent terminals, data communications, and computer output on microfilm have created new needs for standards. The increase in use of computers in manufacturing. business and medical systems has also surfaced the need for standards that provide their effective use in these application areas. A revised statement of standards objectives is expected to be available for official agency review and comment in June 1976.

The Office of Management and Budget retained responsibility for the management of the Data Elements and Codes program from 1966 until August 1973. when OMB's responsibilities witl respect to Government-wide automatic data processing standards were transferred to the Secretary of Commerce by Executive Order 11717 dated May 9. 1973. While the approval authority for all Federal Information Processing Standards remains with the Secretary of Commerce. the management of the Data Standards Program was delegated to the NBS Institute for Computer Sciences and Teclunology. In assuming this new responsibility. NBS amended Subtitle A of Title 15 of the Code of Federal Regulations by adding a new Part 6 which inplements the provisions of Section III (f) (2) of the Federal Property and Administrative Service Act of 1949. as a mended (70 Stat. 1127). This new Part 6, effective December 5. 1973 (also republislied as FIPS PUB 28) provides policy and identifies responsibilities of Executive Brancl departments and independent agencies for a Government-wide program for the standardization of data elements and representations used in Federal automited data systems.

(8) ASSIGNED NBS

RESPONSIBILI'TY: Recommend procedures to be used in Federal Government for adopting 
Federal standards and developing and implementing plans therefor.

Procedures for the development, coordination and implementation for data standards have been issued as Part 6 Title 15 of the Code of Federal Regulations and promulgated in FIPS PUB 28.

Procedures governing the operation of interagency and public advisory committees that are established to consider standards matters are provided in Department of Commerce Administrative Order 201-2.

In the cooperative development of voluntary standards with industry, the operating procedures of ANSI and other industry standards groups are followed.

Currently, we are preparing operating procedures for the FIPS program based upon those for data standards in Part 6 Title 15 of the Code of Federal Regulations. The major issues still remaining to be resolved in preparing these procedures are (1) an effective mechanism for determining standards priorities and (2) an effective mechanism to monitor the implementation of standards and to assess the significance of their use in improving Federal ADP services.

In this regard, NBS has recommended to $O M B$ that a reporting procedure be established, wherein each individual system and installation would report to $\mathrm{OMB}$ on a regular basis the extent that standards have been or will be implemented.

(9) ASSIGNED NBS

RESPONSIBILITY: Provide leadership of an executive branch program for standardizing data elements and representations.

The Office of Management and Budget was responsible for the Federal data standards program from the implementation of the Brooks legislation in 1965 until May 1973 when, by Executive Order 11717, the President transferred to the Department of Commerce those ADP standards functions performed by OMB. Specifically, this transfer authorized the Secrutary of Commerce to approve standards on behalf of the President, and transferred to NBS the program responsibilities for data standards.

In November 1973, NBS prepared and obtained Secretary of Commerce approval of a Federal Regulation, codified as Part 6, Title 15 CFR, Code of Federal Regulations, which established a Federal program for the standardization of Data Elements and Representations and replaced the earlier OMB instructions in their Circular A-86. This Regulation assigns to NBS the leadership role in the management of Federal Government activities relating to the development, implementation, and maintenance of data standards. The Secretary of Commerce approves standards for Federal-wide use in behalf of the President.

In support of this new responsibility, NBS requested an additional $\$ 308 \mathrm{~K}$ in its 1976 Budget submission to establish the data standards program. Congress authorized $\$ 154 \mathrm{~K}$ of this request which has been allocated to NBS for the data elements and codes program.

One of the more significant efforts being undertaken in support of this new initiative was the establishment of an interagency task group (FIPS Task Group 17) charged with the development of standards and guidelines for use in constructing and maintaining data element directories and to develop performance standards for the automated process required to maintain and utilize such directories. The use of data element directories is needed as an essential adjunct in providing effective security to data files as prescribed by the Privacy Act of 1974.

NBS provides advisory, technical, and administrative support to this task group effort which is expected to produce, within this calendar year, an Executive Guide on Data Element Directories in Managing Data Resources, a guide for constructing and maintaining data element directories, and a technical guide that provides performance standards for automated data element directories.

NBS also arranges for the development of data standards with Federal agencies having assigned mission responsibilities. In FY1975, the first program assignment was arranged with the Civil Service Commission for the development of data element and representation standards used in the exchange of data for automated civilian personnel systems. These standards are intended to improve the effectiveness of civilian personnel support systems in all Federal departments and agencies. Arrangements are in process from $\mathrm{DHEW}$ to take the leadership role in developing data standards for defining and coding ethnic groups. Other arrangements for the development of standards in selected program areas will be made with appropriate Federal agencies. Data standards used in statistical reporting systems, freight movement systems and highway-traffic safety systems are planned and are under consideration with $\mathrm{OMB}$ and the Department of Transportation.

Before the end of FY1976, NBS will publish technical guidelines for the use of Federal departments and agencies in the development, implementation, and maintenance of standards for the representation of computer processed data elements.

Six Federal data standards have been established as FIPS. Five of these are for coding 
geopolitical entities (e.g., countries, states, countries, Standard Metropolitan Statistical Areas (SMSA's) and Congressional Districts), and are widely used in statistical reporting systems of the Federal Government and by State and local governments and the public. Two of these Federal standards (i.e., codes for states and counties) have been adopted by ANSI as voluntary industry standards. Four additional data standards for representing cities, map coordinates, time and measurement units are expected to be approved and published during FY1976 and FY1977.

(10) ASSIGNED NBS RESPONSIBILITY: To the extent feasible and desirable, develop and recommend means for measuring compliance with Federal standards.

\section{COMPLIANCE REPORTING}

Measuring compliance with approved standards is a major concern of NBS. It is recognized that the effectiveness of the standards program cannot be assessed based simply on the number of standards that are approved and published, but must include data on the extent that the use of standards has effectuated savings or increased performance in the Federal use of ADP. NBS has highlighted the need to identify and implement feedback mechanisms that allow our assessment of the impact of standards. NBS recommended to OMB in NBS Report 10608 of September 1971 that a reporting system be initiated in which Federal agencies provide information on the extent of standards implementation and the benefits or problems that have been experienced in the use of standards. This has not yet occurred.

There has been an expected, resultant, long-standing confusion and uncertainty associated with the lack of any compliance mechanism in the implementation of Federal Information Processing Standards within the Federal Government. This disquieting situation has existed since the first FIPS standard was issued in 1968. The Brooks Act, which established the FIPS program, does not address the issue of mandatory compliance or enforcement, nor do the OMB policy guidance papers or Executive Orders issued since 1965. Its only direct mention is a letter dated December 15, 1966, from the Acting Director of OMB to the Secretary of Commerce in which NBS was directed to, among other things, "the extent feasible and desirable, develop and recommend means for measuring compliance with Federal standards."
Since 1971, NBS has continually cited the confusion surrounding the lack of an explicit compliance mechanism as a significant factor in the degradation of the creditability and effectiveness of the FIPS program-a deficiency which impacts on both NBS and the Secretary of Commerce. Individuals within OMB have in 1976 expressed to NBS the informal view that Executive Order 11717 dated May 9, 1973, gives the Department of Commerce all needed authority to enforce compliance or use, as appropriate, with its FIPS standards and guidelines. No formal assurance of this has been given; presently, by memorandum dated April 23, 1976, NBS has asked the staff of the DOC General Counsel to resolve whether the Secretary of Commerce has the legal authority informally intimated by OMB staff.

Certainly, any Federal standards program intended to meet legislated requirements, such as those of the Privacy Act of 1974, needs an accompanying explicit compliance and enforcement mechanism. NBS has been keenly aware of, and has many times documented, its concern over the resulting lack of effectiveness within the Federal Government of its FIPS program.

When the legal authority of the Secretary of Commerce has been determined, NBS will either undertake the establishment of an adequate compliance mechanism or will formally notify OMB of the need for clarifying policy guidance.

\subsubsection{Standards Assessment}

The NBS 1974 study on the impact of ASCII as a Federal standard was the first attempt to make an assessment of a standard. Other means such as sampling techniques and selected studies are being investigated for obtaining information on the effects of the implementation of standards.

\subsubsection{Standards Validation, Testing and Calibration Services}

NBS also developed and initiated testing techniques for determining the extent that marketplace products and services meet approved standards. In the software area, COBOL complier testing is now operational and is being performed on a Federal-wide basis through the cooperation of the Department of the Navy. FORTRAN compiler test programs have been developed by NBS and are being tested by industry prior to the establishment of a formalized FORTRAN testing service in parallel with the Federal adoption of the revised FORTRAN standard.

NBS also provides basic references and calibration services for ADP products designed in accordance with standards. These standard reference materials and calibration services are used by the computer industry for quality control tests during the production phase and by Government agencies in the procurement of ADP products. 
Magnetic computer tapes and disks acquired for Federal use are tested by GSA for compliance with standards. NBS provided technical assistance to GSA in initiating this testing service in the design of test equipment and test methods. NBS also provides the basic references for measuring signal quality amplitude for magnetic media. These reference materials are recognized in both national and international standards and have been of significant value in improving the overall quality of magnetic tape available to the worldwide community of ADP users.

\subsection{Research}

The OMB Policy Guidance Letter to the Department of Commerce of December 15, 1966, assigned the following responsibilities to NBS:

- To supplement agency research efforts when necessary to meet Government-wide requirements or to provide solutions to problems of concern to several different agencies.

- To initiate efforts to solve large-scale and difficult problems sufficiently unique to special needs of Government that outside interests are not likely to undertake vigorous and timely action.

- To evaluate and apply advanced concepts to the development, organization and implementation of automatic data processing, computer and related systems, including the innovation or extension of techniques needed for improved cost effectiveness in the conduct of agency programs through the use of computers and related techniques.

- To conduct exploratory research in order to provide the technological bases for future standardization activities and to maintain the competence of the technical staff engaged in technical advisory services, testing and evaluation, and standardization activities.

- To identify continuing research and development requirements for use by the Center, other agencies, academic and other organizations and industry in planning and coordinating $R$ and $D$ programs in the area of computer and information sciences and technology.

- To participate in the conduct of an annual review of the accomplishments of a programs for research in computer sciences and techniques.

To the limit of extent that resources have permitted, NBS initiated research efforts in response to thses assigned responsibilities. Some of these activities were initiated prior to FY1970 on a very limited scale. From FY1970 through FY1973 a slightly expanded "exploratory development" program was conducted. Illustrative projects performed during these periods are provided below in section 5.3.2.

\subsubsection{Background}

During the early years of NBS activity and response to the Brooks Act, only a few specific topical research projects were identified. These projects often supplemented specific other agency research efforts and were conducted in cooperation with these other agencies. In FY1974, all directly appropriated funds were reprogrammed from this exploratory development area to other higher priority areas so as to concentrate the limited available resources on current, high priority requirements. Although the nature of the more specific program activity presently performed does involve, from time to time, developmental aspects, it is not currently possible to devote any resources directly to the performance of these assigned responsibilities.

NBS does not now and has never been able to devote the resources necessary to conduct exploratory research in order to provide the technological bases for future standardization activities and to maintain, in an organized and systematic manner, the competent staff engaged in technical advisory services, testing and evaluation, and standardization activities, in part because of the lack of resources, and also the lack of a willingness to participate by OMB, and the Office of Science and Technology when it existed, NBS has never participated in the conduct of an annual review of the accomplishments of and programs for research in computer sciences and techniques as assigned in the OMB Policy Guidance Letter.

\subsubsection{NBS Response to Assigned Responsibilities}

The following short project summaries illustrate the types of research activities that were carried out on a very limited scale during the first several years following Brooks Act enactment (prior to fiscal year 1970):

\section{(1) Research in Pattern Recognition}

Objective: This project was concerned with the study of techniques for utilizing computers and other special electronic and optical devices in the analysis and manipulation of information found in patterns of both natural and artificial origin in practical applications of interest to the Government. Included in the applications was the identification of inchividuals through fingerprints, footprints, voiceprints, and handwriting. The research was directed toward the use of electronic computers, graphic display equipment, electro-optical sensors and readers, teleprocessing, and large-scale file manipulation 
techniques. Research was conducted in the automation of pattern recognition and identification and included the definition of artificial languages capable of describing and manipulating the information contained in patterns. Methods were studied for automatically intercomparing patterns and for determining whether a given pattern belonged to an established set of patterns.

Impact on succeeding program entity: On the basis of this research effort, a request was received from the President's Special Action office on Drug Abuse Prevention, seeking a unique method of identification for use with drug addicts to be treated under the Methadone program. This resulted in a successful technique for identification based on the use of prints from the soles of the feet.

As another consequence of this effort, a request was received from the FBI for a study of the feasibility of automating the identification of fingerprints. This exploratory study was supported with NBS funds for about one year, after which it was concluded that the automation of this process should be feasible, and an approach was developed. Accordingly, a joint effort was initiated under FBI sponsorship.

This effort has led to a major successful program in cooperation with the FBI in which NBS has developed fingerprint matching algorithms and techniques that are key to the current major FBI fingerprint automation project. In addition, NBS continued to provide primary engineering consultative services to the FBI on this fingerprint automation program.

Research outputs: One Technical Note on footprint identification. One paper on the feasibility of automating fingerprint identification.

(2) Research in Techniques for Manipulating and Organizing Chemical Information

Objective: This project was an outgrowth of earlier research performed by NBS in the automatic storage, manipulation, and retrieval of chemical information. The project was jointly supported by the Army Research Office, the National Institutes of Health, and the National Science Foundation. The project was concerned with an examination of the characteristics of large files, and the development of structures for large files of heterogeneous scientific and technical information including chemical structure representations. Techniques were studied for manipulating information in either formatted or amorphous form, building of files with incomplete data, with provisions for adding additional data in the future, creation of multilevel files with provisions for generic information and varying degrees of specificity, and the interstructuring of files which may be part of larger files but geographically separated therefrom. List processing was studied as a means of maintaining flexibility, providing for file maintenance, and overcoming the constraints associated with fixedlength and formatted files. Techniques were investigated for organizing and manipulating files in order to achieve systems of subfiles, special files, and keying and crossreferencing as required for a system of multilevel, multisubject files. Techniques were explored for formulating queries of varying specificity and for responding to such queries.

Representative information files were computerized and programs were prepared for a variety of experimental investigations in file organization and manipulation. Alternative ways of representing structures of chemical compounds in digital form were explored. Computer algorithms were devised for the compaction of numeric and alphanumeric information in order to achieve significant savings in storage space and search times.

Research Outputs: One NBS Report on techniques for manipulating chemical information.

Interagency Report on one file organization for a large chemical information system.

The following project summary illustrates the types of research activities that were performed from FY1970 through FY1973 as a part of the " exploratory development" program.

\section{(1) Methods of Software Quality Control}

Objective: Explore the problem of the production and effective utilization of reliable. high quality software. Develop new approaches and techniques for large scale programming development, including project management, programming methods. languages, and mathematical analysis of software.

Impact: This research provided the basic techniques and thorough understanding essential to the Institute s current program in software engineering. For example. ihe current effort to develop a "Software Engineering Handbook" is based in part on the results of this research project. 
Research Outputs: STAPLE FORTRAN Pre-Compiler implemented and used experimentally, demonstrating feasibility of structured programming in present environment. Two Technical Notes, 13 papers.

(2) Controlled Accessibility

Objective: To develop the software and hardware technology which is essential to effective control of data access.

Impact on Succeeding Program Entity: This early research and development work in the computer security area resulted in Institute staff obtaining an essential headstart in developing the products of the current computer security program. For example, as a part of the research two workshops were held involving key private sector and academic experts in this area. The results of those workshops were incorporated in the initial guidelines issued as a part of the computer security program, which were prepared with very short lead time after initiation of the formal program in computer security.

Research Outputs: Data encryption algorithm to be used as a standard. Three FIPS PUBS were produced.

\section{Case Studies}

The following case studies depicit NBS fulfillment of its Brooks Bill responsibilities in selected technical areas of highest visibility and interest.

\subsection{Computer Systems Performance Measurement}

Assigned Responsibility Addressed By This Effort:

(1) P.L. 89-306 (Brooks Bill)

P.L. 89-306 provides that the Secretary of Commerce is authorized: (1) to provide agencies, and the Administrator of General Services in the exercise of the authority delegated with scientific and technological advisory services relating to automatic data processing and related systems; and (2) to make appropriate recommendations to the President relating to the establishment of uniform Federal automatic data processing standards. The Secretary of Commerce is authorized to undertake the necessary, esearch in the science and technologies of automatic data processing computers and related systems as may be required.

(2) Office of Management and Budget Policy Guidance to the Department of Commerce (National Bureau of Standards in the Implementation of P.L. 89-306)

\section{-Basic Policy}

The provisions of P.L. 89-306 will be administered in a manner that is consistent with the prime objective of encouraging the use of ADP by Government agencies to achieve greater productivity and reduced costs in the discharge of their respective agency program responsibilities.

\section{--Initial Guidelines}

- Provide criteria to assist in evaluating software and hardware developments that may be considered during the system studies.

- Provide technical guidelines for preparing solicitations of proposals, including the specification of system requirements.

- Provide guidelines, criteria and techniques for evaluating and selecting equipment and related software, giving priority emphasis to criteria for measuring the effectiveness and efficiency of software. Data on this subject will also be furnished to GSA for consideration in the procurement of computers.

- Provide guidelines for evaluating installation and systems performance on a continuing basis.

(3) Office of Management and Budget (Office of Federal Procurement Policy)

Assigned NBS the lead responsibility for implementing the Commission on Government Procurement's Recommendation D-14, development of standard programs for use by Federal agencies as benchmarks for evaluating automatic data processing equipment (ADP) proposals.

Executive Summary: The complexity of today's computer operations presents a considerable challenge to the Federal installation manager responsible for the effective and efficient operation of his ADP inventory. To help Federal managers meet this challenge, NBS first mounted a program of surveillance and support for the emerging technology which enabled NBS to provide technical advisory services in computer performance measurement and evaluation and which contributed significantly to the maturing of the technology. Recent program effort has been oriented toward serving the Federal ADP community directly through assessment, adaptation and transfer of computer sys- 
tem performance measurement technology, and the corresponding development of technical reports, handbooks, and guidelines to facilitate the introduction of performance programs at all Federal ADP installations.

Date Initiated: July 1969

Date Terminated: Continuing

Goals and Objectives: The goal of this program is to improve the effectiveness and efficiency of Federal computer installations through the definition of performance measures and the development of a technology for measuring and evaluating both installed and proposed computer systems. Program objectives include: (1) assessment of new and existing performance measurement technologies, and conceptual approaches to performance metrics; (2) adaptation of the more promising concepts and techniques to the unique requirements of Federal installations; and (3) transfer of pertinent concepts and techniques to Federal installation managers in the form of technical reports, handbooks and guidelines.

\section{Products:}

(1) Guidelines for Benchmarking ADP Systmes in the Competitive Procurement Procurement Environment (FIPS PUB 42), December 15, 1975.

(2) Benchmarking and Workload Definition: A Selected Bibliography with Abstracts, J. L. Walkowicz, (NBS SP-405), November 1974.

(3) Benchmarking and Computer Performance Measurement. a Survey Report, (NBS-IR), August 1975.

(4) Computer System Capacity Fundamentals, Kuck, D. J., (NBS TN-851), October 1974.

(5) Report on Computer Performance Evaluation for the FIPS Coordinating and Advisory Committee, Federal Information Processing Standards Task Group 10, March 1973.

(6) Computer Performance Evaluation: Report of the 1973 NBS/ACM Workshop, Bell, Thomas E., Barry W. Boehm and S. Jeffrey, (NBS SP-406), September 1975.

(7) Computer Performance Evaluation. Proceedings of the Ninth, Tenth and Eleventh Meetings 1974-1975, Highland, Harold J. (Ed.), FIPS Task Group 10, Computer Performance Evaluation Users Group (CPEUG), September 1975.
(8) Computer Performance Evaluation. Proceedings of the Eighth Meeting of Computer Performance Evaluation Users Group (CPEUG), Highland, Harold J. (Ed.), December 4-7, 1973, (NBS SP-401), September 1974.

(9) Papers Presented at the Fifth Meeting of the Computer Performance Evaluation Users Group, (L. G. Hanscom Field, Bedford, Mass., April 18-20, 1972).

(10) Symposium on the Simulation of Computer Systems, (National Bureau of Standards, Gaithersburg, Md., June 4-6, 1974), Highland, Harold J. (Ed.;, SIGSIM (Special Interest Group in Simulation) of the Association for Computing Machinery. N.Y.. 1974.

(11) Symposium on the Simulation of Computer Systems, (National Bureau of Standards, Gaithersburg, Md., June 19-20, 1973). Highland, Harold J. (Ed.), SIGSIM (Special Interest Group in Simulation) of the Association for Computing Machinery, N.Y., 1973.

(12) The Exec-8 Log System. Part 1-Description, Maryland Univ., College Park, Md., Rept. No. TR-434, prepared under NBS Grant 5-9017 by J. M. Mohr, A. K. Agrawala and J. F. Flannagan, January 1976.

(13) Analysis of the System Management Facilities of IBM Operating System MVT, Tesseract Corp., San Francisco, Calif., prepared under NBS Contract $5-35929$ by Gary Durbin, Peter Lamasney, Edward Newman and Edward Syrett, 1975.

(14) Validation of the System Management Facilities of IBM Operating System MVT, Tesseract Corp., San Francisco, Calif., prepared under Contract 5-359929 by Gary Durbin, Todd Kinney and Edward Syrett, 1976.

(15) Validation of Teleprocessing Networks in the Competitive Procurement Environment, Mitre Corp., Bedford, Mass., Rept. No. MTR-3012, prepared under NBS Contract 4-36062 by M. J. Sullivan, April 1, 1975.

(16) ADP System Procurement: Concept and Feasibility of an Application Benchmark Library, Mitre Corp., Bedford, Mass., Rept. No. MTR-3013, prepared under NBS Contract 4-36062 by P. L. Loring, March 28, 1975.

(17) Data Management System Selection: An Intermediate Data Base Representation, Mitre 
Corp., Bedford, Mass., Rept. No. MTR-3014, prepared under NBS Contract $4-36062$ by W. Amory, March 1975.

\section{Recipients of Products:}

- Managers of the 6,981 Federal computer installations

- Federal procurement and selection officers

- System designers (both hardware and software)

- State and local governments

- The computer industry

- All ADP users both in the Federal Government and in the private sector.

Relevant Circumstances: The NBS program in computer performance evaluation began in 1969 as a direct response to the measurement challenge presented by complex systems whose effectiveness depends to a large extent on the type and number of tasks (the workload) they process, many of them concurrently, in the course of daily operations. In new procurements, neither the system nor the workload exist in quantifiable form, yet the planned application must be translated into an actual workload for comparative testing and evaluation for a variety of computer systems. To deal with such complexities in the Federal community, the NBS program in computer measurement and evaluation was established when much of the technology of computer performance measurement was still in its infancy.

Involvement in the early development of CPME has been a significant factor in determining the current state of the technology. Through direct sponsorship, technological counsel and organizational support, NBS has been instrumental in the establishment of a Federal center for CPME consulting services (FEDSIM), the formation of Federal users groups in CPME (CPEUG) and Simulation (SSCS), the definition of Federal policies with respect to benchmarking and simulation in ADP procurements (SICS), and in providing forums for the free exchange of ideas and information among recognized authorities in the field (e.g., Computer Capacity Conference).

An event that has had considerable impact on the NBS computer system performance measurement program was the establishment of the Federal Computer Performance Evaluation and Simulation Center (FEDSIM) by GSA and the Air Force on March 3, 1972. While organizationally an operating component of the U.S. Air Force's Data Automation Agency, FEDSIM is financed by GSA's ADP fund; GSA bills agencies using FEDSIM services to reimburse the fund, making direct appropriation unnecessary. Under FPMR 101-32.1403, FEDSIM was designated as the mandatory source for Federal agencies wishing to procure either simulation and performance evaluation services or tools. FEDSIM either provides the service itself, contracts for the service for the agency, or authorizes the agency to procure the services. Because agencies tend to be more familiar with FPMR requirements than with the provisions of P.L. 89-306, the creation of FEDSIM has greatly reduced the number of agencies requesting NBS consultation in the area of PM\&E and has impaired NBS' ability to interact directly with Federal agencies in understanding their specific problems and requirements and in finding test-beds for developmental standards and technical guidelines. Since NBS does not perform service work of the type reserved for FEDSIM, a reasonable solution would be to delineate the respective functions of both organizations in the same section of the current FPMR. It is believed that this would clarify any existing confusion on the part of Federal agencies.

The creation of FEDSIM has had a second, more direct, impact on the NBS program in computer performance measurement and evaluation. Historically, FEDSIM was conceived by GSA on the premise that simulation would replace benchmarking as the major basis for comparative evaluation in computer procurements-a function in which GSA has a vested interest. The rationale for having the Air Force run the Center was that the Air Force owned a computer simulator package, and had many personnel experienced in applying it to computer performance problems. Meanwhile, major questions had been raised by the Computer and Business Equipment Manufacturers Association's (CBEMA), at that time Business Equipment Manufacturer Association (BEMA), Data Processing Group (DPG) concerning the use of computer simulators in the procurement process, and NBS was already involved with the technical issue of the use of simulator packages for comparing computers for selection. By August 1971, this issue was absorbing a principal portion of NBS/ICST's PM\&E program resources. This was followed chronologically by: (1) the issuance of FPMR E-23 on June 6, 1972 prohibiting for all practical purposes the use of simulator packages for comparative evaluation of computers in procurements; (2) the "activation" of FEDSIM on July 1, 1972; and (3) a GSA meeting on July 21, 1972 which resulted in agreement for FEDSIM to chair a study group to formulate a plan for developing a methodology for simulation in computer selection.

The impact of this series of events was to engage a large portion of the NBS computer system performance measurement resources in assisting the GSA and FEDSIM and in interacting with CBEMA and the computer vendor industry interests over the better part of FY1971, 1972, and 1973. While this diversion to the problem of the moment was appropriate and necessary, it occurred during a critical phase in the emergence of computer system performance measurement and evaluation technology. Its effect was to put NBS program production well behind Federal requirements for technical guidelines and standards in this area. With the support of the 1972 and 1974 GAO reports calling for PM\&E guidelines, and lead 
agency designation to implement the Commission on Government Procurement's recommendation to develop standard programs for general Federal use as benchmarks. NBS program resources have increased to the current level of approximately 3 man-years per year for the computer system performance measurement program.

In the light of a maturing technology and new Federal regulations that require evidence of CPME activities before additions may be made to existing computer inventories, recent IBS program effort has been directed to the assessment. adaptation and transfer of existing performance measurement technolog: to the managers of Federal ADP installations in a form that is immediately applicable to their requirements. One product of the current program has already been published as FIPS PUB 42. Guidelines for Benchmarking ADP Systems in the Competitive Procurement Environment. In preparation are other guidelines concerned with the establishment of effective computer performance measurement and evaluation programs at Federal computer installations. In a parallel effort, the NBS program is conducting technological assessments of developmental methods for measuring. evaluating and controlling the selection and utilization of modern computer systems.

Impact: Twice within the recent past the GAO has reported to Congress on the "opportunities for greater efficiency" provided by CPME technology and recommended that every Federal computer installation take appropriate steps to initiate CP.IE programs. The GAO reports cited substantial dollar savings actually realized at many industrial and Government installations with CPME activities. Yet, according to NBS estimates. fewer than 5 percent of all Federal computer installations have established such activities. The most important reason for the limited penetration of performance programs into the Federal ADP community is the fact that the evaluation of computer systems remains more art than science. What is needed is a technological center to test. organize and disseminate techniques that are already in use at many locations throughout the country. and to provide guidance to individual ADP installation managers who may be both unequipped and unmotivated to make such determinations for themselves. The NBS program is directed toward establishing such a capability-at ICST - within the Federal Government.

The economic impact of the NBS program can be estimated in terms of the total 6.981 installations valued at $\$ 4$ billion and whose operating and capital expenses for FY 1974 were $\$ 2.8$ billion. The intruduction of uniform practice in the measurement and control of Federal computer installations can yield substantial savings in equipment utilization as well as in new procurements. Second order effects will be reflected in better management and significant reductions in the operating expenses of Federal ADP facilities. The products of the NBS program are completely transferable to state and local guvermments as well as to the private sector.

$\begin{array}{lllc}\text { Funding Profile: } & \text { FY } & 1972 & \$ 155,000^{2} \\ & \text { FY } & 1973 & 122,000 \\ & \text { FY } & 1974 & 152.000 \\ & \text { FY } & 1975 & 190.000 \\ & \text { FY } & 1976 & 197.000\end{array}$

6.2 Adoption of the American Standard Code for Information Interchange (ASCII) as a Federal Information Processing Standard

Assigned Responsibility Addressed by this Effort: The Brooks Act specifies that "The Secretary of Commerce is authorized ... to make appropriate recommendations to the President relative to the establishment of uniform Federal automatic data processing standards. " The ASCll code is an important data processing standard in its own right and in addition serves as a principal building block for many other data processing standards.

Executive Summary: The ASCII code. American National Standard X3.4. was published by the American National Standards lnstitute in 1963 and revised in 1965. 1967. and 1968. It was adopted as a mandatory Federal lnformation Processing Standard by a memorandum from President Jolnnson to Heads of departments and agencies on March 11. 1968. and was subsequently issued as FIPS PLB 1. Specific instructions for its employment in the Federal Government were published in FIPS PLB 7 on Narch 7.1969.

ASCIl was the first Federal lnformation Processing standard (FIPS) to be approved and also was the standard whereby the implementation policy was established by OMB for all subsequent FlPS. i.e.. (1) Heads of agencies can waive the use of standards after advance coordination with NBS. (2) standards are implemented in new acquisitions and applications. and (3) there are no retrofits for standards.

In the fall of 1972. an evaluation of ASCII as a Federal lnformation Processing Standard was undertaken by a new FIPS Task Group. organized specifically for that purpose. The Task Group concluded. anong other things that: (1) Federal agencies have made significant progress in the acounisition of ADP equipment having an ASC.II capability. and (2) ASCll is used extensively in the telecommunications enviromment (i.e.. in the electronic transfer of data between different computers. and among computers and terminals). but very little elsewhere. considering the capability that exists.

The Task Gromp findings were formally reviewed by the FIPSCAC. the ICS'I Evaluation l'anel, and an ad hoc panel of five senior l(.ST staff mentulers.

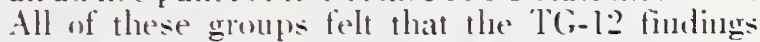
understated the impact of ASC.11. In support of this point of view it may be noted that: (l) virtuall! all of

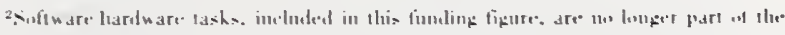

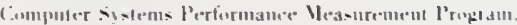


the Federal Government's 7,830 computers (1974 inventory) have the capability for processing ASCII data using vendor supplied soft ware; (2) an estimated three-fourths of the Federal Government's new minicomputers and some of its large scale computers supplied by Digital Equipment Corporation (DEC) and National Cash Register Company (NCR), over 1,500 computers in all, use ASCII as an internal code; (3) ASCII is the dominant code for Federal telecommunications and is used by almost all of the Federal Government's 26,007 terminals (1974 inventory); and (4) both the General Accounting Office and the National Archives and Records Service require the use of ASCII in their reporting procedures.

Task Group 12 and all three of the reviewing bodies felt that FIPS PUB 7 should be rewritten to provide more specific guidance to Federal agencies. This has been done. The rewrite is contained in proposed FIPS PUB 1-1 which will supersede both FIPS PUB 1 and FIPS PUB 7. The new FIPS PUB will (1) reaffirm the continued use of ASCII as a Federal Information Processing Standard, and (2) provide more definitive instructions for its use. The new FIPS PUB is in the coordination phase and will be issued by NBS after issues concerning standards compliance have been resolved.

\section{Date Initiated: Fiscal Year 1966}

\section{Date Terminated: Continuing}

Goals and Objectives: The principal goal of the adoption of the ASCII Code is to provide a standard for interchanging information between and within Government computer systems without having to translate from one character code to another. A secondary goal is to facilitate the exchange of computer software among Federal agencies and to the extent appropriate between Federal agencies and State and local governments and industry and the public.

Continuing objectives are to reduce the cost of data interchange within and between Federal computer systems and between Federal computer systems and those of State and local governments and to improve the reliability of data interchange.

Products: The direct products of the Federal Government ASCII effort are the following four FIPS PUB's:

\section{(1) Code for Information Interchange, (FIPS PUB} 1), November 1, 1968;

(2) Perforated Tape Code for Information Interchange, (FIPS PUB 2), November 1, 1968;

(3) Recorded Magnetic Tape for Information Interchange, (FIPS PUB 3), November 1, 1968; and
(4) Implementation of the Code for Information Interchange and Related Media Standards, (FIPS PUB 7), March 7, 1969.

The first three FIPS PUBS declare the ASGII Code and related paper and magnetic tape standards as defined in American National Standards X3.4-1968, X3.6-1965, and X3.221968 respectively, to be Federal Information Processing Standards. The declaration is based on a White House memorandum to Heads of departments and agencies, dated March 11, 1968, signed by Lyndon B. Johnson, then President of the United States.

The fourth FIPS PUB gives instructions for implementing ASCII and the related media standards in the Federal Government. It consists of two parts-a copy of the White House memorandum of March 11, 1968, referred to above, and a memorandum to Heads of departments and agencies from the Secretary of Commerce titled "Application of Federal ADP Code and Media Standards" dated March 7, 1969.

Indirect products of the Federal Government ASCII effort are the other Federal Information Processing Standards based on ASCII. These include: (1) standards for the representation of data on other media, (2) data communications standards, (3) standards for code extension and code expansion, (4) optical character recognition standards, and (5) standards for programming languages. ASCII continues to be the basic code for the continued development of related hardware, software and media standards, both National and International.

Recipients of Products: The principal users of ASCII standards are Federal Government computer users. There are, however, three other populations that are affected by them-nonFederal Government U.S. computer users, U.S. vendors of computer products and services, and the international ADP community.

\section{- Federal Government Computer Users}

Federal Information Standards in general, and the FIPS dealing with ASCII in particular, are addresied to the Federal ADP user. The ASCII standards are mandatory upon him, unless waived by his agency. They are applied for the most part, when computers and related equipment are procured, or otherwise brought into the Federal Inventory.

Federal procurement, including the procurement of computer products, is managed by the General Services Administration. GSA has issued a Federal Property Man- 
agement Regulation requiring that the mandatory provisions of FIPS PUBS be implemented in Federal solicitation documents. This applies to FIPS PUBS in general including the ASCII related FIPS PUBS referenced above.

Thirty-five waivers of the ASCII standard have been granted to date.

\section{- Non-Federal Government U.S. Computer} Users

Liaison with State and local government computer users in the implementation of ASCII is effected in several ways. First, new standards based on ASCII are coordinated with representatives of state governments prior to being approved. Second, state governments are on the automatic distribution list for completed ASCII standards. Third, State and local government computer installations are represented on the FIPSCAC and on some of the FIPS Task Groups where ASCII is considered through their professional associations, National Association of State Information Systems (NASIS), and Government Management Information Systems (G-MIS). Many State and local governments have adopted ASCII as a standard for their own use.

\section{- Vendors of Computer Products and Services}

The Federal Government is the largest single computer user in the United States. It possesses about $4.5 \%$ of the nation's computers. If these were combined with State and local governments and other computer users who employ ASCII and used as a single purchasing block, considerable marketplace leverage could be exercised.

\section{- International ADP Community}

The international ADP community also is influenced by the U.S. Government adoption of ASCII. The influence is exerted in several ways. First, many copies of the ASCII FIPS PUBS are purchased abroad. Secrond, many American producers of computer products that reflect the ASCII standards sell their wares abroad. Third, many of the U.S. companies that are influenced by the Federal Government ASCII Standards are, in fact, international companies that do business with the U.S. Government.
Relevant Circumstances: Byte oriented, as contrasted with pure binary, computers were introduced in the early 1950's. In such computers, each byte (group of bits) represent a character. The set of all such characters, together with their associated bit patterns, are referred to collectively as a character code or simply a code.

\section{- Pre-ASCII Codes}

A character code used extensively in computer design in the 1950's and early 1960's was binary coded decimal (BCD). This code has 6-bits permitting the representation of $2^{6}$ or 64 different characters. The BCD characters consist of the letters of the alphabet (upper case only), the decimal digits, punctuation symbols, and special symbols such as parentheses, plus and minus signs and asterisk. For historical reasons, the bit patterns assigned to these symbols are related to the way in which the symbols are coded on punch cards.

BCD is still in use today, and there are several versions of it differing from one another. The differences affect even the bit patterns associated with the 51 characters used in American National Standard FORTRAN. These differences cause difficulties in transferring programs from one BCD computer to another even when standard FORTRAN is used.

Other 6-bit codes that were used extensively were FIELDATA and XS-3, and at least one of these, FIELDATA, is still in use today.

In order to transfer information (data, programs, files and character coded control signals) from one computer to another using a different character code, it is necessary to translate from one code to the other. The translation may be simple or complex depending upon whether the elements of the two character sets correspond in a one-toone manner.

Programs written in higher level languages are generally expressed in terms of characters, and are intended to be independent of just how those characters are coded on particular computers. There is a difficulty with this, however, since the results of a program comparison depend on the collating sequence of the character set employed, and this in turn is determined by the character code. Thus, unless special precautions are taken in writing comparisons, a program in a higher level language will not run correctly on a machine with a different 
character set, even when character-bycharacter translation is performed correctly.

\section{- Voluntary Standardization of ASCII}

The difficulties caused by differing character codes have been recognized in voluntary standards making bodies in both Europe and the United States, and efforts to develop a standard code were begun in the early 1960 's.

In the United States it was felt that the demand for a code that would accommodate both an upper and a lower case alphabet was so compelling that the standard code should have at least 7 bits. Such a code could be used in the new 8-bit computers then being designed. Moreover, if the code were restricted to 7 bits, it could be used also in the new telecommunications systems which were then beginning to proliferate. Thus, a 7-bit code was agreed upon. Since the trend for new computers was from 6 to 8-bits, it was considered unnecessary to standardize a 6-bit code in addition.

The result of the U.S. voluntary standardization effort was the ASCII code. It was issued by the United States of America Standarcts Institute (USASI), the predecessor of ANSI, in 1963 and revised in 1965, 1967, and 1968.

ASCII is a 7-bit code with $2^{7}=128$ characters. Ninety-four of the characters are graphic symbols (upper and lower case alphabet, decimal digits, punctuation and special symbols), 32 are used for control functions, and the remaining two are "space" and "delete."

The adoption of ANS X3.41-1974 (Code Extension Techniques in 7 or 8 -bits) made ASCII fully compatible with 8-bit computers and also provided an extension capability for ASCII that is non-existent with any other widely used code.

An alternate assignment of the 128 ASCII bit patterns is known as an extended set, and the assignment of a complete table of 256 8-bit patterns as an expanded set. Extended sets suitable for use with ASCII in special applications are being registered. Provision is made, through the ASCII control characters SO (Shift Out), SI (Shift In) and ESC (Escape) to employ such character sets with a minimum of inconvenience.

The representation of the ASCII Code on 9 channel magnetic tape was standardized at the same time as the code itself. There is no standard way of representing ASCII on the 7 channel magnetic tape commonly used with computers employing 6-bit codes, nor is one expected.

The International Organization for Standardization (ISO) issued standard codes at about the same time. There were two of then-the ISO 6-bit code and the ISO 7-bit code. ASCII is identical with the English language version of the ISO 7-bit code.

\section{- Federal Government Action}

One of the first actions undertaken by NBS in fulfilling its responsibilities under the Brooks Bill was to adopt the ASCII Code as a Federal Information Processing Standard. Implementing instructions for the use of the standard are given in FIPS PUB 7. Its principal provisions are:

- All computers and related equipment configurations brought into the Federal Government inventory on and after July 1, 1969, must have the capability to use the Standard Code for Information Interchange and the formats prescribed by the magnetic tape and paper tape standards when these media are used.

- The ASCII character set and implementing input/output media standards shall be used whenever data is interchanged between two installations which have equipment conforming to the standard.

- When a system conversion of any magnitude is planned (new or more powerful hardware, machine-independent software or, especially, remote-access operation), an agency must not only acquire the prescribed hardware or software capability, but must include in its plans the actual introduction of ASCII character set, code, media, and sequence standards as soon as considerations of economics and personnel permit.

If instances arise in which an agency cannot comply with the provisions of the standard, the head of the agency is authorized to waive application of these instructions. Generally, two contitions apply in those exceptional cases which would warrant waivers:

(1) Significant, continuing cost or efficiency disadvantages will be encountered by the use of ASCII, 
(2) The interchange of information with other systems is minimal and is expected to remain minimal.

All waivers and the reasons, therefore, will be coordinated with the National Bureau of Standards sufficiently in advance of final agency authorization that NBS may consider the impact of the decision on the Federal standards program, and the significance of the action with respect to future national standards participation.

\section{- IBM Action}

IBM had originally intended to use ASCII as the internal code for system 360 , and a preliminary announcement had been made to that effect. When the computer finally appeared, however, the 8-bit 264 character Extended Binary Coded Decimal Interchange Code (EBCDIC) was used in its place. IBM subsequently offered a data interchange software package that translated between ASCII and EBCDIC.

The failure of IBM to support ASCII as its corporate standard has had a major impact on the marketplace and users, both government and non-government. This action by the dominant manufacturer has kept ASCII from achieving the maximum benefits as foreseen in the objectives of its early development.

Impact: ASCII was the first standard issued under the Federal Information Processing Standards Program having been approved by President Johnson on March 11, 1968. It is also perhaps the most fundamental since a character code underlies all computer hardware and software, and a character code standard serves as the basis for many other standards. Accordingly, in the fall of 1972, after four years experience with ASCII it was decided to evaluate it as a Federal Standard. This was the first time the Department of Commerce had attempted to evaluate systematically and comprehensively the significance and impact of a Federal Information Processing Standard since the Congress assigned the responsibility for developing such standards to the Secretary of Commerce in 1965. ASCII was the only Federal Information Processing Standard with which there had been enough experience up to that time to warrant such an evaluation.

It was decided that the evaluation shonld be carried ont by a new FIPS Task Gronp. number 12 , organized as a public advisory committee and having representation from non-Federal
Government computer users, computer hardware and software vendors and professional ADP societies as well as Federal Government employees.

The starting point of the evaluation was the FIPS TG 12 Charter. In the charter the Task Group was given the general objective of advising the Secretary of Commerce on matters regarding:

- The effect of ASCII, as a means for increasing the efficiency of Federal computer utilization, and

- The extension of the implementation of ASCII required to enable it to meet its intended objectives as stated in FIPS PUBs $1,2,3$, and 7 .

In addition, the charter identified six specific issues for the Task Group consideration as follows:

(1) FIPS PUB 7 provides implementation instructions for ASCII and its representation on perforated paper tape and $800 \mathrm{cpi}$ magnetic tape. These instructions state that all computers and related equipment configurations brought into the Federal Government on or after July 1, 1969. must have the capability to use ASCII and be able to receive and generate data on 800 cpi magnetic tapes and perforated paper tape recorded in ASCII. Federal departments and agencies have already been queried for an initial determination of the extent of ASCII implementation. Later fieries will address associated conversion difficulties and other related problems.

(2) FIPS PUB 7 also states that ASC.II shall be used whenever data is interchanged between two installations which have equipment conforming to the standard. The extent that ASCII is specified in these interchange sitnations will be identified.

(3) FIPS PUB 7 specifies those ASCil related character sets that are permissible for Federal use (i.e. basic set. subsets. extended sets, and expanded sets). The present nse of these allowable sets and related standardization or implementation problems will be determined.

(4) FIPS Pl'B 7 provides procedures for obtaining waivers on implementing ASC.II standards. The effectiveness of these procedures for standards managenent will be ascertained. 
(5) FIPS PUB 7 states that existing computer systems would be converted to ASCII on an evolutionary basis as equipment is replaced, reprogrammed, or redesigned. The extent to which this has occurred will be determined.

(6) ASCII is a fundamental standard in that it provides a base line for the derivation of a family of uniform standards. Other standards necessary to achieve increased compatibility will be decided.

The Task Group approach to carrying out its responsibilities under the charter was to survey Federal Government computer users, nonFederal Government computer users, and computer vendors. To this end three working groups were established-one to survey each of the three target populations. As a result of the surveys, TG-12 developed the following comments on the six specific points listed in its charter:

(1) Federal agencies have made significant progress in the acquisition of ADP equipment having ASCII capability.

The actual use of ASCII, however, appears to be proportionately less than might be expected from the capability that exists, except in the telecommunications environment.

(2) The fraction of active data interchanged between installations is small. Whenever data is interchanged between two installations which have equipment conforming to the standard, the use of ASCII is very low except for telecommunications.

(3) With the exception of the telecommunications environment, the present use of ASCII character sets in active data is negligible. Of those allowable subsets, the 64 character set has more frequent use. EBCDIC (the IBM Code) appears to be used more extensively than ASCII. Insufficient tables and guidelines exist to assist agencies in converting to and from a variety of non-ASCII codes and ASCII. There are insufficient graphics to meet all user requirements; definition of this requirement is a limiting factor.

(4) The waiver procedures are subject to broad interpretation and allow each agency to determine its own course of action with respect to ASCII implementation. The effectiveness of these procedures could be improved by providing more specific policy/guidance.
(5) The evolutionary conversion to ASCII as equipment is replaced has made some progress, i.e., hardware capability is being acquired. There has been very little conversion as a result of reprogramming and redesigning of systems.

(6) Subsequent to the Secretary of Commerce Charter for FIPS TG-12 a new Federal Information Processing Standard "Objectives and Requirements of the Federal Information Processing Standards Program" was issued dated February 15, 1973. This publication identifies standards and guidelines that may be essential for implementation of ASCII. TG-12 findings did not reveal additional areas for standardization.

In addition, the Task Group developed a list of five findings which it identified as "Advice on Matters Regarding ASCII":

(1) The multi-code environment is here and will remain for some time;

(2) Modern technology facilitates continuance of the multi-code environment;

(3) There is a valid mono-code environment of undetermined extent;

(4) There are national and international standards to support the mono-code environment; and

(5) The impact of economic versus innovative technical growth is not adequately known.

The Task Group Report was reviewed by the FIPSCAC, the ICST Evaluation Panel, an ad hoc panel of five senior ICST staff members established specifically for the purpose, and many individuals.

All of the reviewing bodies and most of the individuals felt that although the data developed by TG-12 was valid, its interpretation as given in the findings understated the impact of ASCII. In support of this point of view, the following observations have been made.

- ASCII is the dominant code used in telecommunications (TG-12).

- Three-fourths of the new minicomputers being offered use ASCII as an internal code (Auerbach report). Most new Government mainframes acquisitions are minicomputers. 
- Two of the manufacturers on large scale computer mainframes (NCR and DEC) use ASCII as an internal code. The remainder read, write and process ASCII using vendor supplied software.

- In connection with its Standard Forms Program and National Archives and Records Service requires that applicable Federal Information Processing Standards including ASCII be used.

- In reports from the regulatory agencies, the General Accounting Office requires that Federal Information Processing Standards including ASCII be used.

All reviewers agreed with TG-12 that FIPS PUB 7 should be rewritten to provide more specific guidance to Federal agencies.

More specific guidance has been written. It is contained in proposed FIPS PUB l-1 which will supersede both FIPS PUB 1 and FIPS PUB 7. This proposed FIPS PUB was submitted to Federal agencies for information and comment on November 25, 1975, and was published in the Federal Register to solicit the views of members of the private sector on December 29, 1975. It reaffirms the continued use of ASCII as a Federal Standard and provides revised implementing instructions.

$\begin{array}{llrr}\text { Funding Profile: } & \text { FY } & 1966 & \$ 50,000^{3} \\ & \text { FY } & 1967 & 50,000^{3} \\ & \text { FY } & 1968 & 50,000^{3} \\ & \text { FY } & 1968 & 50,000^{3} \\ & \text { FY } & 1969 & 50,000^{3} \\ & \text { FY } & 1970 & 41,000^{3} \\ & \text { FY } & 1971 & 41,000^{3} \\ & \text { FY } & 1972 & 41,000 \\ & \text { FY } & 1973 & 20,000 \\ & \text { FY } & 1974 & 20,000 \\ & \text { FY } & 1975 & 14,000 \\ & \text { FY } & 1976 & 14,000\end{array}$

The figures include ICST funded work with ANSI and ISO that directly supports the Federal Government ASCII effort.

\subsection{Computer Peripheral Interface Standards}

Assigned Responsibility Addressed By This Effort: Public Law 89-306 (the Brooks Act) provides NBS with responsibility for establishing uniform Federal standards enabling the economic procurement and efficient utilization of ADP facilities.

Executive Summary: This project is primarily involved with the establishment of Federal standards that define the interfaces between peripheral devices and their controllers as well as between controllers and data channels or central processor units. These interface standards will enable the independent competitive procurement of ADP peripheral components as well as the configuration of ADP systems employing peripherals drawn from the Federal inventory. In support of the standards de velopment effort, this project is also involved with the conduct of technologic and economic analyses. Examples of these analyses include: (1) evaluating computer system architectural trends to forecast the location and nature of future interface points, (2) assessing the Government's continuing experiences in the procurement, operation, utilization, and maintenance of ADP systems furnished by multiple suppliers, and (3) analyzing the comparative life-cycle costs associated with single-versus multi-vendor ADP installations.

\section{Date Initiated: FY 1966}

\section{Date Terminated: Continuing}

Goals and Objectives: The goal of this project is to minimize the overall life-cycle costs associated with the procurement and utilization of ADP systems within the Federal Government by enabling the configuration of central processing units and peripheral components from independent and competitive sources. The objectives include the establishment of a family of device specific and device independent peripheral interface standards.

\section{Products:}

(1) Report by the Center for Computer Sciences and Technology, National Bureau of Standards entitled Means of Achieving Interchangeability of Computer Peripherals, dated March 1972.

(2) Guideline for Planning, Selection, Installation, and Operation of Multi-Vendor Computer Systems, scheduled December 1976.

(3) Standard for Minicomputer-Device Level Interface, scheduled September 1977.

(4) Standard for Computer Channel Level-Device Controller Interface, scheduled September 1977.

(5) Standard for High Performance Disk Drive/ Controller Interface, scheduled July 1978.

\section{Recipients of Products:}

- Government ADP installation managers.

- Government ADP procurement specialists.

- ADP industry (major system suppliers and independent suppliers of peripheral components).

Relevant Circumstances: Conferences were held in September 1969 at Charlottesville, Virginia, and in July 1970 at Myrtle Beach, South Carolina, to formulate Federal Government policies and priorities with respect to ADP procurement, standards, and 
other timely critical issues. Both conferences were attended by over 40 top management officials from a dozen Government agencies, the Interagency Committee on ADP, the General Accounting Office, and various segments of the computer industry, including system suppliers and independent peripheral suppliers. Both conferences confirmed "the continuing urgency for appropriate $\mathrm{I} / \mathrm{O}$ interface standards that would provide the flexibility needed by users for the selective configuration of computer systems to achieve required performance at least cost and facilitate multi-vendor procurements."

In spite of these clear expressions of Government (and other user) interests and ignoring repeated pressures from NBS over the next several years, the major ADP system suppliers recognized that the establishment of peripheral interface standards would lead to erosion of their markets; they successfully avoided making progress in the development of standards.

Among the more significant findings of the 1972 NBS report entitled "Means of Achieving Interchangeability of Computer Peripherals" was that "... The Federal Government should increase its support to voluntary national and international standards development activities." Acting in support of this recommendation, NBS has increased the commitment of resources and directed concurrent efforts at several levels within the voluntary standards development arena.

During 1973, for example, largely in response to NBS urging, both X3 and X3T9 were encouraged to solicit broader representation and to include Computer Industries Association (CIA) and peripheral equipment suppliers among their respective memberships. Similarly, through direct contacts with the CIA constituency, NBS encouraged increased participation by the peripheral suppliers in ANSI standards activities. As a result of these and other NBS efforts at both the X3 and X3T9 levels during early 1974, the U.S. position with respect to the Japanese proposed international channel level interface standards was reversed; X3T9 focused attention on technical issues and began to work constructively on the development of an international standard. Technical evaluation of the Japanese proposal, followed up by a meeting with the Japanese in July 1974 (arranged for by NBS) led to the development of a number of minor improvements to the Japanese proposal that were accepted by ISO/TC97/SC13 at its meeting in October 1974. During 1975, at the instigation of the Computer Industries Association participants on X3T9 (and with NBS support), the committee initiated action to draft a proposed American national channel level interface standard based upon the IBM System 370 channel-tocontroller interface specification. This document is presently the subject of an X3T9 letter ballot-for consideration of being forwarded to $\mathrm{X} 3$ for further processing.

In addition (also in response to earlier NBS efforts), X3T9 initiated work on minicomputer interface standards by constituting a task group (X3T92). At its first meeting during February 1975, this task group determined that it would focus on the development of device level interface standards and established a program of work that identified some 12 candidate device types for consideration.

As a normal activity associated with standards committee participation, NBS has drafted and submitted a number of technical memoranda and proposals for resolving various issues at the X3T92, X3T79, and X3 levels.

While the results of these ANSI and ISO interface standards activities are as yet incomplete, it appears clear that the increased level of NBS participation in these activities over the past two years has been a significant factor in determining their present direction. ANSI X3 approval of the proposed American national channel level interface standards appears likely within the next year and this should be suitable for adoption as a Federal standard. The channel level interface standard is one member of the family of standards recognized by the 1972 NBS report as being needed for achieving interchangeability of computer peripherals. Other members of this necessary family of interface standards appear likely to result from the effort of the X3T92 task group in its approach to the development of device level standards for minicomputers. Whether or not the entire family of required standards will eventually be approved as American National Standards is of course critically dependent upon the willingness of the major U.S. computer mainframe manufacturers to accept and voluntarily build to such standards; it is not presently clear that a sufficient industry-wide consensus exists to accomplish the necessary degree of voluntary standardization. Meanwhile, the Government may employ those interface standards that are produced with increasing leverage toward the objective of successfully procuring and using the least expensive ADP facilities that satisfy its requirements. In addition, the Federal Government may develop or adopt interface standards at its own initiative, coordinating such development through the FIPS Task Group on ADP Interface Standards identified below.

Although the major ADP system suppliers have consistently opposed and until recently successfully prevented the development of peripheral interface standards, it appears that efforts of the consumers (including NBS) and lately the CIA may produce some meaningful results. Meanwhile, beginning in about 1972, and in part as a result of technical assistance provided by NBS, the Government has accrued savings of about $\$ 120$ million 
by procuring plug compatible replacement (tape, disk. and memory) peripheral components employing the mandatory requirements contract as a procurement vehicle.

During early 1975 additional resources were made available to - XBS. making it possible to formulate a renewed four task program to provide a better focus for both the (internal) Government and (external) industry efforts to achieve peripheral interface compatibility. The first two parts of this NBS program established a FIPS task group to provide a mechanism for assessing the Government experiences with multi-vendor ADP installations and produce a FIPS Guideline clearly stating the means for avoiding or resolving frequently reoccurring problems. The third part of this NBS program established a contractor effort leading to the identification of the degree de facto interface standardization already achieved in the manufacture of high performance disk drives. The results of this contract effort should be useful in the documentation of a device level standards proposal for consideration by ANSI. The fourth part of this NBS program proposed the conduct of several specific economic and technological efforts-namely. lifecycle cost comparisons for single versus multivendor ADP installations and ADP system architectural trend analyses to identify future interface points amenable to standardization and to clearly understand the architectural impact of proposed standards.

This effort was designated as a joint NBS/GSA Interface Program, and GSA enthusiastically agreed to provide support in accomplishing two parts of the four-part program-participating in the FIPS task group and performing the life-cycle cost analysis.

The GAO report on the "Study of the Acquisition of Peripheral Equipment for Úse with Automated Data Processing Systems “ issued on June 24. 1969. recommended that immediate steps be taken by agencies of the Executive Branch-"requiring replacement of leased components that can be replaced with more economical plug-to-plug compatible units." Supporting this recommendation. it was estimated that the Government could potentially save as much as $\$ 100$ million. The report recognized that the establishment of computer peripheral interface standards would be an important step in promoting additional competition in the computer industry.

As noted previnusly. even without the establishment of interface standards, but by employing the mandatory requirements contract. the Government has accrued savings in excess of $\$ 120$ million since 1972. Now it is anticipated that some degree of industry standardization may be achieved and that within the next year at least two ANSI standards can be produced. Thus, it appears that future sar- ings far in excess of those originally estimated by GAO may be possible.

Funding Profile:

FY 1966

FY 1967

$\$ 5.000$

FY 1968

35,300

FY 1972

FY 1973

$\$ 15,000$

32,600

FY 1974

9.600

FY 1969

32.000 est.

FY 1975

45.100

FY 1970

32.000

FY 1971

2.000

FY 1976

96.300

97.100

\subsection{Remittance Processing System}

Assigned Responsibility Addressed by this Effort: This work involved the application of computer science and technology in meeting specific operational needs for furthering the economy and efficiencr of essential Gorernmental functions and was clearly under the purview of P.L. 89-306 as directed by OMB guidance.

Executive Summary: Every year nearly a hundred million Federal tax returns are processed at the ten Regional Internal Revenue Service Centers. While many steps are involved in processing each return. those steps associated with depositing taxpayer remittances have a high sense of urgency as prompt deposits save interest costs on money that the Treasury would otherwise have to borrow.

Necessary functions included computer entry and subsequent verification of data from tax documents. printing an audit trail number and amount on remittances. endorsing the remittances. preparing deposit listings and marking the original documents with a locator number to facilitate future retrieval.

Internal IRS studies had indicated potential adrantages could be realized through comsolidation and additional automation of some of these functions. When solicitation of the private sector proved unsuccessful. IRS requested that the Institute for Computer Sciences and Technolog: undertake the derelopment of a prototype Remittance Processing System that would interface with the existing lRS data processing system and would consolidate a number of the required steps at a single work station. eliminate duplicate transcription. speed posting time and facilitate reconciliation of listings. The prototype was to be installed and tested at an IRS Service Center. and if successful. would serve as the basis for preparing specifications for the competitive procorement of production equipments in sufficient quantities for all ten Regional service Centers.

A prototype Remittance Processing System was developed through the integration of a number of commereially arailable components and subsistems and was installed at the Philadelphia Regional IRS Service Center during the summer of 
1973 for test and evaluation. These tests extended over many months and encompassed the regular quarterly IRS load peaks. During this period, a number of design improvements were implemented by ICST, while routine maintenance was provided by a private sector contracting arrangement.

At the end of the test period the IRS response was so overwhelmingly favorable that NBS was requested to continue the contracted maintenance so that the prototype system could continue to be used operationally until it could be replaced by production equipments. NBS agreed and undertook the preparation of procurement specifications in close cooperation with the sponsor. A procurement action followed and it is anticipated that ICST will continue to provide technical assistance in connection with contractor selection, contract monitoring and acceptance testing of the production Remittance Processing Systems.

\section{Date Initiated: August 1971}

Date Terminated: Project not terminated; estimated termination date: September 1977.

Goals and Objectives: To develop and fabricate a prototype Remittance Processing System to prove a new IRS "concept" for the processing of taxpayer remittances and provide a basis for the development of technical specifications for the commercial procurement of sufficient devices to equip alI ten IRS Service Centers.

Products: A functional work station reflecting extensive human engineering that interfaces to the IRS Direct Data Entry System (DDES) computer complex as a terminal. Tax documents are delivered to the terminal operator in batches which are termed blocks. For each document, the operator keys in a small amount of selected information. The DDES computer responds by displaying at the terminal the full set of data fields which had been originally entered at an earlier processing step. The operator verifies the accuracy and, if necessary, corrects the original entry data. Upon receipt of the verification signal, the computer transmits a number of data elements to the terminal printing mechanisms and notifies the operator to proceed. The operator inserts the remittance in a slot where it is transported to a printing mechanism which prints the amount on the face of the remittance and an audit trail and endorsement on the back. The remittance is then transported to an output stacking hopper. The operator then inserts the tax document or package of documents in another slot where a label carrying a printed Document Locator Number is affixed in a prescribed location. Concurrently, another printing mechanism prepares a multiple copy listing of the remittances which serves the function of a deposit slip. The processing speed is approximately five remittances per minute.
Recipients of Products: IRS Regional Service Centers are the primary recipients of this product. All taxpayers are indirect beneficiaries as a result of the reduction in processing costs to IRS. In addition, NBS gained valuable experience in interfacing a complex computer terminal system on an already existing computer and terminal complex in such a manner as to preclude any electronic interference in or with the existing complex.

Relevant Circumstances: There were a number of particularly challenging technical problems involved in the development of the Remittance Processing System. Of these, the more significant were problems involving the printing of the Document Locator Number on tax documents, interconnecting the system to the existing complex, and, înally, human engineering the work station.

Tax documents to be handled by the Remittance Processing System may range from a single small sheet of paper to a thick stack of large sheets. Each must be assigned a permanent 14-digit Document Locator Number which serves as an identifier and facilitates retrieval. Impact printing was considered, but the difficulties associated with the variable packet thickness made this approach unattractive. Ink jet printing could accommodate the required range of packet thickness but did not provide the necessary permanence and smear resistance when used on some types of paper. The solution finally adopted was to print the number on a strip label which was then cut and attached to the document using heat sensitive adhesive. The implementation of this approach required the design of special electromagnetic, thermal and pneumatic mechanisms which ultimately provided a viable solution to the problem.

In interconnecting the Remittance Processing System to the existing IRS computer and terminal complex, it was mandatory that under no circumstances, including catastrophic failure of the prototype, should the normal operation of the existing complex be impaired. In order to provide the necessary degree of electrical isolation and protection, optical coupling was used to connect to the data communication links of the computer complex. This proved to be completely effective and no prototype malfunctions have adversely affected other system functions.

For the operators' work station, it was necessary that there be convenient access to a keyboard and a number of special controls and access to the mechanisms for printing remittances and document locator numbers. In addition, good operator visibility was required for both a soft display terminal, special status displays and the outputs of three printing devices. Finally, space had to be provided to accommodate the blocks of working documents. Numerous mock-up arrangements were configured and one was selected which has proved to be near-optimum as judged by operator acceptance. 
Impact: The Remittance Processing System has proved to be a highly successful project. The RPS combines what were formerly six individual processing procedures. Tests on the prototype have demonstrated that the productivity of IRS personnel using this system is increased by a factor of six. Processing time and error rate have both been reduced by a factor of two. Its use permits a full audit trail for the first time and facilitates the processing of any necessary tax return related correspondence. Full implementation of this system with approximately 300 terminals distributed nationwide in the 10 IRS Regional Service Centers will result in annual cost avoidance of over $\$ 3,000,000$. For the private sector, it was a prerequisite to issuance of a commercial contract estimated to exceed $\$ 5,000,000$ in value.

Funding Profile:

$\begin{array}{llr}\text { FY } & 1972 & \$ 400,000 \\ \text { FY } & 1973 & 524,000 \\ \text { FY } & 1974 & 348,000 \\ \text { FY } & 1975 & 236,000 \\ \text { FY } & 1976 & 186,000\end{array}$

\subsection{Performance Measurement of Computer Networks}

Assigned Responsibility Addressed By This Effort: Advisory and Consulting Services. Research on Computer Sciences and Techniques.

Executive Summary: This project is directed towards developing an acceptable method of evaluating computer networks and network services. The principal outputs are tools and techniques for performing this evaluation, and guidelines for Federal agencies to assist them in using these or other available techniques for their evaluation.

Performance evaluation is approached from the point of view of the service delivered to the end user of the system or the customer for the service. New models of this type of performance have been developed, and new measurement tools and techniques have been produced to implement these models. Procedures have been developed both for empirical measurement and measurement under controlled conditions.

Assistance has been provided to a number of agencies in applying these and similar procedures to the measurement of systems and services for the purposes of procurement or service improvement efforts. The first in a series of FIPS Guidelines in this area has been circulated to agencies for comment. A cooperative program with GSA in the area of remote terminal emulation (measuring systems and services under controlled conditions) is underway and expected to provide the froundation for new Federal procurement policy.
Date Initiated: May 1971

Date Terminated: Currently active

Goals and Objectives: The objectives of this project is the development of guidelines for Federal agencies on the measurement of computer network systems and services to provide a basis for the orderly selection, procurement, and improvement of such systems and services. Source selection techniques for comparing and predicting the performance of large teleprocessing computer systems will be developed, within the overall objective of reducing the time and costs of comparative evaluation for system source selection.

\section{Products:}

(1) Performance Measurement of Remote Access Computer Systems, M.D. Abrams, (NBS Report 10381$) 1970$.

(2) Performance Measurement of Remote Access Computer Systems, published in Bul. Electrotech. Lab. (Tokyo), 1970.

(3) Paper describing NBS work presented at IEEE Workshop on System Performance Evaluation held at Argonne National Laboratory, 1971.

(4) A presentation was made to a plenary session of the Computer Utilization Group at the Organization for Economic Cooperation and Development, Paris, on the state-of-the-art of computer performance evaluation in the United States. March 1972.

(5) A paper, "Measuring and Modeling ManComputer Interaction," was presented at and appears in the Proceedings of the First Annual SIGME Symposium on Measurement Evaluation. March 1973

(6) A special connection to the MEDLINE system at the National Library of Medicine (NLM) was installed with the full cooperation of NLM staff. This connection employs the "data coupler," a new hardware device for full duplex recording that has been designed, constructed and installed by ICST staff. The Network Measurement Machine has also been used to collect data related to the use of MEDLINE by terminal users at the University of Hawaii and other locations on the ARPA Network who access MEDLINE on a regular basis through the NBS-ARPA Network node. June 1973.

(7) Preliminary results of the MEDLINE Measurements were reported in a paper entitled "Performance Measurements of Computer- 
Communication Networks" given at the NATO Advanced Study lnstitute on Computer Communications Networks held at the University of Sussex in England. September 1973.

(8) The special facilities for connecting the NMM to the NBS Univac 1108 were installed. March 1974 .

(9) A paper describing the NMM was delivered at the Annual Meeting of the American Association for the Advancement of Science. March 1974.

(10) A paper "Computer Communications Network Performance Measurement" was accepted for EUROCON '74 and appeared in the proceedings of that conference. March 1974.

(11) A paper "Measuring Service Delivered in Interactive Computing" apppeared in the Proceedings of the Second Jerusalem Conference on Information Technology. March 1974.

(12) A paper, "A New Approach to Performance Evaluation of Computer Networks," was presented at the NBS IEEE Symposium, Computer Networks: Trends and Applications. June 1974.

(13) A series of internal papers documenting the design of the Terminal Environment Simulater (TES) was completed. A working baselevel TES was demonstrated by interconnecting the Network Access Machine (NAM) with the Network Measurement Machine (NMM) in order to access a remote system and control the dialogue sent to that system. September 1974.

(14) A meeting was held with NBS/ICST, the Air Force, ESD/MCS, (Hanscom Field), and CBEMA regarding use of the Air Force's Remote Terminal Emulator systen in procurements in an attempt to resolve technical and policy issues on the use of the Air Force RTE in computer procurement. September 1974.

(15) Following several meetings with personnel from GSA, an ad hoc committee was formed with the objective of gaining GSA acceptance of application of measurement drivers (of which the Terminal Environment Simulator is a sample) in teleprocessing network procurement. An outline for a position paper was prepared. A draft was completed by ICST technical staff and used for subsequent discussions. December 1974.

(16) A paper, "Consumer-Oriented Measurement of Computer Network Performance," was presented at the National Telecommunications Conference and was published in the proceedings. December 1974.

(17) Validation of the NMS Data Analysis Package was completed. Validation procedures for the NMM were designed, implemented, and tested. March 1975.

(18) Summary statistics for 60 interactive (demand) conversations with NBS Univac 1108 were produced and presented to the Computer Services Division. June 1975.

(19) The Service Concept Applied to Computer Networks, M. D. Abrams and I. W. Cotton, (NBS Tech. Note 880) 1975.

(20) The prototype Terminal Environment Simulator was applied to two time-sharing services, include the NBS UNIVAC 1108. A script was executed on each system 100 times during different user loading and times of day. An internal report describing the procedures and resulting statistics was written. September 1975.

(21) A meeting was held between the research associates and Dr. Paul Oliver of the Navy's ADPE Selection Office ADPESO). The pros and cons of using a remote terminal emulator (RTE) in the selection of large teleprocessing systems were discussed. September 1975.

(22) A predictive response time algorithm for computer network services was designed and tested by a series of experiments employing the DEC System-10 and the Network Access Machine. September 1975.

(23) Interpretation of Data in the Network Measurement System, S. W. Watkins and M. D. Abrams (Tech. Note 897), 1976.

(24) The Network Measurement Machine-A Data Collection Device for Measuring the Performance and Utilization of Computer Networks, R. Rosenthal, D. E. Rippy, and H. N. Wood (Tech. Note 912), 1976.

(25) A draft of the FIPS Guideline to the Selection of Interactive Computer Service Delivered Through Computer Networks was released for external review. February 1976.

Recipients of Products: This project was initiated under the Brooks Act mandate to provide scientific and technical advisory services to other agencies in the efficient and effective selection and use of ADP equipment. These agencies, through direct contact with NBS and through the technical reports and guidelines issued, and to be issued, are the primary recipients of the products of this project. 
GSA is a direct recipient of NBS technical expertise in this area. As confirmed by a letter from Dr. Ruth Davis to Mr. Theodore Puckorius, dated May 4, 1976 NBS is supporting GSA's Project Plan for incorporating the use of remote terminal emulation in the Federal EDP procurement process.

Relevant Circumstances: It is well recognized that one of the critical leverage points in ensuring the effective and efficient use of ADP equipment by the Federal Government is at the procurement stage. At this point, the Government is best assured that it procures the systems and services meeting its needs at least cost. This requires some means of measuring the performance of alternative systems and services, in order to compare them with each other and with Government requirements. However, there is currently not a satisfactory method for live-testing or predicting the performance of computer network systems or services satisfactory to both the vendor and the Government in the competitive procurement environment. This problem area has been mutually identified by both computer system and service vendors and the Federal Government as a critical issue, solution to which would enhance the rational decision making process in the procurement process. Such a capability could also be applied to system improvement efforts.

Impact: A minicomputer-based Network Measurement System has been developed in support of the development of guidelines and assist ance to Federal agencies. Terminology is being defined and employed to identify acceptable criteria which performance measurement tests should meet.

A FIPS guideline has been prepared on the selection of interactive computer services delivered through computer networks. It is currently being circulated for comment among Federal agencies prior to being formally issued. Specific assistance has been provided to a number of agencies in preparing for the procurement of improvement of network systems or services. Technical inputs are currently being provided to GSA to be used in the formulation of new Federal procurement policy for such systems and services.

This work will provide sufficient measurement techniques and guidance to implement existing policy concerning procurement of ADP according to functional capability.

Funding Profile:

\subsection{Data Encryption Standard}

Assigned Responsibility Addressed by this Effort:

- Organic Act: Promote strength in science and technology for the public benefit

- Brooks Act and OMB Implementation Guidance:

- Provide scientific and technological advisory and consulting services to executive agencies on automatic data processing

- Recommend Federal standards related to automatic data processing equipment

-Make ongoing research and development known and available to Federal agencies

- Executive Order 11717: Set Government-wide standards

- OMB letter (12 March 1972): Work with industry on Federal computer security requirements and solutions

- OMB Circular A-108: Issue standards and guidelines on computer and data security.

Executive Summary: A Federal Information Processing Standard has been recommended for the cryptographic protection of computer data. The end product of this effort will be a uniform method for protecting transmitted or stored data which can be utilized by Federal agencies and others according to guidelines developed by NBS for use of the standard. Encryption may be used to protect against threats of computer fraud, accidental or intentional undetected modification of data, and invasion of personal privacy. High interest in and need for the standard has been expressed in both Government and the private sector. Electronies manufacturers are planning to produce the encryption devices implementing the algorithm when it becomes a standard.

\section{Date Initiated: February 1971}

Date Terminated: Continuing

Goals and Objectives:

Goal: To develop standards and guidelines for the protection of data processed in computer systems.

Objective: To protect confidential and valnable dat a and protect individual privarey through applieation of techmolugical measures for cont rolling adecess to dat a allel protecting its integrity. speccificalls!

(1) to provide a cryptographice algarith which can be used to encrypt and deerypt tata in many applieations and enviromments: 
(2) to establish a standard for the cryptographic protection of unclassified computer data while it is being communicated in computer systems and networks;

(3) to provide guidelines for the use of that algorithm; and

(4) to provide a service for validating commercial implementations of the standard algorithm.

\section{Products:}

(1) A data encryption algorithm to cryptographically protect data;

(2) A proposed data encryption standard for consideration by Federal agencies;

(3) A finalized Federal data encryption standard;

(4) Guidelines for implementing and using the standard;

(5) Experimental hardware testbed for the data encryption algorithm used:

(a) in the operation of an NBS validation service which determines the compliance of commercial encryption/decryption units with the proposed Federal standard

(b) in the preparation of Federal guidelines for use of the proposed data encryption standard in computer systems and network.

\section{Recipients of Products:}

- Federal agencies which have valuable or sensitive information requiring crytographic protection.

- Prospective suppliers of crytographic devices.

- Public ADP organizations requiring cryptographic protection.

Relevant Circumstances: NBS initiated an effort leading to a proposed data encryption standard after identifying an urgent need for a method for protecting computer data during transmission and in storage. There were several commercial devices available which provided some level of security but these had not been analyzed for adequate security. A public solicitation for cryptographic algorithms was initiated by NBS and submitted algorithms were evaluated for their adequacy. The proposed algorithm satisfies the requirements which were established for a standard.
Major emphasis was placed on making all information regarding the standard equitably available to all interested parties.

Comments from Federal agencies and the public were solicited first on the encryption algorithm hefore it was proposed as a standard and then on the proposed standard incorporating the algorithm. The issues of competition in the anticipated marketplace, the methods of implementing the standard, and the procedures for effectively utilizing the standard were addressed in the comments and the responses. The issue of manufacturing devices implementing the proposed standard by foreign and domestic companies outside the United States for use within the United States has been raised by the Department of Justice. IBM, the developer and submitter of the algorithm, holds foreign and domestic patents which may cover devices implementing the algorithm. The Department of Commerce requested and IBM agreed to grant nonexclusive, royalty-free licenses under the patents to make, use and sell apparatus which complies with the standard. The legal staffs of the Department of Commerce, the Department of Justice and IBM are presently preparing the wording for a revised license agreement acceptable to the parties concerned.

The issues of implementation costs for the Data Encryption Standard and the security provided by the standard in various application environments are continuing to be addressed by NBS. A workshop is being convened to assess technology as it relates to the proposed standard. The results of the workshop will be utilized in preparing guidelines for implementing and using the standard. The guidelines will provide potential users of the standard, particularly Federal ADP organizations, the information necessary to assess the security risks which may be alleviated by using the standard and the potential cost/risk ratios to be expected in the near future.

Impact: A recent survey of 2940 Federal general purpose computer systems showed that 27 percent of them were utilizing networking or remote access. Encryption has been recommended by NBS as the means of protecting data in such an environment. The proposed standard has already had a significant impact in both the public and private sectors: nearly 1600 copies of the algorithm, as published in the Federal Register, have been requested from NBS. Both the Federal Reserve Board and the American Bankers Association have already taken specific actions with respect to the proposed data encryption standard. The Federal Reserve Board is testing it between several nodes of its network. The American Bankers Association Subcommittee on Bank Cards has recommended the adoption of the proposed standard. Crytographic systems utilizing the data encryption standard may now be designed and employed which give a significant increase in the security of computer data. Without such a standard, this development work would be difficult if not impossible. 
Thus. the standard provides a universal means for secure communication of data between users of the standard algorithm. who have established a mutual secret encryption key for a specific communication. Cost savings and ease of communication will result from the standardization and reduction of research and development required in each agency. Agencies exposure to fraud. costly accidents. and consequences of the revelation of confidential data will be reduced.

Funding Profile: The following figures are approximate. as the encryption project involves the participation of different parts of ICST. and as no cost centers are exclusively assigned for the encryptionrelated activities within the computer security program.

$\begin{array}{llr}\text { FY } & 1973 & \$ 7,000 \\ \text { FY } & 1974 & 33,000 \\ \text { FY } & 1975 & 52,000 \\ \text { FY } & 1976 & 144.000\end{array}$

6.7. COBOL Standards and Validation Routines

Assigned Responsibility Addressed by this Effort: This effort meets Brooks Act requirements to develop Federal standards and compliance measures; and to support voluntary national standards in business, financial, and administrative computer applications.

Executive Summary: The National Bureau of Standards has actively participated in the development and standardization of COBOL since its inception in 1959. COBOL was established as the first Federal standard programming language in 1972 and was revised in December 1975 to adopt the revised and improved national standard. Working with the General Services Administration and the Department of Defense, NBS established in April 1973 the Federal COBOL Compiler Testing Service to do the first Government-wide quality control testing of compilers.

\section{Date Initiated: January 1966}

\section{Date Terminated: Continuing}

Goals and Objectives: The NBS objectives are to insure that all Federal agencies achieve maximum benefits from COBOL in effective computer utilization and interchange through Government-wide coordination, evaluation and cooperation to advance the language development, standardization and utility. NBS provides the initiative for the availability and dissemination of quality control techniques to be applied to products conforming to the standard.

\section{Products:}

(1) Federal Standard COBOL (FIPS PUB 21), 1972.

(2) Federal Standard COBOL (FIPS PUB 21-1), 1975.
(3) Interpretation Procedures for Federal Standard COBOL (FIPS PUB 29), 1974.

(4) Aids for COBOL Program Conversion, FIPS PUB 21 to FIPS PUB 21-1 (FIPS PUB 43), 1974.

(5) Standard COBOL Coding Form, (FIPS PUB 44 (FIPS PUB to be published).

(6) Validation of COBOL Compilers, Federal Property Management Regulation 101-32.1305-1a; 1975.

(7) The CODASYL Approach to Data Management, Symposium, April 1973.

(8) Untangling the COBOL Standards Maze, Seminar, 1974.

(9) Structured Programming in COBOL, Seminar, 1976

(10) Apprisal of Federal Government COBOL Standards and Software Management: Survey Results, (NBSIR to be published)

Recipients of Products: All Federal agencies.

Relevant Circumstances: Neither the Federal Government nor NBS control COBOL development or standardization; rather, that process is accomplished through voluntary industry efforts. NBS, however, by legislative intent, does promote "the development and testing of voluntary commercial standards" which can be adopted as Federal standards. This NBS role is manifested by the active participation of NBS staff members in the industry efforts from the start of the development of COBOL in 1959 (prior even to P.L. 89-306) and continuing in the current NBS program. Although no one person, agency or company has dominated the broad-based development and standardization of COBOL, NBS has an effective role in the process, for it was largely NBS that provided technical guidance, financial support for publications, and-most important, perhaps-a continuing resolve to see to completion the first attempt at a common, business-oriented language standard.

Impact: Federal computer installations using COBOL are not limited to a small special-interest group of users; more than $61 \%$ of the domestic Federal installations which have general management classification computer systems use the language. The Bureau's impact on COBOL and COBOL usage is difficult to isolate, as its pervasiveness makes it ill-suited to measurement. During the recent history of Federal COBOL compilers testing, an order of magnitude decline in discrepancies has been measured. Early NBS chairmanship in key committees was a seminal factor in COBOL development. Because of the NBS resolve to extend the Federal COBOL standard, significant 
influence was generated to cause timely pursuit of national and international COBOL development and standardization.

$\begin{array}{llrr}\text { Funding Profile: } & \text { FY } & 1973 & \$ 69,600 \\ & \text { FY } & 1974 & 79,700 \\ & \text { FY } & 1975 & 141,000 \\ & \text { FY } & 1976 & 80,000\end{array}$

\subsection{Mechanical Translation}

Assigned Responsibility Addressed by this Effort: Research in two categories of mechanical translation by computer, namely translation of artificial languages and translation of natural languages, was carried out by the Applied Mathematics Division.

Executive Summary: From experience in using one of the first stored-program computers, SEAC, NBS mathematicians found very early that it would be advantageous to prepare computer programs in higher level languages and require the computer itself to translate these into its own language. Accordingly, NBS undertook research in this field and made early contributions to the art of compiler and assembler design.

As computer development mushroomed during the 1950 's and early 1960's there were massive efforts to automatically translate natural languages, such as Russian into English, sponsored by both Government and the National Science Foundation. NBS participated in this research and maintained cognizance of other efforts.

Date Initiated: Research was started on a small scale in 1952.

Date Terminated: Research was discontinued in 1971.

Goals and Objectives: The first NBS goal in the mechanical translation of artificial languages was the development of assemblers to translate symbolic language to machine language for the SEAC and PILOT computers. A subsequent goal was the development of compiler-level languages. In natural language translation, the first goal was to develop a computer program to translate Russian into English. However, as the magnitude and difficulty of this overall task became apparent, the goal shifted to solving only a few of the technical problems in translating Russian, as well as Chinese, into English.

Products: An assembler called SEBBE was developed and used by NBS programmers in solving many problems on the SEAC. NBS personnel published key technical papers that contributed to the development of compilers and assembly-language libraries, and chaired working committees that designed the COBOL and ALGOL languages. In natural language translation, NBS published a few technical papers as well as surveys of work in the field that contributed to cooperative efforts throughout the country.

Recipients of Products: The emerging computer industry was the major recipient of NBS contributions to artificial languages. Other Government agencies benefitted from NBS assistance and consultation in areas related to mechanical translation and artificial languages.

Relevant Circumstances: As manufacturers began to build compilers it became apparent to them that to be competitive they must provide assemblers and compilers, and some soon developed excellent translators for symbolic languages and higher level languages such as FORTRAN and COBOL. By the time of the Brooks Act there was no justification for NBS to compete with the very advanced technology in the private sector, and no further work was undertaken. However, it soon became clear that the standardization of artificial languages and the validation of translator performance could produce economies in computer utilization and this became a major NBS endeavor under the Brooks Act.

Impact: Through technical contributions and membership in the SHARE organization beginning in 1957, NBS assisted in establishing a common symbolic assembly language known as SAP. This in turn led to libraries of high quality subroutines and a major advance in the field of computer software: The same subroutine could be used by many different computer laboratories throughout the country with great savings in programmer effort. This experience validated the concept and lent impetus to the establishment of higher level compiler languages as standards. In part through NBS contributions, the COBOL language was adopted and implemented by most major computer manufacturers and one large computer series was designed completely around the ALGOL language. However, in spite of its technical excellence and support by NBS, ALGOL yielded to FORTRAN as the standard language for mathematical computations.

NBS made a further significant impact on the compiler field in that many people with early experience at NBS on its computers and their languages went out to manufacturers, universities, and user installations where they distinguished themselves and contributed to the advance of computer science.

In natural language translation, it became apparent that computer speeds and memory capacities were inadequate to deal with the problem. Problems with idiom, the need for encoding extensive exceptions to the rules of grammar, and required 
massive. fast-access, memory for storing vocabulary were major contributions to the difficulties. Then in $1965^{\circ}$ an automatic Language Processing Advisory Committee reported to the National Research Council that immediate practical applications of machine translations were not encouraging. ${ }^{1}$ However, the Committee did recommend National Science Foundation support for research in computational linguistics. Under other agency support, NBS continued with a small ongoing research project in mechanical linguistics that resulted in four publications on Chinese character analysis and two papers on chemical structure diagrams. Since this research did not have the needed priority for continuation in terms of Brooks Act responsibilities, and since other support was not adequate. it was discontinued in 1971 .

Funding Profile: Over the period 1958-1971. a total of approximately $\$ 345.000$ was spent on automating natural language translation and mechanical linguistics. Over the period 1952-1967 approximately $\$ 220,000$ was spent on the development and translation of artificial languages.

\subsection{FORTRAN Standards and Validation Routines}

Assigned Responsibility Addressed by this Effort: Under provisions specified by the Brooks Act the Secretary of Commerce is authorized:

- to promote the development and testing of voluntary commercial standards for automatic data processing equipment. and

- to recommend Federal standards related to automatic data processing equipment. techniques. and computer languages

in order to increase compatibility in automatic data processing in the Federal Government.

Executive Summary: The FORTRAN programming language is the universal language for expressing numerical calculations. NBS has actively participated in the development and standardization of FORTRAN since 1966. 'The language specifications have been expanded to meet the needs of both Government and industry. necessitated by both the adrances in hardware. programming techniques and classes of scientific and engineering problems to be solved. These proposed revised FORTRAN specifications are currently undergoing public review and comment. Techniques for validating the FORTRAN language compilers have been formulated. implemented and tested by NBS using the 1966 FORTRAN standard as the model.

Vatimal Research Cnuncil. Language and Machines. Computers in Translation and Linguistirs, National Aradrmy of Sriences. 1960. and an updated validation system to meet the specifications of the revised FORTRAN Standard as a Federal FORTRAN standard is in the process of implementation.

\section{Date Initiated: April 1966}

\section{Date Terminated: Continuing}

Goals and Objectives: To develop the FORTRAN programming language into a meaningful. workable and testable Federal Standard for use by Federal agencies and their contractors for the purpose of assisting in the:

- Compatibility of program interchange across computers,

- Development of computer program libraries.

- GSA computer sharing exchange.

- Training and retraining of FORTRAN language users, and

- Preparation for more use of computers by scientists via terminal devices.

\section{Products:}

(1) NBS Special Publication 399. Volumes 1. 2 and 3: NBS FORTRAN Test Programs and magnetic tape containing the programs. for sale by NTIS and NBS Magnetic Tape $\# 5$. and documents only. available through the U.S. Government Printing Office.

(2) Draft proposed American National Standard FORTRAN issued March 1 . 1976. for the four-month public review and comment. as a proposed replacement for \$3.9-1966 FORTRAN and X3.10-1966 Basic FORTRAX.

\section{Recipients of Products:}

- Federal agencies.

- FORTRAN compiler vendors. and

- FORTRAN user community (national and international).

Relerant Circumstances: Becanse the American National standards FORTRAN X3.9-1966 and X3.10-1966 lacked snfficient and non-ennflicting specifications. this document was not promulgarled as a Federal standard. In 196\%. at the repuess of NBS. THE A VSI technical committer that developed the standards was reinstigated to clarify these specifieations. After issuing two sets of clarifieation reports in 1969 and 1971. it was deemed necessary to undertiake a complete resision of the standard to repair the numerous fanlts and 
omissions in order to bring the FORTRAN language specifications to a state required for an economic solution to program portability. Although the FORTRAN language development and standardization is a process accomplished through voluntary industry effort, NBS took a leading role in defining and promoting technical concepts of the language to insure easier program interchange across computers of different architecture. The fact that NBS intends to specify this standard as a Federal FORTRAN standard, develop and perform validation programs to measure compiler compliance to this standard, significantly contributed to the development of a firm set of language specifications.

The NBS FORTRAN Test Programs developed between 1966-1974 to measure compliance to the 1966 FORTRAN standard and used by both Government and industry, set the style, organization and documentation for programming language compiler testing acceptable to both vendors and users, and these methods have been copied for other language validation programs. The lack of funds caused this effort to be spread over an eight year period.

Impact: An estimated investment in FORTRAN programming in existence in 1963 was over two billion dollars. Today, a conservative estimate of over 25 billion dollars could be made. Most of the scientific and engineering endeavor in the U.S. is performed by private industry with a significant part of this effort paid for by public funds. Therefore, except for the Government scientific laboratories, most of the FORTRAN programs created for the benefit of the Federal Government are written by organizations sponsored by the Government, such as contractors for NASA and AEC. These programs are either contracted by the Federal Government for use on Government collected data, or created by the Federal Government for use on Government collected data, or created by the contractor for contractor use in the testing and construction of a Federally procured product such as an aircraft or a nuclear weapon. It has been stated that more FORTRAN programs are interchanged than those of all other programming languages combined. Almost twice as many different hardware systems have FORTRAN compilers as its nearest competitor, COBOL. The FORTRAN language is most universally employed to teach programming in schools and has superseded ALGOL as the language for numerical work in both the European countries and Japan. The revised FORTRAN standard, containing a proper subset to be implemented on small and minicomputers, is a specification of user and supplier requirements within the framework of an economic compiler development and efficient program execution, thus enabling the language to be effectively used to build preprocessors, in process control and realtime applications as well as for scientific and engineering calculations, for which the language was originally intended.
The proposed Federal FORTRAN Standard together with the validation system, to test FORTRAN compiler conformance to the standard to be required in a Federal procurement, will ensure uniform interpretation of the language, promote easier FORTRAN program interchange, and less specific hardware dependency.

$\begin{array}{llcc}\text { Funding Profile: } & \text { FY } & 1967 & \$ 15,800 \\ & \text { FY } & 1968 & 40,400 \\ \text { FY } & 1969 & 40,400 \\ \text { FY } & 1970 & 52,500 \\ \text { FY } & 1971 & 50,600 \\ \text { FY } & 1972 & 41,500 \\ \text { FY } & 1973 & 59,800 \\ \text { FY } & 1974 & 53,100 \\ \text { FY } & 1975 & 83,200 \\ \text { FY } & 1976 & & 79,400 \\ & \end{array}$

Total

$\$ 516,700$ expenditures to date

\subsection{BASIC Standards and Validation Routines}

Assigned Responsibility Addressed by this Effort: Under the Brooks Act, this effort is assigned to provide recommendations for a Federal computer language standard on BASIC and to develop a compiler validation routine to measure whether a Federally acquired BASIC compiler has been properly implemented on Federally owned or leased computers.

Executive Summary: In order to provide uniform Federal BASIC language standards and compiler validation routines NBS initiated this effort in June 1973. The goal was to provide a common language base for the many dialects of BASIC available on the proliferating number of minicomputers and time sharing facilities available to Federal BASIC users. Federal Task Group 16 was formed to work in conjunction with the ANSI X3J2 committee on BASIC Standards. Furthermore, NBS in parallel with the language standardization effort, made the commitment to develop a BASIC compiler validation program. As soon as ANSI X3J2 has completed its work, the parallel Federal effort will then be able to promulgate the Federal BASIC Standard and validation routines.

\section{Date Initiated: June 1973}

\section{Date Terminated: Continuing}

Goals and Objectives: The ultimate aim is to provide Federal BASIC users with a uniform, reliable high level language oriented toward time sharing and minicomputer environments in order to reduce programmer costs by increasing productivity. In order to do this the specific objectives of this effort are to provide uniform language specifications for Federal Government adoption and use during acquisition of BASIC computers and to provide an automated vali- 
dation tool to test conformance of the compiler with the Federal Standard.

\section{Products:}

(1) Federal Standard BASIC (FIPS PUB) (to appear soon after ANSI adopts a BASIC standard)

(2) NBS BASlC Test Programs (Preliminary Version to appear mid-1976)

Recipients of Products: BASIC compiler vendors, Federal software purchasing agents, Federal ADP installations, Federal BASIC programmers.

Relevant Circumstances: With the increase of the number of dialects of BASlC and increasing minicomputer utilization, NBS initiated the development of a BASIC standard with the award of contract 3-35965 on June 4, 1973, to Professor J.A.N. Lee at the University of Massachusetts. Professor Lee proposed a nucleus standard aimed at small minicomputers. The final report contained a proposed set of language specifications and validation routines for Federal adoption. Since ANSI had not formed a standardization committee for BASIC, FIPSCAC approved FIPS Task Group 16 in September 1973 to respond to Federal Government needs in BASIC and to complement any national ANSl effort established by X3. TG-16 was also charged to develop and recommend to NBS a Federal BASIC standard responsive to Governemnt users. ANSl formed the BASIC subcommittee X3J2 in January 1974. After establishing liaison with X3J2, TG-16 voted not to develop a separate standard but to provide the ANSI effort with input of Government requirements. TG-16 would also recommend or not to NBS the final ANSI standard. In February 1975, TG-16 and NBS proposed a structure for future BASlC language enhancements and in November 1975 began discussion of the preparation of a FIPS PUB on a Federal Minimal BASIC standard. In conjunction with the language standardization effort NBS has been in the process since 1974, of preparing a comprehensive set of BASIC compiler validation tests. In general, standardization of the language BASIC is a voluntary industry effort. NBS, through TG-16, has provided direction to the ANSI X3J2 committee on structuring of the BASIC language extensions and has maintained active staff participation in the $\mathrm{X} 3 \mathrm{~J} 2$ language standardization process since its inception in 1974. However, the adoption of a Federal standard for BASIC, along with the validation routines, can provide leverage so that the BASIC compiler developers not only provide a standardized BASIC to Federal agencies but because of developer cost considerations provide the same compilers on a national basis.

Impact: From Federal ADP equipment inventories and industry surveys it is possible to identify that approximately 60 percent of the Federal government's 4,000 special managment classification computers provide BASIC as a principal high level language. Most Federal minicomputers fall into this category. One industry survey has estimated that for general purpose computation BASIC programs comprise approximately 2 percent of the total number of programs. Therefore, a Federal standard for BASIC and associated validation routines would directly impact software utilization on Federal minicomputers. Since there are a great number of dialects and enhancements for BASIC as shown in a recent ACM survey (April 1976) this effort would provide the necessary standard and measurement tool in order to assure at least a common core of language features for Federal BASIC users in order to assure program transportability on small CPU machines, the utilization of which is increasing as indicated by industry sales figures.

\section{Funding Profile: \\ Standard \\ Validation \\ FY $1974 \$ 10,000$ \\ FY $1975 \quad 25,000 \quad 9 \overline{5,000}$}

\subsection{Computer Technology Transfer in Medicine}

Assigned Responsibility Addressed By This Effort: Provide advisory service as required under the Brooks Act.

Executive Summary: In 1967 the Department of Health, Education, and Welfare (DHEW) began to sponsor the development of a computer programming tool for use in medical automation. Over a period of several years, certain processing capabilities had been singled out as desirable in a medical environment. These "translated" into a set of machine functions that would help technicians to manage massive files of variable length, unformatted strings of data (an important but not uniquely "medical" problem). Virtually all of the functions identified had been successfully implemented before, some on large computers, some on small ones, but never had they all been done in an integrated fashion on a single computer. As a result, existing systems were deemed inadequate for this class of medical application. The tool was named MUMPS (for Masschusetts General Hospital Utility Multi-programming System), a computer programming language and operating system designed for rapid access to patient and other health-related information. By 1968 a prototype system was operational. DHEW continued to fund development of the tool and began to fund various medical institutions to use it in their development of clinical laboratory information systems. By early 1972 it was estimated that $\$ 5$ million in DHEW research funds had been spent in defining and constructing the tool and in developing medicallyoriented computer programs in the new language. Futhermore. it was estimated that by 1977 DHEW would have spent an additional $\$ 5$ million in re- 
search funds alone. No estimates were given regarding operational expenses that might be incurred by DHEW's Public Health Service hospitals and clinics, those of the Veteran's Administration, those of the three military services, or of the Nation's remaining 7,000 non-Government health care facilities. By 1972 the language was being used in some 200 medical institutions. In response to its increasing usage and varying user requirements, seven "dialects" of the original language had been developed. This gave rise to the feeling within HEW that immediate attention should be given to developing a standard language that would embody the most useful features of each of the dialects and would be able to grow in an orderly fashion. If this were done, it was argued, future investments in both systems and applications could be protected, to the benefit of all cooperating health care institutions.

Unique capabilities of ICST personnel were indepth knowledge and practical experience relative to the specification, implementation, standardization and use of high level computer programming languages and processors. It was in April 1972 that the ICST was asked to study various alternatives and recommend a future course of action. By October 1972 a general plan had been formulated and ratified, and from January of 1973 until June of 1975 an intensive development and standardization program was carried out.

Date Initiated: April 18, 1972

Date Terminated: June 30, 1975

\section{Goals and Objectives:}

- To establish an environment conducive to the transfer of MUMPS-oriented medical automation technology,

- To plan and play a lead role in the execution of a detailed development, standardization and technology transfer program, in accordance with the sponsor's direction.

\section{Products:}

(1) Administrative Reports and Directives

- MUMPS-A Preliminary Study

- Constitution of the MUMPS Development Committee

- Minutes and various reports for nine meetings of the MUMPS Development Committee

- Summary Proceedings of the Task Group on MUMPS Standardization

- Various articles published in the trade press

(2) Technical Reports

- A Comparative Analysis of Six Dialects of the MUMPS Language
- MUMPS Automated Documentation Aids

- A MUMPS Implementation on the NOVA Computer

- MUMPS Language Specification

- MUMPS Transition Diagrams

- MUMPS Portability Requirements

- MUMPS Primer

- MUMPS Programmers' Reference Manual

- MUMPS Translation Methodology

- MUMPS Interpreter Validation Program User Guide

- MUMPS Globals and Their Implementation

- Design of a Multiprogramming System for the MUMPS Language

- Implementation of the MUMPS Language Standard

- MUMPS Documentation Manual

\section{(3) Computer Programs}

- MUMPS Programmed Translator

- MUMPS Interpreter Validation Program

- MUMPS Automated Documentation Programs

\section{Recipients of Products:}

- Trade Press Publications: Approximately 10,000 medical institutions, research centers, and commercial service organizations

- Technical Reports: Approximately 500 institutions

- Computer Programs: Approximately 50 institutions

\section{Relevant Circumstances:}

- Market forces in 1972 ideal for cooperative effort in the part of Government, industry, and academic communities

- Promised availability of a wide range of products motivated users and suppliers to cooperate

- During the final year, partly because of changes in the sponsor's organization and program emphasis, funding was applied in inverse proportion to the work at hand. This necessitated drastic cutbacks in the production and dissemination of publishable material.

Impact: There are three principal indicators of the success of a specification project such as this, namely, the extent to which commercial interests implement the specification, the extent to which users avail themselves of the resulting products, and the relative quality and completeness of the products in comparison to products developed by a similar process. Regarding the first point, in April 1976 there were known implementations of the language specification available on machines produced by five differ- 
ent computer manufacturers; in addition, implementations were known to be in process on machines produced by an additional six manufacturers. Regarding the second point, usage information is very difficult to come by, since much of it is treated as privileged. It is, however, becoming increasingly clear that manufacturers and users are treating the specification as one that is pertinent to nonmedical as well as medical applications. This is evidenced in a recent ANSI X3 SPARC resolution to make the specification available to its constituency for balloting upon as an American National Standard, and in the system's increasing application outside the health records area, in such areas as reservation systems and inventory control systems.

On the third point, quality is somewhat difficult to judge. The resulting products (1200 pages of technical manuals and several hundred computer routines) comprise a fairly complete package of documentation and support software.

$\begin{array}{llr}\text { Funding Profile: } & \text { FY 1972 } & \$ 17,100 \\ & \text { FY 1973 } & 88,500 \\ & \text { FY 1974 } & 346,200 \\ & \text { FY } 1975 & 141,000\end{array}$

\subsection{APT}

Assigned Responsibility Addressed By This Effort: Recommendation of uniform Federal automation data processing standards, as required under the Brooks Act.

Executive Summary: APT is the most widely used higher level language for programming numerically controlled machine tools. The Federal Government uses APT as the major language for programming 2,400 such machine tools valued at over $\$ 350$ million. This language is judged as the highest priority standard in the application of computers to manufacturing. A draft standard is expected in 1977.

Date Initiated: $\quad$ March 11, 1975

\section{Date Terminated: Continuing}

Objectives: To develop a Federal Information Processing Standard on APT that is responsive to Federal needs; to establish a dialogue with the Government APT community that insures a wide spectrum of user participation in the work of the task group; to maintain a Federal APT standard consistent with Government users needs; and to maintain a dialog with ANSI and other standards efforts in the private sector relevant to Government use of APT.

\section{Products:}

(1) Symposium assessing Government need and use of APT, March 11, 1975

(2) Coordination of Federal inputs to ANSI committee on APT 1975/76

(3) Draft Standard expected 1977
Recipients of Products: Government users of AP'T

Relevant Circumstances: APT is the most widely used language in computer aided manufacturing applications in the Federal Government. Despite extensive efforts at standardization in EIA and ANSI committees on NC and APT, in the APT Long Range Program at Illinois Institute of Technology Research Institute, and in Computer Aided ManufacturingInternational, it is still impossible to exchange either APT source code or output tapes between Federal agencies. This is particularly aggravating for the production of spare and repair parts in the facilities of the Department of Defense. This problem also impacts NASA, ERDA, NBS, and other users of APT and its subsets and users of products that produce APT-like outputs, such as many interactive graphics design systems. The GAO has criticized DoD for lack of standardization in the use of numerical control (NC).

Impact: Representatives to the first AP'T symposium unanimously agreed that a Federal standard was needed for APT. At least 32 different facilities using APT have been identified. The Navy has identified that the Government would save $\$ 3.8$ million per year in programming costs from an adequate language standard. In addition, APT is a key to the whole area of interface and language standards for computer aided manufacturing systems. The overall magnitude of impact is measured by the fact that Federal Government has over 200,000 employees in manufacturing operations and procures over $\$ 50$ billion in manufactured goods each year. Improved standards will lead to the improved diffusion of numerical control and computer aided manufacturing technology which will reduce these operating and procurement costs. A Federal APT Standard is a first step.

$\begin{array}{llrr}\text { Funding Profile: } & \text { FY } & 1975 & \$ 10.000 \\ & \text { FY } & 1976 & 20.000 \\ & \text { FY } & 1977 & 75.000\end{array}$

\subsection{Compnter Information Services}

Assigned Responsibilities Addressed by this Effort: The Brooks Act, authorized the Secretary of Commerce to provide agencies with scientific and technical advisory services relating to automatic data processing and related systems. The Poliey Guidance paper from the Bureau of the Budget to the Secretary of Commerce on December 15. 1966. recognized assignment of these responsibilities to the National Bureau of Standards Center for Computer Sciences and Technology and in the initial guidelines called for the Center 10 maintain a wareness of "state-of-the-art developments in ADP equipment. techniques, and languages"; and to evaluate these developments "in terms of their current or potential impact upon the Government's use of equipment and software and its ADP management policies." "The guidelines further called for the maintenance of a "reference index of 
computer programs to minimize the need for the development of programs already developed, tested, and in use elsewhere."

The Policy Guidance points out that it is essential for NBS staff to be fully aware of on-going system developments and suggests that "in addition to the possibility of NBS maintaining a current index of projects in progress, consideration should be given to requiring agencies to provide NBS, for a central reference file, copies of the reports of such information systems studies."

Executive Summary: The Computer Information Services were initiated, as a response to the requirement included in P. L. 89-306, for provision of advisory services in ADP, in May 1966 and are continuing today. The organizational unit primarily responsible for these services was first called the Technical Information Exchange, later the Office of Computer Information, and now the Computer Information Section (CIS), ICST. Information and technical advisory services are supported by the computer sciences and technology information resources of the CIS. These resources include over 70,000 documents: technical reports and journals, trade press and news bulletins, commercial up-date services and a reference index to computer programs. Indexes to these materials are prepared using a computer-based information management system developed by the CIS. Services provided include preparation and compilation of statistical data on computer use, technical analyses and reports on trends and emerging technologies that will impact computer applications, and state-of-the-art reviews of particular aspects of computer sciences and technology. Support is also given to other Federal agencies in the application of the CIS information management system for compiling indexes to their own collections.

Computer Information Services face problems in managing limited resources, due to rapid increases in the amounts and costs of computer literature and documentation, and in the complexity and scope of the field itself. The CIS is seeking to make more effective use of the resources availahle through online access to commercial search services, to effect more extensive cooperative arrangements with the NBS Library and other sources in the area, and to produce and disseminate more analytical studies and reports to extend its provision of advisory and information services more widely in the Federal community.

Date Initiated: May 1966 as Technical Information Exchange, later the Office of Computer Information, now the Computer Information Section.

\section{Data Terminated: Continuing.}

Goals and Objectives: The goal of the Computer Information Services is to provide current and complete information and technical advisory services to ICST,
NBS, other Federal agencies, and the private sector as appropriate, in the area of automatic data processing and related subjects. The objectives of the activity are to: (1) maintain a reference index of computer programs already developed or in use, to advise Federal agencies of their availability and utility; (2) collect, organize and maintain specialized information resources in computer sciences and technology, and maintain current awareness of state-of-the-art developments in the ADP area; and (3) analyze and evaluate information and data from the specialized collections, to provide technological assessments of trends and impacts of ADP on Government applications. These objectives respond to the mandate of the Brooks Act cited above.

The Computer Information Services includes a specialized information collection of over 70,000 documents: technical reports and journals, trade press and newsletters, conference proceedings, and commercial up-date and alerting services. The reference index to computer programs comprises over 80 directories of software developed or in use, and available for sharing and exchange. CIS constantly reviews this collection for currency and completeness. The reference service on computer programs will supplement the services of the Federal Software Exchange Center being established by the General Service Administration.

The technical reports in the CIS collection include accounts of ADP applications and system design studies in other Federal agencies. Materials as received are cataloged, and indexes prepared using a system developed and operated by the Computer Information Section, ICST. The indexes are of personal author, keyword, keyword-out-of-context (KWOC), corporate author, and report number. Sets of indexes are accompanied by a bibliography where all the data for each document indexed is listed in its citation."

The indexes produced in-house are supplemented by access to data bases offered through commercial search services and by subscription to other relevant reference tools. The collection of the CIS is also supplemented by use of the materials in the NBS Library and other computer-related collections in the Metropolitan Washington, D.C. area.

\section{Products:}

(1) Indexes, such as the Annual Indexes to the Computer Literature; "Computer Literature Bibliography, Vol. 2, 1964-1967," W. W. Youden, NBS Special Publication 309 (1968); "AFIPS Conference Proceedings Index, Vols. 1-37," AFIPS Press (1971).

(2) State-of-the-art reports, such as Automatic Typographic-Quality Typesetting Techniques: A State-of-the-Art-Review, M. E. Stevens and J. L. Little, NBS Monograph 99 (1967); $A u$ tomatic Indexing: A State-of-the-Art Report, M. E. Stevens, NBS Monograph 91 (1965) 
(3) Literature reviews, such as Research and Development in the Computer and Information Sciences, M. E. Stevens, NBS Monograph 113, Vols. 1-3 (1970); Cooperation, Convertibility, and Compatibility Among Information Systems, A Literature Review, M. Henderson et. al., NBS Misc. Publication 276 (1966)

(4) Technological assessments, such as Standardization, Compatibility and/or Convertibility Requirements in Network Planning, M. E. Stevens NBS Report 10252 (1970)

(5) Bibliographies, produced by ICST programmatic areas with support from the Computer Information Section or by the CIS directly, such as Controlled Accessibility Bibliography, S. K. Reed and M. M. Gray, NBS Tech. Note 780 (1973); Annotated Bibliography of the Literature on Resource Sharing Computer Networks, NBS Special Pub. 384 (1973); Evaluation of Information Systems: A Selected Bibliography with Informative Abstracts, M. M. Henderson, NBS Tech. Note 297 (1967); Annotated Bibliography on Technological Forecasting, M. M. Gray and D. A. Nagy, NBSIR 74-463 (1974); Bibliography on Magnetic Bubble Technology, R. B. J. Warnar (1975); Bibliography on Charge-Coupled Devices, R. B. J. Warnar (1975)

Recipients of the Products: In operating the highly specialized computer information system, the Computer Information Services activity responds to specific inquiries from users in ICST, NBS, other Federal agencies, staff members of independent offices and organizations (including quasi-official) of the Federal Government, staff members of state and local governments, and users in the various segments of the private sector (industry, academia, foundations, etc.).

Computer Information Services are available to these users and form an important base for advisory and consulting activities, technological developments, and report preparation. The approximately 1,500 inquiries received each year from the variety of users listed above are for such diverse informational needs as data on specialized programming concepts, on software packages for management and allocation of fire fighting resources, and manufacturers producing optical character readers.

In addition to these recipients of computer information services, the entire computer community has access to the reports listed above and other similar ones scheduled for early completion. These are made widely available through GPO and NTIS channels, as well as in answer to specific requests.

Another class of recipients of Computer Information Services products includes those agencies and offices who have requested support in adopting and adapting the information handling system of the
Computer Information Section to their own needs. These agencies include DHUD managing its international housing information files, SESA using the system for survey methodology data, and the Engineering Standards Information Service at NBS producing indexes to their collection of engineering information.

\section{Relevant Circumstances}

The provision of technical advice and information, as required by the Brooks Act, is directly supportive of NBS programmatic objectives relating to regulation and to productivity and quality of working life. There has been a growing need for relevant technical advice and information on the part of those Federal agencies and commissions responsible for the formulation and implementation of public policies relating to computer technology. Also, the growing body of computer-related scientific and technical information requires and provision of products and services attuned to the needs of users and customers of computer applications.

In order to supply technical information and advisory services more effectively and efficiently, Computer Information Services activities will stress the preparation and dissemination of statistical reports on computer applications in Government and the private sector, of technical analyses of trends and emerging technological developments of the computer field, and of overview reports on particular computer applications and their societal and economic impacts. In addition, the CIS is increasing its use of outside information resources by on-line access to data bases available through commercial searching services.

Impact: The major commodities of the Computer Information Services activities are information and technical advisory services. The assessment or measurement of the value of such services and their impact on users are difficult. Survey of users shows that the services saved both time and money for a large majority of them, but we lack specific quantified data on the amount of time and money saved. The ranges for such savings, where we could get quantifiable data, were from several hours to several weeks of time, and from a few dollars to over $\$ 500$ saved by a user.

Examples of money saved by NBS users responding to the survey were avoidance of the purchase of a special reference resource costing $\$ 385$, which the Computer Information Section had, and a savings of more than $\$ 500$ on equipment selection and purchase based on information made available through these services.

The users of the Computer Information Services generate about 1,500 requests per year for information and technical advisory services. Some 87 percent of these requests are from Federal organizations, covering nearly all the existing departments, offices, and independent agencies. These represent a consider- 
able investment in computer acquisitions and utilization. Computer Information Services contribute significantly to the effectiveness of such use by responding to the needs of Federal agencies for current and comprehensive information on computer developments.

Funding Profile: Funding from internal sources for the period FY 1967-FY 1976 are as follows:

$$
\begin{gathered}
\text { Congressional } \\
\text { Appropriated } \\
\text { Funds }
\end{gathered}
$$

$\begin{array}{lrr}\text { FY } & 1967 & \$ 105,000 \\ \text { FY } & 1968 & 202,000 \\ \text { FY } & 1969 & 225,000 \\ \text { FY } & 1970 & 249,400 \\ \text { FY } & 1971 & 220,400 \\ \text { FY } & 1972 & 233,700 \\ \text { FY } & 1973 & 203,000 \\ \text { FY } & 1974 & 170,000 \\ \text { FY } & 1975 & 220,000 \\ \text { FY } & 1976 & 220,000\end{array}$

\subsection{NBS PILOT Multiple Computer System}

Assigned Responsibility Addressed By This Effort: The PILOT multiple computer system was developed by the Data Processing Systems Division, which was assigned the reponsibility for experimental data processing research and development.

Executive Summary: The development of digital computing machinery at the National Bureau of Standards started in 1946 because of the interest of the Bureau of the Census in the possible use of electronic digital techniques for tabulating purposes. The outgrowth of this effort led to the development of the SEAC computer which became the nucleus of the NBS data processing activity. SEAC was followed by the development of SCOOP and DYSEAC. After several years of extensive use, it became evident that these machines lacked the speed and flexibility to carry out the Bureau's increasingly diverse program of experimental data processing. Consequently, the Bureau undertook to develop a new PILOT data processor with the necessary features for this work. During the period from 1958-1962, the PILOT multiple computer system was designed and built. This initial configuration became operational in 1962 but could not meet its intended uses without expansion of its peripheral capabilities. It was used extensively for other applications in number theory, chemical patent searching, and engineering calculations.

Passage of the Brooks Act in 1965 led to a restructuring of program efforts at NBS. The establishment of a Center for Computer Sciences and Technology led to an evaluation of the experimental data processing program at NBS.The rapid development of commercial hardware and software and the changing role of
NBS led to the decision to decommission the PILOT multiple computer system in favor of more advanced alternatives.

Date Initiated: Appropriation request submitted to Congress in FY 1957.

Date Terminated: The PILOT project was terminated in April 1967.

Goals and Objectives: The Bureau of Standards became involved with data processing in 1946 at the request of the Bureau of the Census. Development of the SEAC computer attracted the interest of the Air Force and other agencies. Within NBS, the Data Processing Systems Division was formed and given the mission of research and development in electronic data processing.

As the experimental data processing programs expaned, new objectives were identified.

One objective was to devise an effective experimental tool for investigating large-scale problems in the processing of business data for management use.

Another objective was to simulate the characteristics of different kinds of existing data processors so that equipment characteristics most suited to the needs of each particular agency could be selected.

A third objective was to provide a facility to investigate techniques applicable to the control of aircraft on the civil airways.

A fourth objective was to provide a system for assistance in laboratory experiments.

To meet these objectives; a system was required which could accommodate a wide range of analog and digital devices. It was also to be capable of concurrently performing multiple tasks and its programs had to be controllable by external means with minimum effect on machine operations.

The design which was developed to meet these objectives envisaged three computer systems. The primary computer would handle the bulk of the calculating workload, the secondary would handle instruction sequencing and indexing operations; and the third would handle all input and output transfers. All three computers would operate concurrently in this pilot data processor.

Products: Hardware was acquired and the basic system built and debugged during the period 1958-1963.

Concurrently with the construction of PILOT at NBS; a nearly identical machine was built at the Ballistics Research Laboratory (BRL) in Aberdeen, Maryland. This machine used the logical and mechanical design concepts of the PILOT computer system. 
Although the NBS PILOT data processor was never fully implemented for its intended purposes; it was used extensively from 1964 to 1967 for other applications.

The development in 1965 of transistor component boards to replace the vacuum tubes produced a machine of much greater reliability. This design was adopted by BRL and incorporated into their computer facility.

Recipients of Products: Over 5,000 machine hours were logged by the Applied Mathematics Division in number-theoretic calculations. These programs used large amounts of computer time but required little in the way of peripheral devices.

The Patent Office sponsored a project in which the PILOT was used for computer-assisted chemical patent searching.

Engineering calculations were made using the OMNITAB compiler which was written for the PILOT computer system in 1964.

Relevant Circumstances: PILOT was the last of the large-scale vacuum tube digital computers. Commercial computers developed in the late $1950^{\circ}$ s were built with transitor circuitry. Extensive development of soft ware made computers much easier to use than before.

The development of large mass storage devices and business languages such as COBOL and PERT enabled commercial machines to offer powerful solutions to business data and management problems.

Simulation became possible when two simulation languages, GPSS and SIMSCRIPT, were written for commercial equipment.

Expansion of facilities by the FAA and other agencies to investigate techniques for air traffic control resulted in a deemphasis of this activity at NBS.

The emergence of the minicomputer provided laboratories with an economical tool for assisting in laboratory experiments.

Thus, most of the intended uses for the PILOT sy'stem were fulfilled by commercially produced equipment during a period of rapid technological advancement in the early 1960 s.

Finally, the passage of the Brooks Act in 1965 changed the role NBS had been performing in the tield of electronic data processing

A study made by Dr Werner Leutert in 1966 recommended that the PILOT system be shut down and surplused before the NBS relocation to its new Gaithersburg site. It was concluded that it would be more cost effective to use the newly acquired MOBIDIC computer as the basic research computer and augment it with the core memories and disk files which were part of the PILOT computer system. Use of the MOBIDIC, coupled with the Bureau's CDC 3100 and the IBM 7094, would then adequately meet the data processing requirements.

Impact: The PILOT design, as incorporated into the Ballistics Research Laboratory computer at Maryland, resulted in a powerful data processor which was in constant operation from 1961 to 1972. This facility operated on a three-shift, seven-day week to calculate ballistic tables for military projectiles and missiles.

Many features of the PILOT system, such as multiple index registers, multiple computers, separate $\mathrm{I} / \mathrm{O}$ computers have been adopted and exist in modern day data processing systems.

Funding Profile: Over the period 1957-1966, a total of $\$ 2,252,000$ was allocated to the PILOT project. Of this amount, $\$ 1,852,000$ was actually obligated.

\subsection{Development and Use of A Computer-based Graphical Display Terminal (MAGIC II)}

Assigned Responsibitity Addressed By This Effort: To provide advisory services to Federal agencies and perform research on advanced computer technology for use by Federal agencies.

The MACIC II intelligent graphics terminal was developed as a testbed facility to investigate and demonstrate to Federal agencies concepts and techniques of design and use of a computer-based graphics terminal and the tradeoffs involved in providing local data storage and computing capability with the graphics terminal: based on the current technology (1965). As such, MAGIC II represents one of the early successful intelligent graphics terminals but was quickly obsoleted due to rapid advances in both computer and graphics technologies which in the industry in the mid and late $1960^{\circ} \mathrm{s}$. Through this effort (1965-1973) Federal agencies received technical awareness, advice, and guidance to enable them to better utilize computer graphics. MAGIC II hals recently been superseded by a state-of-the-art intelligent graphics terminal and is being surplused.

Date Initiated: November 1965

Date Terminated: November 1973

\section{Goals and Objectives:}

(1) to increase the feasibility of use of computer graphics by Federal agencies:

(2) to increase the exposure and awareness of Federal agencies to the utilization of computer graphics:

(3) to develop a research tool for investigating and 
demonstrating computer graphics concepts and techniques, particularly with regard to the distribution of data storage and computational capabilities between central processor and graphics display terminal and the tradeoffs involved.

Products: Federal agencies received technical advice and guidance to enable them to better utilize computer graphics.

\section{Recipients of Products: Federal Operating Agencies.}

Relevant Circumstances: The state-of-the-art in computer-based graphics in 1965 was such that few, if any, interactive, intelligent graphics display terminals existed. Little had been done to investigate the concepts and techniques involved or to investigate the tradeoffs in distributing data storage and processing capabilities between a central processing facility and a remote graphics terminal. Most graphics facilities in existence at that time relied wholly on a large, expensive central processor dedicated to driving the display. From the hardware standpoint, integrated circuits were beginning to appear commercially. Advances in transistor and CRT were beginning to appear commercially. Advances in transistor and CRT technologies were beginning to produce CRT displays with promising capabilities.

Based on these considerations and fundamental concepts previously developed through MAGIC I (the immediate predecessor of MAGIC II), it was felt late in 1965 that significant contributions could be made concerning intelligent graphics terminals. Manpower, funding and opprtunity were available, and concepts were developed and decisions made during a period when the need appeared greatest. However, despite development using current state-of-the-art technology, the nearly-concurrent advent of minicomputers, cheap integrated circuits, cheap core memory, and rapid advances in CRT display and related technologies coupled with utilization constraints imposed by the antiquated MOBIDIC B central computer facility, combined to quickly obsolete the architecture and utility of the testbed facility. Consequently MAGIC II has not been used to any significant extent since October, 1973 and is presently acting only as a backup facility for the recently acquired state-of-the-art, IMLAC full graphics, CRT display terminal. It is our plan to surplus MAGIC II by the end of FY 76 .

\section{Description}

MAGIC II contains a general-purpose display console with full hardware vector, character and circle generation capability and includes a beam-port CRT with which a random-access slide projector can be used to combine optically and electronically generated images on the display screen. Interactive accessories available to the operator include light pen, joystick, alphanumeric keyboard, a set of programm- able function buttons, and temporarily, a graphical tablet.

A special-purpose digital computer containing a small core memory $(6,000$ characters $)$ and a drum memory (approximately 300,000 characters) was designed and constructed to drive the display console. A specially configured hardware list processor is used, optimizing and expanding list processing techniques developed using MAGIC I. Such list functions as insert, delete, block transfer of lists, list scanning, and list arithmetic and logical operations are incorporated for efficient display data manipulation and for minimizing the number of instructions necessary to perform typical display functions. The processor incorporates both high speed character-parallel and low speed bit-serial data communications capabilities for connections with a central system.

Paper design of MAGIC II was initiated in late 1965 and continued through 1966 . By early 1967 , the basic hardware design had been frozen and procurement of major components was initiated. Construction of the system began in the spring of 1967 and the system became operational on a stand-alone basis in June of 1968. From this time through early 1969 , the optical hardware was installed for rear-port slide projection and a high-speed data link was designed and installed for data communications with the MOBIDIC B computer facility. Through the remainder of the lifetime of MAGIC II, minor hardware corrections and improvements were made as the need arose.

Throughout the operational lifetime of MAGIC II, numerous utility programs were developed for both stand-alone and interactive use, including low level language assemblers, debuggers, and diagnostic programs. Notably, a cross assembler for MAGIC (GRAS-GRaphical ASsembler) was developed to run on the MOBIDIC $\mathrm{B}$ computer and an interactive Graphical Text Editor was developed for combined MAGIC/MOBIDIC use.

The most sophisticated application of MAGIC II was the development of a Thermal Design program package which functioned interactively between the operator, MAGIC II, and MOBIDIC. The program enabled designers of electronics packages to model the thermal flow and heat load at various points within a selected volume of electronic equipment.

Impact: The development and utilization of MAGIC II satisfied the goals and objectives stated earlier. As an early predecessor of modern minicomputer driven CRT display terminals, it demonstrated the viability and desirability of providing local storage and profcessing capabilities within the graphics display. At least 40 Federal agencies presently using computer graphics received an introduction to computer graphics through this effort. 
Funding Profile:

$\begin{array}{ll}\text { FY } & 1966 \\ \text { FY } & 1967 \\ \text { FY } & 1968 \\ \text { FY } & 1969 \\ \text { FY } & 1970 \\ \text { FY } & 1971 \\ \text { FY } 1972 \\ \text { FY } 1973 \\ \text { FY } 1974 \\ \text { FY } 1975\end{array}$

Other

Agency Appropriated

Funds Funds

\begin{tabular}{rrr}
$\$ 105,000$ & & $\$ 110,700$ \\
59,000 & & 119,900 \\
102,200 & & 139,300 \\
79,500 & & 50,800 \\
74,300 & & 40,800 \\
58,700 & & 29,500 \\
38,700 & & 37,500 \\
13,000 & & 0 \\
8,600 & & 0 \\
0 & & 0 \\
${$\cline { 1 - 1 }$\$ 539,000} }$ & & $\$ 528,500$
\end{tabular}

Total Funds $\$ 1,067,500$

\section{References}

The following list of reports detail the hardware configuration and the major utilizations of MAGIC II:

(1) MAGIC II, A Remote Graphical Display Terminal, D. E. Rippy, (NBS Report 9956)

(2) MAGIC-A Machine for Automatic Graphics Interface to a Computer, D. E. Rippy and D. E. Humphries (Proc. FJCC, Vol. 27) 1965. (Describes MAGIC I, the predecessor to MAGIC II)

(3) GRASS a Graphical Assembler for MAGIC II, J. A. Hudson, (NBS Report 9955) 1968.

(4) Man-Machine System Organization Final Report-Phase I, T. N. Pyke, Jr., (NBS Report 10051$) 1968$.

(5) Performance Measurement of Interactive Graphics Systems in Support of Computer Aided Design and Engineering, T. N. Pyke, Jr., et al, (NBS Report 10451) 1971.

(6) An Experiment for the Study of System Design and Instrumentation for Remote Computer Graphics Utilizing a Graphical Text Editor, J. A. Hudson, et al, (NBS Report 10 143) 1969.

(7) Data Structures for Computer Graphics, M. D. Abrams (NBS Report 10 144), 1969.

(8) Computer/Display Interface Study, Quarterly Report \# 1, 1 A pril 1966-30 June 1966, Technical Report, ECOM-95829-1, July 1966.

(9) Computer/Displuy Interface Study, Quarterly Report \#2-3, 1 July 1966-31 December 1966, Technical Report, ECOM95829-2, January 1968.

(10) Computer/Display Interface Study, Quarterly Report \# 4-5, 1 January 1967-30 June 1967, Technical Report, ECOM9.5844-4

(11) ComputerlDisplay Interface Study, Quarterly Report \# 6, 1 July 1967-30 September 1967, Technical Report, ECOM$95844-4$, July 1967.

(12) Computer/Display Interface Study, Final Report, April 1969, Trectunical Ro:port, ECOM-95844, April 1969.

\subsection{Computer Magnetic Storage Media}

Assigned Responsibility Addressed By This Effort: Based upon the Brooks Act, the NBS Magnetic Media Group:

- Provides the Government agencies in general and the General Services Administration in particular with scientific and technical advisory services related to the quality, procurement, and specification testing of magnetic storage media. These services include the design and construction of specialized and unique reference measurement systems and the production of reference materials needed for comparative specification testing.

- Engages in the necessary research which leads to the development of standard reference materials, calibration services, and guidelines. These enable the users of computer magnetic media in Government automatic data processing operations to perform in an efficient and cost effective manner.

Executive Summary: The media program was initiated in response to requests from both industry and Government that NBS develop and provide them with benchmarks and measurement bases in the form of NBS Standard Reference Materials (SRM's) and disk calibration services. These NBS products were developed and are now used by all manufacturers of computer magnetic media and associated equipment and by Government procurement and specification testing laboratories. These products are issued in the form of magnetic tapes, cassettes, and cartridges and disk calibration services and assure the media manufacturers of product uniformity. This leads to improved data interchangeability and more efficient operation by Government and commercial ADP systems. These benchmarks also improve the testing capability of Government procurement and specification laboratories such as GSA Magnetic Surfaces Laboratory (MSL).

\section{Date Inititated: Fiscal Year 1966}

\section{Date Terminated: Continuing}

Goals and Objectives: To develop benchmarks and measurement bases in the form of SRM's and disk calibration services through the following sequence of program objectives:

- Develop reference magnetic media measurement and calibration systems,

- Develop reference magnetic media surface respository groups,

- Develop calibration techniques, 
- Calibrate candidate surfaces and product SRM's, and,

- Document the preceding processes and issue the products through the NBS Office of Standard Reference Materials and the NBS Office of Measurement Services.

To continue with the development of new measurement systems and calibration services as requested by the industry and Government whenever feasible.

To continue to engage in the American National Standards Institute and International Standards Organization media standards committee activities and to produce documentation such as FIPS PUBS.

To research various areas of the computer magnetic storage media phenomenology and to improve measurement capabilities where possible.

To offer consultant services and to document or publish the results of all of the preceding activities.

Products: The following products were developed by the Magnetic Media Group based upon the objectives listed in item 6:

(1) Reference signal amplitude measurement systems were developed and constructed by the Group for the calibration of SRM's and disk surfaces. These systems are also in use at the GSA Magnetic Surfaces Laboratory.

(2) In cooperation with the media industry, the Magnetic Media Group has assembled into its repository the primary groups for the $12.7 \mathrm{~mm}(0.5 \mathrm{in})$ computer tapes, the $3.2 \mathrm{~mm}(0.125 \mathrm{in})$ digital cassettes, the $6.3 \mathrm{~mm}(0.25 \mathrm{in})$ digital cartridge, and the low, medium, and high rigid disk reference surfaces.

(3) The following SRM's and disk calibration services were developed by the Magnetic Media Group.

- Secondary Standard Magnetic Tape (Computer Amplitude Reference) SRM 3200. This SRM was first issued in 1969.

- Secondary Standard Magnetic Tape Cassette (Computer Amplitude Reference) SRM 1600. This SRM was first issued in 1974.

- Secondary Standard Magnetic Tape Cartridge (Computer Amplitude Reference) SRM 3216. This SRM was first issued in 1976.

- Low density disk calibration service. This service was made available in 1973.
- Medium density disk calibration service. This service was made available in 1974 .

- High density disk calibration service. This service was made available in 1976.

(4) The following products are under development or consideration (based upon personnel and budgetary constraints):

- A computer-based measurement system for calibrating new flexible magnetic disk SRM's is under development. Estimated completion date: FY 77.

- A system for calibrating a high density magnetic reference computer tape SRM for $6250 \mathrm{bpi}$ applications is under development.

- A measurement systen for calibrating reference magnetic stripe cards is under consideration. This will be a minicomputer-based system.

- The potential for producing a reference bubble device measurement system and SRM is under consideration. This will be a minicomputer-based system.

(5) The Group has been issued a patent on a signal dropout measurement system which is in use at both NBS and GSA (MSL) It has also published papers relative to archival factors in data storage and to the effects of various devices and fields on stored data.

(6) The following descriptive publications have been produced by the Group:

- Calibration of NBS Secondary Standard Magnetic Tape (Computer Amplitude Reference) Using the Reference Tape Amplitude Measurement "Process A," S. B. Geller, P. A. Mantek, and N. G. Cleveland (Spec. Pub. 260-18) 1969.

- Calibration of NBS Secondary Standard Magnetic Tape (Computer Amplitude Reference) SRM 3200 Using the Reference Tape Amplitude Measurement "Process A" Model II, S. B. Geller (Spect. Pub. 260-29) 1971.

- Calibration of Secondary Standard Magnetic Tape Cassettes (Computer Amplitude Reference) Phase I, S. B. Geller and P. A. Mantek (Tech. Note 731) 1972.

- A Universal Dropout Tester for Magnetic Storage Media, S. B. Geller (Tech. Note 739) 1972.

- Calibration of Unrecorded Low and Medium Density Type Magnetic Disk Pack Surfaces, N. P. Goumas (Tech. Note 884) 1975. 
- The Effects of Magnetic Fields on Magnetic Storage Media Used in Computers, S. B. Geller (Tech. Note 735) 1972

- Erasing Myths About Magnetic Media, S. B. Geller (Datamation), 1976

- Archival Data Storage, S. B. Geller(Datamation) 1974.

- NASA Feasibility Study on reference instrumentation tape, July 1974.

Product Impact:

$\begin{array}{llllll}1975 & 1976 & 1977 & 1978 & 1979 & 1980\end{array}$

(1) Cassettes ${ }^{4}$ (Controlled by NBS-SRM 1600)

Millions of

$\begin{array}{lllllll}\text { units sold } & 4.8 & 7.1 & 9.6 & 12.9 & 15.2 & 18.1\end{array}$

Millions of

$\begin{array}{lllllll}\text { dollars } & 16.7 & 23.0 & 28.9 & 38.7 & 45.6 & 54.2\end{array}$

(2) Cartridges (3M (Controlled by NBS-SRM 3216)

Millions of

$\begin{array}{lllllll}\text { units sold } & .153 & .24 & .442 & .649 & .857 & 1.05\end{array}$

Millions of

dollars

$\begin{array}{llllll}2.2 & 3.3 & 5.8 & 7.8 & 9.5 & 11.5\end{array}$

(3) Flexible Disks (SRM under development)

Millions of

$\begin{array}{lllllll}\text { units sold } & 1.42 & 2.44 & 3.7 & 4.9 & 6.5 & 7.89\end{array}$

Millions of

dollars

$\begin{array}{llllll}8.4 & 13.4 & 18.6 & 23 & 29 & 34\end{array}$

(4) Cassette" Drives (Controlled by NBS-SRM 1600)

Thousands of

$\begin{array}{lllllll}\text { units } & 172 & 218 & 235 & 302 & 343 & 366\end{array}$

Millions of

dollars

$\begin{array}{llllll}97 & 117 & 140 & 155 & 173 & 182\end{array}$

(5) Rigid Computer Disk Spindles Installed (19721975)

$1972-130,000$

$1973-155,000$

$1974-175,000$

$1975-190,000$

$1976-225,000$

(6) Plug Compatible U.S. Equipment Installed (1970-1975)

(Controlled by NBS SRM 3200 and Disk Calibration Services)

\footnotetext{
Venture Corporation
}

(Millions of

\begin{tabular}{lrrrrrr}
\multicolumn{2}{l}{$\begin{array}{l}\text { dollars)1970 } \\
\text { Tape }\end{array}$} & 1971 & 1972 & 1973 & 1974 & 1975 \\
$\begin{array}{l}\text { drives } \\
\begin{array}{l}\text { Disk } \\
\text { drives }\end{array}\end{array}$ & $\$ 185$ & $\$ 210$ & $\$ 276$ & $\$ 342$ & $\$ 407$ & $\$ 500$ \\
& 370 & 480 & 522 & 640 & 772 & 920
\end{tabular}

(7) Reels of Magnetic Computer Tapes Sold (19731975): (Controlled by NBS SRM 3200)-(Millions of units)

$1973-19 \mathrm{M}$

$1974-23 \mathrm{M}$

$1975-28 \mathrm{M}$

(8) Disk Packs Sold (1973-1975): (Controlled by NBS disk calibration services)

\begin{tabular}{|c|c|c|c|}
\hline & 1973 & 1974 & 1975 \\
\hline $\begin{array}{l}\text { Low Density } \\
\text { Packs } \\
\text { Medium Densit }\end{array}$ & 200,000 & 220,000 & 210,000 \\
\hline Packs & 700,000 & 800,000 & $1,100,000$ \\
\hline $\begin{array}{l}\text { Packs } \\
\text { Pan Densit }\end{array}$ & 120,000 & 210,000 & 400.000 \\
\hline
\end{tabular}

To date, the following quantities of SRM's and disk calibration services have been sold at the following costs:

Unit

SRM 3200

SRM1600

SRM3216

Low density disk calibration service

Medium density disk calibration service

High density disk calibration service

$\begin{array}{rr}\text { No. of } & \text { Cost per } \\ \text { Units } & \text { Unit } \\ 120 & \$ 705 \\ 45 & 144 \\ 10 & 165 \\ 8 & 240 \\ 12 & 300 \\ 2 & 312\end{array}$

Relevant Circumstances: At the present time, there are no feasible techniques available for maintaining magnetic media reference measurement bases other than through reference signal levels which are derived from actual media surfaces on SRM's or dedicated disks. Attempts at the electronic sinumlation of the levels have been unsuccessful due to the multivariable and nonlinear nature of the magnetic recording processes.

The need for and use of these SRMI's and calibration services is an unquestioned and integral part of magnetic media industry operations. The continued high demand for NBS standard referenec matterials and calibration services are evidence that the computer industry recognizes the NBS manguetic media program as a necessiny means of providing the roference standards and measurements for the whole industry, a service which the industry (1) expects fiom an objective Government laboratory. (2) finds unprofitable to provide for itself. and (3) would alceept with 
more reluctance and less trust from an industry competitor. In fact, considerable pressure had been exerted by industry for NBS to institute the media program.

NBS magnetic media work is mandated under the Brooks Act, providing standards and guidelines directly to Federal agencies as well as to GSA which controls the procurement of magnetic media for Federal agencies.

The continuing worldwide need for precise measurement standards for magnetic storage media is evidenced by the fact that ADP standards committees of both the American National Standards Institute (ANSI) and the International Organization for Standardization (ISO), have specifically requested that NBS continue to develop measurement and calibration techniques in support of magnetic storage media standards.

Impact: The directly measurable indicators of the effects of SRM's and calibration services are technical in nature and appear as definite improvements in product signal quality. For example, it has been found in the case of the $12.7 \mathrm{~mm}(0.5 \mathrm{in})$ magnetic computer tape, that since the advent of the reference computer tape-SRM 3200 (120 sold to date) that the variation of the average signal amplitudes as measured from random samples of commercially available computer tapes has decreased from 50 percent (in 1969) to less than 15 percent about the established reference levels. This reduced signal level variation from tape-to-tape improves Federal ADP applications which incorporate these media. This is due to the potential for improved data interchangeability among installations. It is important to note that a single SRM 3200 controls the quality of many millions of reels of computer tapes.

The SRM 3200 has also been adopted by the magnetic stripe card industry as their magnetic reference media.

In the case of the SRM 1600 reference cassette, the NBS Group made an important decision which resolved a dispute between Japan and European countries over the final cassette signal amplitude reference level which is now maintained by the NBS SRM 1600 .

Since the SRM 3216 digital cartridge is now used to control a relatively new storage device, this device will be easily and well controlled at the outset. Production and compatibility problems for digital cartridges will be minimized because of the early activities of the Magnetic Media Group in producing SRM 3216.

The NBS Magnetic Media Facility is presently the worldwide source for the SRM 3200, the SRM 3216, and the high density disk calibration services. The
German PTB offers a digital cassette which is compatible with the SRM 1600.

The group was instrumental in establishing the final reference signal amplitude levels for the rigid disks.

The operations of the Magnetic Media Group are essential to the improved economic and technical operations of the very large media industry which has both domestic and foreign bases. The following is a summary of the sales volume of some of the products which are or will be influenced by the Group operations. Of the three low cost storage devices (the cassette, the cartridge ( $3 \mathrm{M})$, and the flexible disk), the cassette appears to have the greatest sales volume at present.

$\begin{array}{llrc} & & \text { STRS } & \text { OA } \\ \text { Funding Profile: } & \text { FY 1972 } & \$ 197,799 & \\ & \text { FY } 1973 & 180,450 & \\ & \text { FY 1974 } & 155,376 & \$ 100,000 \\ & \text { FY 1975 } & 188,322 & 19,649 \\ & \text { FY 1976 } & 146,170 & 15,000\end{array}$

5 As of $5 / 12 / 76$.

\section{APPENDIX A}

Since the passage of the Brooks Act, the General Accounting Office has conducted many studies, surveys and audits on opportunities for savings in the use of computers in the Federal Government and on the implementation of the Brooks Act. Twelve of the reports issued by GAO contain comments or findings about NBS. NBS has found the GAO Reports to be fair, accurate and helpful. These reports generally found NBS not having adequate resources or not doing an adequate job. All of them found that NBS needed to do more just to minimally meet Government needs and its own Brooks Act responsibilities.

This appendix contains a listing and synopsis of GAO reports issued over the past decade that comment on the NBS program relevant to its mission under the Brooks Act.

\section{GAO REPORTS COMMENTING ON NBS RE- SPONSIBILITIES UNDER BROOKS ACT}

Study of the Acquisition of Peripheral Equipment for Use with Automatic Data Processing Systems

\section{June 1969}

Federal agencies should replace leased components with rore economical plug-to-plug compatible units. Specific guidelines for the evaluation and selection of plug-to-plug compatible equipment should be provided. 
Acquisition and Use of Software Products for Automatic Data Processing Systems in the Federal Government

June 1971

OMB should arrange for the formulation of a master plan for the acquisition and use of software. $\mathrm{OMB}$ should provide coordinated management and central policy direction to users for determining the most economical and efficient means for obtaining computer software. GSA should employ singlepurchaser concept, use advertised procurement contracts, arrange non-restrictive contractual arrangements for software, consider buying software products outright and maintain an inventory of computer software. NBS should establish and maintain an inventory of computer software. NBS should establish and maintain a reference index of computer programs, make detailed technical evaluations of computer programs for use of all Federal ADP installations, and promulgate Federal standards for computer languages and program documentation.

Opportunity for Greater Efficiency and Savings Through the Use of Evaluation Techniques in the Federal Government's Computer Operations

\section{August 1972}

OMB should encourage the development of computer performance evaluation techniques. Techniques suggested included: agency consideration of computer evaluation techniques to improve the efficiency of computer performance; development of productivity and performance criteria; periodic reports on agency efforts to evaluate the efficiency of computer operations.

Means for Increasing the Use of Defense Technology for Urgent Public Problems

\section{December 1972}

OMB should establish a government-wide policy for technology transfer and issue guidelines for formal active transfer efforts. A way to achieve an active technology transfer process is to establish a centralized interdisciplinary team to serve as consultants to agencies seeking information and guidance concerning the availability of technology and resources relevant to their needs and advise technology developers of potential secondary applications. NBS would be an appropriate agency for this role.

Emphasis Needed on Government's Efforts to Standardize Data Elements and Codes for Computer Systems

\section{May 1973.}

Secretary of Commerce should determine where standards would be most beneficial and establish standardization priorities; issue policy delineating theory and terminology and provide for preparation of guidelines, methodology and criteria to be followed by agencies in standardization efforts; assign specific agencies responsibilities for developing standard data elements and codes in specified areas and monitor implementation of data standards to insure their uniform adoption and use.

Improvement Needed in Documenting Computer Systems

\section{Oct. 1974}

GSA issue guidance to agencies that use computers specifying assignment of responsibility for periodical review of computer systems. Reviews should insure that computer systems have been documented properly in accordance with NBS standards.

Increased Use of Computer-Output-Microfilm by Federal Agencies Could Result in Savings

\section{Nov. 1974}

GSA should inform Federal managers of benefits of using COM; suggest that agencies investigate whether COM could increase productivity and lower the cost of information systems; encourage Federal agencies to share existing COM equipment.

Executive Branch Action on Recommendations of the Commission on Government Procurement

\section{March 1975}

OMB should establish priorities and milestones for implementing actions lacking completion dates. Recommendation 14 proposed develnping and issuing a set of standard programs to be used as benchmarks for evaluating vendor ADP proposals.

Uses of Minicomputers in the Federal Government: Trends, Benefits, and Problems

\section{April 1976}

GSA should, through forums with other Government agencies and industry associations, simplify Government-wide procurement requirements for minicomputers giving recognition to the difficulties cited by agencies pertaining to the purchase of minicomputers with a low-aggregate-dollar value. Most NBS computer standards are applicable to minicomputers; however, changes to the COBOL standard need to be made to accommodate 
minicomputer needs and standards for FORTRAN and BASIC need to be developed. High level programming language standards are desirable to help reduce the cost of converting programs from large-scale data processing systems to minicomputers.

Improvements Needed in Managing Automated Decisionmaking by Computers Throughout the Federal Government

\section{April 1976}

OMB should require that each agency determine whether any of its computer operations involve automated decisionmaking applications. Agencies should review their operations to determine whether incorrect actions are being taken as a result of these applications and insure correct decisions before initiating any new automated decisionmaking applications. NBS should issue technical guidelines for developing, using, technically evaluating, documenting and modifying these applications in the Federal Government. Guidelines should contain certain criteria for independent technical reviews and for monitoring applications to insure problems are detected and corrected promptly.

Managers Need to Provide Better Protection for Federal Automatic Data Processing Facilities

May 1976

OMB should issue policy directing that specific assignments of responsibility for physical security of ADP systems be made at each Federal installtion using computer systems. Officials should use NBS guidelines for protecting data processing assets and data when developing and implementing physical security and risk management programs.

Manufacturing Technology-A Changing Challenge to Improved Productivity

June 1976

National Center for Productivity and Quality of Working Life should develop a national policy and appropriate means for achieving balanced productivity growth in the industrial/manufacturing base. The National Center should seek the cooperation and assistance of the Department of Commerce and other appropriate agencies. DoC should strengthen its efforts to support and develop productivity enhancing technology related to manufacturing, and to encourage others to actively support these objectives. DoC could serve as a focal point to coordinate Government and private work in developing, standardizing, and diffusing manufacturing technology, and assist state and regional productivity organizations in efforts to advance manufacturing technology.

\section{APPENDIX B}

\section{ICST PUBLICATIONS}

The following is a complete list of the publications of ICST and its predecessor organizations dating from October 1965 to December 1975.

All of these publications were prepared under the authorities assigned to the Secretary of Commerce by the Brooks Bill. The list is divided into four categories: Part A lists reports deriving from NBS scientific and technological advisory services, Parts $\mathrm{B}$ and $\mathrm{C}$ relate to Federal automatic data processing standards, and Part D lists reports deriving from NBS research in computer science and technology. The research generally supports both scientific technological advisory services and Federal automatic data processing standards. Many of the documents could have been listed in two or even three of the categories; however, they have been listed only in the category to which they principally relate.

A. Publications related to Scientific and Technological Advisory Services.

B. Completed Federal Automatic Data Processing Standards and Guidelines.

C. Publications related to the development of Federal Automatic Data Processing Standards and Guidelines.

D. Publications Reporting on Research in Computer Science and Technology.

A. Publications related to Scientific and Technological Advisory Services

\section{5}

TELETRAF: Computer Programs for Simulating Circuit_Switched Telecommunication Networks, P. S. Shoenfeld, (NBS Report 8995).

\section{6}

The NBS CORD Time Sharing System; T. N. Pyke, Jr., (NBS Report 9339).

The Concept of Attack Worth of Telecommunications Network Elements, A. J. Goldman, et al, (NBS Report 9345).

Progress Report on the Development of an Automated Information Storage, Selection and Retrieval System for the Outdoor Recreation Areas in the United States, G. E. Glober, Jr., (NBS Report 9414).

CORD-A Time Sharing Executive for a Research Facility, T. N. Pyke, Jr., (NBS Report 9423). 
Report of a Study of Requirements and Specifications for Serial and Monograph Microrecording for the National Library of Medicine, E. J. Forbes, et al. (NBS Report 9446).

Transistorized Building Blocks for Data Instrumentation, P. G. Stein, (NBS Tech. Note 268).

A Grammar for Component Combination in Chinese Characters, B. K. Rankin. III, S. Siegel, A. McClelland, and J. L. Tan. (NBS Tech. Note 296).

\section{7}

The NBS CORD Time Sharing System-A Reference Manual, T. N. Pyke, Jr.. (NBS Report 9495).

Chinese Character Analysis, B. K. Rankin, III, et al. (NBS Report 9537).

Automatic Data Gathering in Precise Laboratory Experiments, P. G. Stein, (NBS. Report 9555).

Study of and Experimentation in Computer Composition of Library Materials, R. W. Worral. et al, (NBS Report 9598).

Shifting Buffer Module, P. G. Stein, (NBS Report 9602).

Buffer Multiplexer Module, P. G. Stein, (NBS Report 9603).

CAS-The CORD Assembly System Assembly Language for the NBS CORD Time Sharing System, C. A. Curtis, (NBS Report 9641).

A Computer-Controlled Calibrator for RadioFrequency Receivers System Description and Programming, P. G. Stein, (NBS Report 9662).

Automatic Typographic-Quality Typesetting Techniques: A State-of-the-Art-Review, M. E. Steven and J. L. Little, (NBS Monograph 99).

The Solid System. II. Numeric Compression, P. A. D. de.Maine, K. Kloss: and B. A. Marron. The Solid System. III. Alphanumeric Compression, P. A. D. deMaine, B. A. Marron. and K. Kloss, (NBS Tech. Note 413).

Evaluation of Information Systems: A Selected Bibliography With Informative Abstracts, M. M. Henderson. (NBS Tech. Note 297).

\section{8}

The Organization and Programming of a Computer Controlled Scanner (FOSDIC VI). J. M. St. Clair. (NBS Report 9805).

Electromagnetic Pulse Signal Classification and
Identification of Nearby SFERICS in the High Altitude Nuclear Detection Studies (Hands) Program Volume II, R. T. Moore, (NBS Report 9839).

Users' Manual for the Pathfinding Importance Number Generator, A. N. Hobbs, et al, (NBS Report 9924).

A Computer Oriented Single-Fingerprint Identification System, J. H. Wegstein, (NBS Tech. Note 443).

Electronic Composition in Printing, R. W. Lee and R. W. Worral, Eds., (NBS Sp. Pub. 295).

Matching Fingerprints by Computer, J. H. Wegstein. J. F. Rafferty and W. J. Pencak. (NBS Tech. Note 466).

Connection Tables from Wisuesser Chemical Structure Notations-A Partial Algorithm, G. F. Fraction. J. C. Walker and S. J. Tauber. (NBS Tech. Note 432).

Input/Output Packages for the Systems 360 Assembly Language Processor, P. A. D. de_laine. (NBS Tech. Note 433).

Computer Literature Bibliography, IV. II. Youden, (NBS Sp. Pub. 309).

\section{9}

Preliminary Study of Inter-Hospital Communication Interface-Phase I, P. Meissner. et al. (NBS Report 10 084).

Simulation of Air Traffic Control Radar Beacon Code Assignment Plans. R. D. Elbourn. (NBS Report 10 117).

$K_{h}$ Subsystem Operating and Maintenance Instructions, D. S. Grubb. et al. (NBS Report 10125).

An Experiment for the Study of Sistem Design and Instrumentation for Remote Computer Gruphics Utilizing a Graphical Text Eelitor. J. A. Hudsun. et al. (NBS Report 10 1+3).

Data Structures for Computer Graphics. M. D. Abrams. (NBS Report 10 14).

A Semi-Automated Single Fingerprint Llentificution Sistem, J. H. Wegstein. (NBS l'ereh. Vinte 481).

Use of a Time Shared Computer Sistem to Control.t Hall Effect Experiment. IT. II. Bullis. II. R. Thurber. T. N. Pyke. Jr.. F. H. I lmer and A. L. Koenig. (NBS Tereh. Note 510). 
K System Baseline Configuration, R. T. Moore, (NBS Report 10 243).

Remote Gamma Source Handling System, J. N. Strohlein, (NBS Report 10 352).

Documentation of BLOKI and BLOK2-Programs for Printing of Selected Tape Blocks, D. C. Friedman, (NBS Report 10 445).

A Selective Roll-to-Roll Printer for Producing Duplicate Microfilm Copies, J. N. Strohlein and T. C. Bagg, (NBS Tech. Note 510).

Automated Fingerprint Identification, J. H. Wegstein, (NBS Tech. Note 538).

The $K_{u 1}$ Subsystem, K. M. Gray, (NBS Report 10 $501)$.

K System Baseline Software Volume I, D. C. Friedman, (NBS Report 10 524).

K System Baseline Software Volume II, D. C. Friedman, (NBS Report 10 524).

Problems of Network Accounting, Monitoring and Performance Measurement, M. E. Stevens, (NBS Report 10 559).

\section{1}

The K-System Code Change Detector, U. T. Jones, (NBS Report 10 450).

Performance Measurement of Interactive Graphics Systems in Support of Computer Aided Design and Engineering, T. N. Pyke, Jr., et al, (NBS Report 10 451).

Chemical and Pharmacological Data Management User's Guide, R. N. Freemire, et al, (NBS Report 10 463).

User's Manual for the ONC Map Plotting Program SIPLOT, G. R. Bolotsky, et al, (NBS Report 10 545).

The K-System Monitor Console, K. M. Gray, et al, (NBS Report 10 552).

Documentation of "QSCAN", A Program for Verifying Upper and Lower-Case Text with Control Symbols, D. C. Friedman, et al, (NBS Report 10 $560)$.

Chemical and Pharmacological Data Management, M. J. Oldfield, et al, (NBS Report 10 569).

The Word in Patent Text, K. Rankin, (NBS Report 10 584).
Programmer's Manual for the ONC Map Plotting Program SIPLOT, Z. G. Ruthberg, (NBS Report 10 619).

Performance Test Report on NBS Fortran Single Precision Tangent and Cotangent, D. W. Lozier, et al, (NBS Report 10 646).

First Interim Progress Report on NBS Project WHERE in Support of USAAMCA Project MNPLS, (NBS Report 10663 ).

Simulation of Air Traffic Control Radar Beacon Code Assignment Plans, E. C. Elbourn and J. F. Gilsonn, (NBS Tech. Note 568).

A Survey of Selected Document Processing System, E. Fong, (NBS Tech. Note 599).

\section{2}

Acoustic, Ultrasonic and Vibrational Disturbances Resulting from the Penetration of Conventional Structural Barriers, R. T. Moore, (NBS Report 10 682).

Time of Flight Interface Unit for Computer Recording of Thermal Neutron Flight Times, D. S. Grubb, et al, (NBS Report 10 697).

User's Manual for Program Defenses, Z. G. Ruthberg; (NBS Report 10 821).

Final Report NBS Project WHERE in Support of USAAMCA Project MNPLS, (NBS Report 10 859).

Manual and Automated Fingerprinting Registration, J. H. Wegstein, (NBS Tech. Note 730).

Manual and Computerized Footprint Identification; J. H. Wegstein, (NBS Tech. Note 712).

\section{3}

SETAB: An Edit/Insert Program for Automatic Typesetting of Spectrosocopic and Other Computerized Tables, R. C. Thompson and J. Hilsenrath, (NBS Tech. Note 740).

Set of Debugging and Monitoring Facilities to Improve the Diagnostic Capabilities of a Compiler, E. Fong, (NBS Tech. Note 763).

Controlled Accessibility Bibliography, S. K. Reed and M. M. Gray, (NBS Tech. Note 780).

Heuristic Cost Optimization of the Federal Telpak Network, R. G. Saltman, G. R. Bolotsky and Z. G. Ruthberg, (NBS Tech. Note 787).

Review of Network Management Problems and Issues, A. J. Neumann, (NBS Tech. Note 795). 
Characterization and Testing of Interactive Graphics for Computer-Aided Design and Engineering, S. Treu, (NBSIR 73-289).

Guidelines for the Use of Computer Technology in the Developing Countries, R. A. Simmons, (NBSIR 73-423).

\section{4}

Field Service Test Model: Computer-Controlled U System. Operations Manual and Software Operating System Appendices for the Automated System, K. M. Gray and J. R. Ellis, informal report.

Network User Information Support, A. J. Neumann, (NBS Tech. Note 802).

Computer Networking: Approaches to Quality Service Assurance; R. B. Stillman, (NBS Tech. Note $800)$.

A Guide to Networking Technology; R. P. Blanc, (NBS Techn. Note 803)

Review of Computer Networking Technology, R. P. Blanc, (NBS Tech. Note 804).

Network Management Survey, I. W. Cotton, (NBS Tech. Note 805).

Government Looks at Privacy and Security in Computer Systems, C. R. Renninger and D. K. Branstad, (NBS Tech. Note 809).

A Mechanized Information Service Catalog, B. Marron, E. Fong and D. Fife, (NBS Tech. Note 814).

A Technical Index of Interactive Information Systems, D. Fife, K. Rankin, E. Fong, J. Walker and B. Marron, (NBS Tech. Note 819).

Cost-Benefit Analysis of Computer Graphics Systems, I. W. Cotton, (NBS Tech. Note 826).

Controlled Accessibility Workshop Report, S. K. Reed and D. K. Branstad, (NBS Tech. Note 827).

Multicommodity Network Plotting via Program NETPLT; Z. G. Rutherberg, G. R. Bolotsky and W. Slater, Jr., (NBS Tech. Note 829).

Report on Planning Session on Software Engineering Handbook, S. L. Stewart, (NBS Tech. Note 832).

Information Handling Needs Within the U.S. Patent Office, S. Jeffrey, (NBS Tech. Note 834).

Barrier Penetration Tests, R. T. Moore, (NBS Tech. Note 837).
Cost Analysis for Computer Communication, R. P. Blanc, (NBS Tech. Note 845).

Dataplot 70: FORTRAN-Callable Plotting Routines, C. V. Young and P. G. Stein, (NBS Tech. Note 847).

Approaches to Privacy and Security in Computer Systems, C. R. Renninger, (NBS Sp. Pub. 404).

Benchmarking and Workland Definition; A Selected Bibliography with Abstracts, J. L. Walkowicz, (NBS Sp. Pub. 405).

Annotated Bibliography Forecasting, M. M. Gray and D. A. Nagy, (NBSIR 74-463).

Development of a National Anthropometric Data Base: A Preliminary Study Report, H. L. Steinbert, (NBSIR 74-506).

Remittance Processing System, P. D. Shupe, Jr., P. Meissner and J. R. Park, (NBSIR 74 577-1).

Report of Conference on Making Service Industries More Productive Through Computers and Automation, M. Henderson and A. McAdams, (NBSIR 74 515).

\section{5}

Cost Recovery in Pricing and Capacity Decisions and Automated Information Systems, J. A. Dei Rossi, (NBS Tech. Note 864).

Computer Program Package for Metric Conversion: Reference Manual, R. K. Anderson and J. O. Harrison, Jr., (NBS Tech. Note 872).

Software Testing and Network Services, R. B. Stillman and B. Leong-Hong, (NBS Tech. Note 874).

The Service Concept Applied to Computer Networks, M. D. Abrams and I. W. Cotton, (NBS Tech. Note 880).

The M40 Fingerprint Matcher, J. H. Wegstein, (NBS Tech. Note 878).

Six Data Base Management Systems: Feature Analysis and User Experience, E. Fong, J. Collica and B. Marron, (NBS Tech. Note 887).

Exploring Privacy and Data Security Costs-A Summary of a Workshop, J. L. Berg, (NBS Tech. Note 876).

Effective Use of Computing Technology in VoteTallying, R. G. Saltman, (NBSIR 75-687). 
B. Completed Federal Automatic Data Processing Standards and Guidelines

\section{8}

General Description of FIPS Register, (FIPS PUB $0)$.

Code for Information Interchange, (FIPS PUB 1).

Perforated Tape Code for Information Interchange, (FIPS PUB 2).

Calendar Date, (FIPS PUB 4).

\section{9}

Implementation of Code for Information Interchange, (FIPS PUB 7).

Congressional Districts of the U.S., (FIPS PUB 9).

\section{0}

States and Outlying Areas of the U.S., (FIPS PUB 5-1).

\section{1}

Vocabulary for Information Processing, (FIPS PUB 11).

Rectangular Holes in 12-Row Punched Cards, (FIPS PUB 13).

Hollerith Punched Card Code, (FIPS PUB 14).

Subsets of Standard Code for Information Interchange, (FIPS PUB 15).

Bit Sequencing of Code for Information Interchange in Serial-By-Bit Data Transmission, (FIPS PUB 16).

Character Structure and Character Parity Sense for Serial-By-Bit Data Communication in Code for Information Interchange, (FIPS PUB 17).

Character Structure and Character Parity Sense for Parallel-By-Bit Data Communication in Code for Information Interchange, (FIPS PUB 18).

\section{2}

Guidelines for Registering Data Codes, (FIPS PUB 19).

Guidelines for Describing Information Interchange Formats, (FIPS PUB 20).

Synchronous Signaling Rates Between Data Terminal and Data Communication Equipment, (FIPS PUB 22).

\section{3}

Recorded Magnetic Tape for Information Interchange (800 CIP, NRZI), (FIPS PUB 3-1).

Countries and County Equivalents of the States of the U.S., (FIPS PUB 6-2).

Objectives and Requirements, (FIPS PUB 23).

Flowchart Symbols and Their Usage in Information Processing, (FIPS PUB 24).

Recorded Magnetic Tape for Information Interchange (1600 CIP, PE), (FIPS PUB 25).

One-Inch Perforated Paper Tape for Information Interchange; (FIPS PUB 26).

Take-Up Reels for One-Inch Perforated Tape, (FIPS PUB 27).

Standardization of Data Elements and Representations, (FIPSS PUB 28).

\section{4}

Standard Metropolitan Statistical Areas (SMSAs), (FIPS PUB 8-4).

Countries, Dependencies, and Areas and Special Sovereighty, (FIPS PUB 10-1).

Federal Information Processing Standards Index, (FIPS PUB 12-2).

Interpretation Procedures for Federal Standard COBOL, (FIPS PUB 29).

Software Summary for Describing Computer Programs and Data Systems, (FIPS PUB 30).

Guidelines for ADP Physical Security and Risk Management, (FIPS PUB 31).

Optical Character Recognition Character Sets, (FIPS PUB 32).

Character Set for Handprinting, (FIPS PUB 33).

\section{5}

COBOL, (FIPS PUB 21-1).

Guide for Use of Internationl System of Units (SI) in Federal Information Processing Standards Publications, (FIPS PUB 34).

Code Extension Techniques in 7 or 8 Bits, (FIPS PUB 35).

Graphic Representation of Control Characters of ASCII, (FIPS PUB 36). 
Synchronous High Speed Data Signaling Rates Between Data Terminal Equipment and Data Communications Equipment, (FIPS PUB 37).

Computer Security Guidelines for Implementing Privacy Act of 1974, (FIPS PUB 41).

Guidelines for Benchmarking ADP Systems in Competitive Procurement Environment, (FIPS PUB 42).

Aids for Program COBOL Conversion (FIPS 2121-1), (FIPS PUB 43).

C. Publications related to the development of Federal Automatic Data Processing Standards and Guidelines

\section{6}

Cooperation, Convertibility, and Compatibility Among Information Systems: A Literature Review, M. M. Henderson, V. E. Giuliano and L. B. Heilprin, (NBS Misc. Pub. 276).

1969

CODASYL COBOL, (NBS Handbook 106).

Some Evolving Conventions and Standards for Character Information Coded in Six, Seven and Eight Bits, J. L. Little, (NBS Tech. Note 478).

\section{0}

Standardization, Compatibility andlor Convertibility Requirements in Network Planning, M. E. Stevens, (NBS Report 10 252).

Performance Measurement of Remote Access Computer Systems, M. D. Abrams, (NBS Report 10 381).

\section{2}

Calibration of Secondary Standard Magnetic Tape Cassettes (Computer Amplitude Reference), S. B. Geller and P. A. Mantek, (NBS Tech. Note 731).

A Computer Terminal Network for Transparent Simulation of the User of an On-Line Retrieval System, S. Treu, (NBS Tech. Note 732).

A Universal Dropout Tester for Magnetic Storage Media, S. Geller, (NBS Tech. Nute 739).

\section{3}

User Procedures Standardization for Netuork Access, A. J. Neumann, (NBS Tech. Nute 799).

\section{4}

A Technical Guide to Computer-Communications Interface Standards, A. J. Neuman, B. G. Lucas, J. C. Walker and D. W. Fife, (NBS Tech. Note 843).

CODASYL Data Description Language, (NBS Handbook 113).

A FORTRAN Analyzer, G. Lyon and R. Stillman, (NBS Tech. Note 849).

The CORASYL Data Base Approach: A COBOL Example of Design and Use of a Personnel File, E. H. Sibley, (NBSIR 74-500).

Standards Analysis for Future WWMCCS Computer Networking, D. Fife, informal report.

NBS FORTRAN Test Programs, Vols. 1, 2, 3, F. E. Holberton and E. Parker, (NBS Sp. Pub. 399).

Computer Performance Evaluation, H. J. Highland, (NBS Sp. Pub. 401).

\section{5}

Computer Performance Evaluation: Report of the 1973 NBS/AMC Workshop, T. E. Bell. B. W. Boehm and S. Jeffrey, (NBS Sp. Pub. 406).

Proposed Implementation for Development of User-terminal Protocols for Coniputer Netuork Access, A. J. Neumann. (NBSIR 75-744).

Criteria for the Performance Evaluation of Data Communications Services for Computer Networks, D. S. Grubb and I. W. Cotton. (NBS Tech. Note 882).

A Basis for Standardization of U'ser-Terminal Protocols for Computer Network Access, A. J. Neumann, (NBS Tech. Note 877).

D. Publications Reporting on Research in Computer Science and Technology

\section{5}

Work Touards Chemical Structure .Manipulation. Stephen J. Tauber. et al. (NBS Report 9007)

Special Purpose Control Module. Andrew T. Pryzbylik. (NBS Report 9064).

Statistical Association Methods for Mechanized Documentation, .11. E. Stevens. V. E. Ginliano, and L. B. Helilprin. (NBS Misc. Pub. 269). 
1966

Very High Speed Transient Recorder, Don R. Boyle, et al, (NBS Report 9032).

A Punched Paper Tape to Digital Magnetic Tape Converter, Andrew T. Pryzbylik (NBS Report 9325).

MOBIDIC - Teletype Interface, Orrington R. Hall, (NBS Report 9338).

Programmed Teaching and Testing with a Digital Computer, J. H. Wegstein, et al (NBS Report 9372).

Experimental Display Sub-system, N. Carlton Montague, (NBS Report 9345).

\section{7}

A Computer Test Program to Assess Adroitness in Indexing Operations, George W. Reitwiesner, (NBS Report 9470).

Wide Band, Large Dynamic Range EMP Receiver, Don R. Boyle, et al, (NBS Report 9556).

Legibility of Alphanumeric Charactes and Other Symbols, D. Y. Cornog and F. C. Rose, (NBS Misc. Pub. 262-2).

Systems Design for the Selective Information Extrator Prototype, Armando Severo, et al, (NBC Report 9538).

A Computer-Controlled Calibrator for RadioFrequency Receivers System Construction and $O_{p-}$ eration, Philip G. Stein, (NBS Report 9663).

\section{8}

A File System for Chemical and Biological Information, Stephen J. Tauber, et al, (NBS Report 9932).

Man-Machine System Organization Final Report-Phase I, Thomas N. Pyke, Jr., (NBS Report 10051 ).

The CL6 Conversational List Processing System, Richard A. Siegler, (NBS Report 9966).

GRASS a Graphical Assembler for Magic II, J. A. Hudson, (NBS Report 9955).

Magic II, A Remote Graphical Display Terminal, D. E. Rippy, (NBS Report 9956).

Valuation of Telecommunications, S. C. Strom, et al., (NBS Report 9977).
Nonnumeric Data Processing in Europe: A Field Trip Report, M. E. Stevens, (NBS Tech. Note 462).

\section{9}

A Set of Elementary Picture Processing Algorithms, J. A. Hudson, et al, (NBS Report 9978).

LLLAMA-A Low Level Language for Assistance in Measurements Automation, P. G. Stein, (NBS Report 10 147).

Auxiliary Data Readout System, W. B. Truitt, (NBS Report 10 187).

\section{0}

Component Combination and Frame-Embedding in Chinese Character Grammars, K. Rankin and J. L. Tan, (NBS Tech. Note 492).

\section{1}

Interlocking Directories-Problems and Prospects of Network Referral Resources, M. E. Stevens, (NBS Report 10 473).

Eliminating Pairs of Digits with Equal Distances from Strings with Check Digits, G. W. Reitwiesner, (NBS Report 10 639).

A Bit Comparison Program for Algorithm Testing, D. W. Lozier, et al., (NBS Report 10 449).

A Preliminary Design of a Data Retrieval Language to Handle a Generalized Data Base: DRL, E. Fong, (NBS Tech. Note 590).

Fortran Program for Arbitrary Precision Arithmetic, L. C. Maximon, (NBS Report 10 563).

A Networking Embedding Problem, B. Marron, et al, (NBS Report 10 617).

\section{2}

The National Bureau of Standards' Linear and Quadratic Programming Subroutines, W. G. Hall, et al, (NBS Report 10 695).

Transparent Stimulation of a Computer, S. Treu, (NBS Report 10 863).

A Set of Problems to Evaluate Scientific Computers, G. W. Reitwiesner, (NBS Report 10 883).

Policing Transcription and Transposition Errors by a Single Check Digit Modulo 10 and $11, \mathrm{G}$. W. Reitwiesner, (NBS Report 10 886).

The Effects of Magnetic Fields on Magnetic Storage 
Media Used in Computers, S. B. Geller, (NBS Tech. Note 735).

\section{3}

A Performance Comparison of Labeling Algorithms for Calculating Shortest Path Trees, J. Gilsinn and C. Witzgall, (NBS Tech. Note 772).

Data Communications System Throughput Performance Using High Speed Terminals on the Dial Telephone Network, D. S. Grubb, (NBS Tech. Note 779).

A Study of Six University-Based Information Sys. tems, B. Marron, E. Fong, D. W. Fife and K. Rankin, (NBS Tech. Note 781).

Static Language Analysis, G. Lyon, (NBS Tech. Note 797).
1974

Complete Clear Text Representation of Scientific Documents in Machine-Readable Form, B. C. Duncan and D. Garvin, (NBS Tech. Note 820).

Research Considerations in Computer Networking to Expand Resource Sharing, D. W. Fife, (NBS Tech. Note 801).

Concepts in Quality Software Design, S. L. Stewart, (NBS Tech. Note 842).

Computer System Capacity Fundamentals, D. J. Kuck, (NBS Tech. Note 851).

\section{5}

Mathematics and Engineering in Computer Science, C. J. Van Wyk, informal report. 


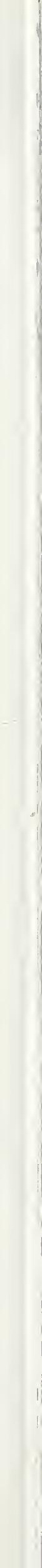


NBS-IT4A (REV. 7.73)

\begin{tabular}{|c|c|c|}
\hline $\begin{array}{r}\text { 1. PUBLICATION OR REPORT NO. } \\
\text { NBSIR } 76-1113\end{array}$ & $\begin{array}{l}\text { 2. Gov't Accession } \\
\text { No. }\end{array}$ & 3. Recipient's Accession No. \\
\hline \multirow{2}{*}{\multicolumn{2}{|c|}{$\begin{array}{l}\text { 4. TITLE AND SUBTITLE } \\
\text { A Ten Year History of National Bureau of Standards } \\
\text { Activities Under the Brooks Act }\end{array}$}} & $\begin{array}{l}\text { 5. Publication Date } \\
\text { Eebruary } 1977 \\
\end{array}$ \\
\hline & & 6. Performing Organization Code \\
\hline \multicolumn{2}{|l|}{$\begin{array}{l}\text { 7. Adiktobls) } \\
\text { Editors: Grace Burns and Shirley Radack }\end{array}$} & 8. Performing Organ. Report No. \\
\hline \multicolumn{2}{|l|}{$\begin{array}{l}\text { 9. PERF ORMING ORGANIZATION NAME AND ADDRESS } \\
\text { NATIONAL BUREAU OF STANDARDS } \\
\text { DEPARTMENT OF COMMERCE } \\
\text { WASHINGTON, D.C. } 20234\end{array}$} & $\begin{array}{l}\text { 10. Project/Task/Work Unit No. } \\
\text { 11. Contract/Grant No. }\end{array}$ \\
\hline \multirow{2}{*}{\multicolumn{2}{|c|}{$\begin{array}{l}\text { 12. Sponsoring Organization Name and Complete Address (Street, City, State, ZIP) } \\
\text { National Bureau of Standards } \\
\text { Department of Commerce } \\
\text { Washington, D.C. } 20234\end{array}$}} & $\begin{array}{l}\text { 13. Type of Report \& Period } \\
\text { Covered }\end{array}$ \\
\hline & & 14. Sponsoring Agency Code \\
\hline
\end{tabular}

15. SUPPLEMENTARY NOTES

16. ABSTRACT (A 200-word or less factual summary of most significant information. If document includes a significant bibliography or literature survey, mention it here.)

This report presents the principal findings of a National Bureau of Standards task force which reviewed the activities and accomplishments of NBS from 1965 to 1975 under Public Law 89-306, the Brooks Act. The Brooks Act is concerned with the effective use of computers by the Federal Government and assigns the National Bureau of Standards responsibility for providing scientific and technological advisory services for automatic data processing, developing uniform Federal ADP standards and undertaking necessary research in computer science and technology. Program activities and a history of funding for each of these three major responsibilities are covered. Also included are case studies of individual program initiatives.

17. KEY RORDS isix to twelve entries; alphabetical order; capitalize only the first letter of the first key word unless a proper name; separated by semicolons)

Brooks Act; ADP standards; computer science research; computers in the Federal Government; scientific and technological advisory services

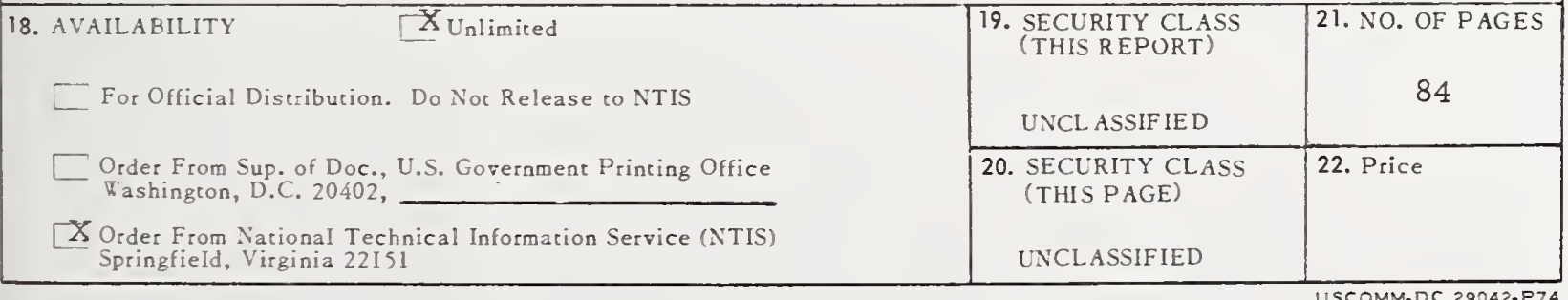




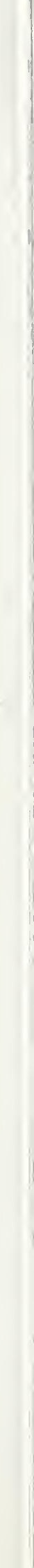



